\title{
5. Das preußische Finanzministerium unter Klepper
}

Über die Motive, die Klepper zur Übernahme des neuen Amtes bewogen haben, ist viel gerätselt worden. Engelmann, der diese Entscheidung mit Klepper seinerzeit ausführlich diskutiert hatte, legt Zeugnis über die verschiedenen Erwägungen ab: „Klepper trat Ende 1931 sein Ministeramt nicht mit der gleichen zielbewußten Energie an, mit der er Anfang 1928 die Leitung der Preußenkasse übernommen hatte. Er war sich dessen bewußt, daß er seine Berufung in die Regierung nicht einer besonderen Aufgabe zu verdanken hatte, deren Lösung wie die seinerzeitige Krise der Preußenkasse und des Genossenschaftswesens gerade von ihm erwartet werden konnte, sondern dem plötzlich eingetretenen Bruch zwischen Ministerpräsident Braun und Finanzminister HöpkerAschoff, der um so gefährlicher war, als die kritisch gewordene Finanzlage Preußens die Gefahr heraufbeschworen hatte, seitens der Reichsregierung als Vorwand zu einem Eingriff benutzt zu werden. [...] Klepper war sich der Defensivposition, in der sich die Staatsregierung schon seit längerer Zeit gegenüber den erstarkten reaktionären Tendenzen in der Reichspolitik befand, bewußt. Er hatte sie in der letzten Zeit seiner Präsidentschaft zur Genüge kennengelernt. [...] Klepper übernahm sein Amt, ohne sich die geringsten Illusionen über die Möglichkeit sachlicher oder persönlicher Erfolge zu machen. "1 Adenauer hatte das klar erkannt und telegraphierte: „Aufrichtig erfreut über Zurückstellung Ihrer Bedenken, spreche ich Ihnen herzliche Glückwünsche aus. ${ }^{\text {2 }}$

Angesichts dieser politischen Risiken und der Ende 1931 äußerst kritischen politischen und wirtschaftlichen Situation im Reich und in Preußen läßt sich der verschiedentlich geäußerte Verdacht, Klepper habe das Amt aus Eitelkeit übernommen, nicht halten, zumal die Undankbarkeit des Amtes offensichtlich allgemein bekannt war. Graf Schwerin von Krosigk berichtet, daß Brüning ihn Anfang November 1931 ,im Auftrag des preußischen Ministerpräsidenten Otto Braun“ gefragt habe, ob er "preußischer Finanzminister werden wolle. Ich lehnte aus den gleichen Gründen ab, aus denen HöpkerAschoff gegangen war; er hatte seine etatpolitischen Maßnahmen nicht durchsetzen können. Der Kanzler hatte diese Stellungnahme erwartet [...]. Schäffer billigte die Ablehnung. Ich sei zu schade, um an dieser Stelle in kurzer Zeit verbraucht zu werden." ${ }^{\text {. }}$ Höpker-Aschoff schrieb am 9. Januar 1948 an Klepper: „Ich habe es nie bedauert, daß ich im Herbst 1931 von meinem Amt zurückgetreten bin und daß Brauns damalige Be-

\footnotetext{
${ }^{1}$ Engelmann, S. 33 f. Der Verdacht, er sei ein reiner „Karrierist“ (Stephan, S. 487), kann nicht aufrechterhalten werden.

${ }^{2}$ HAStK, 902, 51,3, Bl. 136: Adenauer an Klepper, 8.11. 1931, und Dank Kleppers, 15. 11. 1931 (Bl. 51).

${ }^{3}$ Schwerin v. Krosigk, S. 90 (Hervorhebung im Original). Brüning bestätigte: „So gern ich Krosigk an dieser Stelle gesehen hätte, so glaubte ich doch, in seinem Interesse diesen Vorschlag nicht befürworten zu können. Eine Teilnahme an einem Kabinett mit den Sozialdemokraten hätte ihn bei seinen politischen Freunden unmöglich gemacht" (Brüning, Memoiren, S. 482).
} 
mühungen, mich als Finanzminister doch noch wieder einzustellen, erfolglos waren. [...] Ich habe daher auch nie einen Groll gegen Sie gehegt.."

Geld und Ehre waren also kaum zu holen, und die Preußenkasse verließ Klepper nur „schweren Herzens“, wie er sich Engelmann gegenüber „bald nach seiner Übersiedlung in das Ministerbüro einmal privatim äußerte. [...] Er habe sich zwar vier Jahre lang mit Arbeiten aufhalten müssen, die ihn nur schrittweise seinen Zielen nähergebracht hätten und die ihm weder leicht gemacht worden seien, noch je gedankt werden würden, aber es sei doch im ganzen vorangegangen“. Klepper habe, so meint Engelmann, „die Zukunft $[\ldots]$ noch nie so pessimistisch angesehen $[\ldots]$, nachdem er an den ersten Kabinettssitzungen teilgenommen habe. Es sei um die preußische Regierung noch viel schlimmer bestellt, als er es sich vorher schon gedacht habe", und Engelmann fügt hinzu, daß er "derartige Zeichen von Resignation" an Klepper kaum erlebt habe, dennoch habe er seine Arbeit „in alter Form“ begonnen ${ }^{5}$, gemäß dem Motto: „loyal und seriös!“ und getragen von der Hoffnung, die ihn trotz eines widrigen Schicksals sein ganzes Leben vorantrieb, doch noch seine politischen Ziele durchsetzen zu können.

Aufgrund einer schon im Frühsommer 1933 geschriebenen Artikelserie über das Scheitern der Weimarer Republik lassen sich Kleppers Beurteilung der politischen Situation von 1931 sowie seine Erwartungen an sein neues Amt genauer rekonstruieren 6 Grundlegend sind zunächst seine Überlegungen zu den Parteien der Weimarer Koalition und der Art ihrer Machtübernahme im November 1918, die er als „Umwälzung“ bezeichnete, insofern als der Staat ,aus den Händen der alten herrschenden Schicht auf Klassen über[ging], die bisher von der Macht ausgeschlossen waren [...], die sozialdemokratische Arbeiterschaft, die liberalen Mittelschichten und den katholischen Volksteil“, die beiden letzteren hätten sich zunächst „abwartend“ verhalten”. Diese sogenannte Weimarer Koalition, welche die Macht nicht usurpierte, sondern notgedrungen übernehmen „mußte“, war „von vornherein kein in sich geschlossenes Gebilde“. Alle drei waren vorbelastet und insofern in ihrer Handlungsfreiheit und ihrem Machtwillen eingeschränkt: die Sozialdemokraten „durch den Vorwurf ideologischer Unzuverlässigkeit“ von links und die Demokraten durch die „Scheu des mittelständischen Bürgertums vor dem sozialistischen Zukunftsstaat“, während das Zentrum sich „kulturpolitisch leicht kompromittiert" fühlte. „Jeder der drei Partner hatte also gewisse Hemmungen, sich mit den anderen zu zeigen. "8 Die darin begründete Schwierigkeit, eine klare Linie, sowohl in der Wirtschafts- wie in der Innenpolitik, zu verfolgen, wurde ebenso durch

\footnotetext{
${ }^{4}$ Höpker-Aschoff an Klepper, 23. 11. 1947. Er fügt hinzu: „Allerdings habe ich - ganz offen gesagt - bisher angenommen, daß nicht nur Hirtsiefer und Heilmann sondern auch Sie dem Ministerpräsidenten geraten hätten, mich nicht wieder einzustellen. Ich nehme gern davon Kenntnis, daß das nicht der Fall gewesen ist."

${ }^{5}$ Engelmann, S. 34.

6 Klepper, Umschwung. Die Artikel erschienen bis auf den letzten, der unveröffentlicht blieb, am 14., 24. Juli und 5. August 1933 im Göteborgs Handels- och Sjöfarts-Tidning. Außerdem erschien: Klepper, Erinnerung an den 20. Juli 1932, in: Neues Tagebuch, 1. Jg., H. 4, 22. 7. 1933.

${ }^{7}$ Klepper, Umschwung, S. 164. Alle folgenden Zitate stammen, soweit nicht anders vermerkt, aus dieser Artikelserie. Vgl. dazu Schumachers Kommentar und vor allem seine Anmerkungen, in denen er auf wissenschaftliche Literatur verweist, die meist Kleppers zeitnahe Geschichtsdeutung bestätigen.

${ }^{8}$ Vgl. dazu Brünings weiter oben zitierte Erwägungen, ob Schwerin v. Krosigk PrFM werden solle, S. 482 .
} 
die starke Ideologisierung der Parteien', ihren entsprechend mangelhaften praktischen Gestaltungstrieb und den fehlenden Willen zur Macht erschwert ${ }^{10}$, wie durch das Fehlen "einer Persönlichkeit von überragender Kraft" ${ }^{11}$, wie es Gustav Stresemann auf dem Gebiet der Außenpolitik gewesen war ${ }^{12}$.

Die Republik zerbrach nach Klepper an den Folgen „zweier grundsätzlicher wirtschaftspolitischer Fehler“: Statt einer Bodenreform wurde eine „Agrarpolitik zugunsten des Großgrundbesitzes und zu Lasten der Bauern“ durchgeführt, und statt die Chance zur Produktion von hochwertigen Fertigwaren zu nutzen, wurde „Industriepolitik zum Schutze der Schwerindustrie und zu Lasten der verarbeitenden Industrie “ betrieben ${ }^{13}$. Und die Republik zerbrach auch an ihren eigenen Fehlern, voran die Volkswahl des Reichspräsidenten, die zur Wahl Hindenburgs, zur „ersten großen Niederlage der Republik“, geführt hatte. Sie zerbrach ferner an dem Versäumnis, die neue deutsche Armee für den Staat zu gewinnen, dessen Offizierskorps Klepper „namentlich in den jüngeren Jahrgängen [für] keineswegs unbelehrbar reaktionär, sondern [für] vielfach politisch interessiert und bildungsfähig“ hielt, und sie zerbrach schließlich an der Unfähigkeit, die republikfeindlichen Wehrverbände zu unterdrücken ${ }^{14}$.

Obwohl Klepper die Verdienste des Weimarer Systems durchaus anerkannte ${ }^{15}$, meinte er, es sei immer „sichtbarer“ geworden, „daß die Republik ohne Entscheidungskampf nicht zu halten war, je näher das Jahr 1930" herangekommen sei. Dazu aber habe es am „Willen zur Macht, dem Bewußtsein der Macht und der Gestaltungsfähigkeit“ gefehlt. Klepper skizziert dann die Situation, die er bei seinem Eintritt in das preußische Kabinett vorgefunden hatte, folgendermaßen: Nachdem das Kabinett Hermann Müller, das er „die willenloseste aller Regierungen“ nennt, „wegen einer Lappalie“ ${ }^{16}$ zurückgetreten sei, „beschloß Hindenburg nunmehr, die Sozialdemokratie endgültig auszuschiffen. Mit dieser Richtlinie bildete Brüning sein Kabinett.“ Die Sozialdemokraten, obwohl immer noch größte Partei, konnten sich, so kritisierte Klepper, nicht entscheiden, ob sie wieder in die Regierung eintreten oder eine Beteiligung der damals noch verhältnismäßig

\footnotetext{
${ }^{9}$ Graf Krockow, Parteien, S. 15. „[...] in der Weimarer Republik [waren] beinahe alle Parteien mehr oder minder ausgeprägt Weltanschauungsparteien. Beinahe alle standen daher dem Parlamentarismus und dem Vielparteiensystem, wenn nicht feindlich, dann doch mit Vorbehalten gegenüber."

10 Vgl. Kirchheimer, Weimar, S. $24 \mathrm{ff}$.

${ }^{11} 2$. Artikel, „Die innenpolitische Entwicklung“, S. $165 \mathrm{f}$.

12 3. Artikel, „Die äußere Politik“, S. 170.

13 1. Artikel, "Wirtschaftspolitik“, S. $161 \mathrm{ff}$. Vgl. Winkler, Staatskrise, V. Kap., S. $205 \mathrm{ff}$.

14 2. Artikel, S. 166.

15 Ebenda, S. 165: Wahrung der Einheit des Reiches, der Weg der SPD und damit der Arbeiterschaft unter parteipolitischen Opfern zu staatspolitischer Verantwortung, die Sicherstellung der geistigen, kulturellen und politischen Freiheit und die außenpolitische Leistung Stresemanns.

16 Genaueres zum Sturz der Regierung Müller vgl. Schulz, Brüning, Morsey, in: Brüning-Festschrift, S. 207-231 und Timm. Theodor Wolff schreibt unter der Überschrift „Um ein Wort“ im Berliner Tageblatt vom 30.3. 1930 dazu: „eine so unfaßbare Torheit“, die die Welt nicht mehr geschen habe, „seit Esau seine Erstgeburt um ein Linsengericht verkaufte“. Zitiert bei: G. Schwarz, S. 234. Schwarz fügt hinzu, „sie wäre vermieden worden, hätte die Sozialdemokratie über einen wirklichen Führer verfügt. Hermann Müller, ,eine ungemein sympathische Persönlichkeit‘ von gewinnender Ehrlichkeit und wertvollen politischen Gaben war dieser Führer nicht.“
} 
schwachen Nationalsozialisten erzwingen sollten, statt dessen versuchten sie „die Quadratur des Zirkels“ und „ermöglichten das doppelte Spiel Brünings“17.

Zwei Merkmale fallen bei der Betrachtung von Kleppers Analyse auf: die Kritik an der mangelnden Entschlossenheit und Kampfbereitschaft der Sozialdemokratie und die Kritik an Brünings Abhängigkeit von Hindenburg ${ }^{18}$. Aus beidem resultierte für Klepper die Erkenntnis, daß nur Preußen, in dem die SPD noch handlungsfähig war und von den demokratischen Parteien unterstützt wurde, in der Lage sein könnte, „den Entscheidungskampf um die Republik“ zu gewinnen, und daß Preußen folglich unbedingt seine Unabhängigkeit vom Reich, das immer stärker unter den Einfluß antidemokratischer Kräfte geriet, wahren mußte. Das bedeutete, daß Klepper sich, obwohl er „selbst eine Reichsreform für notwendig hielt “, in der Endphase der Weimarer Republik eindeutig gegen eine Stärkung des Reiches auf Kosten Preußens entschied, „weil die Ausschaltung Preußens der Weimarer Republik den letzten festen Stützpunkt genommen hätte“19. Das heißt, Klepper hat sich, obwohl er klar erkannt hatte, wie es um die Republik stand, dennoch oder gerade deshalb zur Verfügung gestellt, als Pfeiler dieses „letzten festen Stützpunkts“ Preußen.

Nicht nur Klepper selbst sah seine Ernennung in diesem größeren Zusammenhang. Braun und andere waren sich des Ernstes der Situation wohl bewußt. „Braun, der Höpker-Aschoff und dessen Fähigkeiten hoch einschätzte, [...] fühlte sich von dessen Rücktritt sehr betroffen. “20 Sein Eindruck war, daß „die prekär gewordene Finanzlage Preußens, die ihn als preußischen Finanzminister in steigende Abhängigkeit von der Reichsregierung brachte, und das mangelnde Entgegenkommen, das er dort fand, der Hauptgrund für seinen Rücktritt" gewesen sei ${ }^{21}$. Gerade deshalb wollte Braun Höpker lieber behalten, statt den „politisch noch zu wenig gefestigt und parlamentarisch nicht hinreichend erfahrenen“ Klepper, dessen „starke persönliche Bindung an einzelne Zentrumspolitiker“ ihm ohnehin nicht gefiel, zu ernennen. Doch nicht nur das ließ ihn zögern, sondern auch sein schlechter Gesundheitszustand und vor allem seine Pläne, vielleicht doch angesichts der Aussichtslosigkeit, die nächste Landtagswahl zu gewinnen, ein Stückchen Reichsreform verwirklichen zu können, indem er Brüning das Amt des preuBischen Ministerpräsidenten anbot, womit sich dann eine Vereinigung der beiden Finanzressorts fast von selbst ergeben hätte ${ }^{22}$. Hagen Schulze legt die Gespräche zwischen Braun und Brüning im Detail dar; sie scheiterten an Hindenburg, was Schulze mit dem

17 2. Artikel, S. 167 und die von Schumacher zitierte Literatur.

18 Vgl. u. a.: Muth, Zum Sturze und Ders., Quellen zu Brüning, in: GWU, 14 (1963), S. 221-236; Bracher, Brüning, in: VfZ 19 (1971), S. 113-123; Köhler in: VfZ 17 (1969), S. 276-307; Holtferich in: HZ (1982), Bd. 235, S. 605-629 und Hertz-Eichenrode, S. 336: „Das Minderheitenkabinett Brüning, das seine Unabhängigkeit von Parteienkonstellationen und seine engen Beziehungen zu Hindenburg bewußt herauskehrte".

${ }^{19}$ Klepper an Erwin Widder, 23. 3. 1955.

${ }^{20}$ Schulze, Braun, S. 702 und S. 699 ff. sowie Braun, 352 ff. Höpker-Aschoff war am 12. 10. 1931 zurückgetreten (Rücktrittsschreiben, 13.10. 1931).

${ }^{21}$ Braun, S. 352. Ehni, S. 225 zitiert vier Gründe, die Weichmann Braun gegenüber genannt haben soll.

22 Braun, S. $354 \mathrm{f}$. Vgl. Schulze, Braun, S. $702 \mathrm{f}$. Auf die vielfältigen Pläne zur Reichsreform kann hier nicht näher eingegangen werden, vgl. Schulz, Brüning, S. 451 ff. und Ehni, „Reichsreform und Finanzkrise“, S. $219 \mathrm{ff}$. 
Satz kommentiert: „Damit war eine Sternstunde, eine der letzten der Republik, verstrichen. “23 Dieses Urteil ist nur schwer verständlich. „Dies war sie gewiß nicht“, lautet denn auch der lakonische Kommentar von Gerhard Schulz. Außerdem versucht Schulz durch eine detaillierte Analyse der Ausführungen Hagen Schulzes, der Memoiren Brauns und Brünings sowie anderer Quellen nachzuweisen, daß es „keine beweiskräftigen Gründe für die Annahme [gebe], daß Braun [...] dem Versuch Brünings, Preußen schrittweise in die Reichsverwaltung einzubeziehen, entgegenzukommen versuchte“, und auch die von Brüning betriebene Kandidatur Dietrichs habe Braun im Grunde abgelehnt $^{24}$. Diese Interpretation ist durchaus zutreffend, auch wenn man einräumt, daß Braun von dem ganzen ihm „aufgezwungenen Revirement [...] keineswegs befriedigt“ war. Schließlich hat Braun sich aber doch entschlossen, Klepper zum Finanzminister zu machen, und wie er später in seinen Memoiren schrieb, habe dieser „nicht versagt “25. Für die letztlich positive Einstellung Brauns ihm gegenüber spricht auch die Tatsache, daß Herbert Weichmann, sein persönlicher Referent, Klepper vorgeschlagen hatte ${ }^{26}$, wobei auch andere Sozialdemokraten, wie Ernst Heilmann, diese Berufung unterstützt haben sollen $^{27}$.

Das Tauziehen um den neuen preußischen Finanzminister und der schließliche Kompromißcharakter seiner Ernennung, die am 7. November 1931 erfolgte, waren jedenfalls zusammengenommen mit der hoffnungslosen finanziellen Lage Preußens nicht gerade ideale Startbedingungen für einen noch so jungen Mann in einem so schwierigen Amt, in dem er sich auch noch an seinem Vorgänger, dem man "nahezu Miquelsches Format“28 nachsagte, messen lassen mußte. Im ganzen überwogen die skeptischen Reaktionen auf Kleppers Ernennung zum preußischen Finanzminister. Seine Kabinettskollegen ${ }^{29}$ waren geteilt in ihrem Urteil. Zunächst herrschte offenbar „allgemeine Erleichterung, HöpkerAschoff losgeworden zu sein"30. Heinrich Hirtsiefer, Brauns Stellvertreter, war ausgesprochen zufrieden mit der Wahl ${ }^{31}$ und hat auch mit Klepper ausgezeichnet zusammengearbeitet, während Carl Severing in seinen Memoiren behauptet, er "habe oft nach der Jungfrau von Orleans zitiert, wenn [er] um [seine] Meinung in dieser Ernennung gefragt

${ }^{23}$ Schulze, Braun, S. $703 \mathrm{ff}$. Sie scheiterten auch an der Ablehnung "der preußischen Parteifreunde Dietrichs [...], ihren eigenen Parteivorsitzenden in die preußische Regierung zu wählen" (Biewer, Preußen, S. 25).

${ }^{24}$ Schulz, Brüning, S. $582 \mathrm{ff}$. und 587.

${ }^{25}$ Braun, S. 354.

${ }^{26}$ Schulze, Braun, S. 703. Schulze zitiert einen Brief Weichmanns an Braun, 14. 10. 1931.

${ }^{27}$ PrLT, 264. Sitzung, 16. 12. 1931, Sp. 23187: Paul Schwenk (KPD), „Kein Wunder, denn die Heilmänner hatten ihre Hand im Spiel“.

${ }^{28}$ Grimme an Braun, 17. 10. 1931 (GSTAB, NL-Braun D/2), zitiert von Schulze, Braun, S. 707. Arnold Brecht schreibt in seinen Erinnerungen, S. 119: „Aber im Vergleich mit der Statur seines Vorgängers wirkte er etwas wie ein junger Jagdhund neben dem Bernhardiner."

${ }^{29}$ Siehe Bild des Kabinetts: Heinrich Hirtsiefer (Ztr.) - MfV, Carl Severing (SPD) - IM, Heinrich Steiger (Ztr.) - MfLuF, Adolf Grimme (SPD) - KM, Hermann Schmidt (Ztr.) - JM, Walter Schreiber (DDP) - Handel (KNL).

${ }^{30}$ Schulze, Braun, S. 703. Im Tagebuch von Hans Schäffer heißt es am 7. 11. 1931 (Bd. 15): „Eine Rückfrage bei Staudinger ergibt, daß die Zentrumsminister in Preußen angekündigt haben, die Kabinettsfrage zu stellen, wenn Höpker-Aschoff wieder ernannt würde." Vgl. auch Schulz, Brüning, S. 580.

${ }^{31}$ Braun habe dem Druck nachgegeben, die Linke und das Zentrum jubele (Der Angriff, Nr. 19, 12. 11. 1931, in: BAP, 62 DFA 3, 17632, Bl. 116). Vgl. auch Schulz, Brüning, S. 588. 
wurde: ,Ach, es war nicht meine Wahl“" "32. Es ist nicht festzustellen, ob er diese Meinung auch damals schon hatte, denn seine Memoiren sind nach der Kontroverse zwischen ihm und Klepper am 20. Juli 1932 geschrieben worden, und da war inzwischen viel Porzellan zwischen beiden zerschlagen worden. Höpker-Aschoff sprach sich für Klepper aus, von dem er sagte, er „sei ihm gegenüber stets loyal gewesen“, er sei zwar ehrgeizig, aber „klug und gewandt, christlich-sozial - nicht organisiert - [und habe] mit [der] preußischen Regierung stets gut zusammengearbeitet“, die Reichspolitik halte er für „falsch“ ${ }^{33}$. Die kritische Einstellung Kleppers gegenüber der Reichspolitik scheint schließlich auch ausschlaggebend für eine Befürwortung seiner Kandidatur besonders durch die Staatspartei gewesen zu sein, die zunehmend auf Distanz zum Reich ging. Schulz spricht von

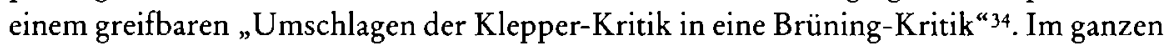
scheint für Klepper gegolten zu haben, was Arnold Brecht so zusammenfaßte: „Demokratisch zuverlässig, sehr fähig und, wenn auch ehrgeizig und etwas forsch, doch in Finanzfragen völlig sachlich und in Verhandlungen - auch gegenüber der Reichsregierung - durchaus fair." 35

Brecht war zu Kleppers Zeit Ministerialdirektor im preußischen Staatsministerium, nachdem er vorher für kurze Zeit im Finanzministerium gewesen war. Sein sachliches und positives Urteil kontrastiert mit dem Dietrich Mendes, des persönlichen Referenten Höpker-Aschoffs ${ }^{36}$. Das negative Bild, das Mende in seinen unveröffentlichten Aufzeichnungen entwirft, ist von seinen persönlichen Einstellungen sowie von seiner starken Bindung an Höpker-Aschoff geprägt. Der erste strittige Punkt war die Personalpolitik. Da Mende keinesfalls Kleppers persönlicher Referent werden wollte, weil das in seinen Augen „Verrat an Höpker-Aschoff“ gewesen wäre, habe er volles Verständnis gezeigt, wenn Klepper Lauffer mitbrachte, was gar nicht zutraf, denn Lauffer blieb bis Juli 1932 bei der Preußenkasse. Dagegen hatte Mende, nach eigener Aussage, kein Verständnis für Kleppers Absicht, sich langfristig von den Ministerialdirektoren Weyhe und Friedrich Grosser zu trennen, obwohl Mende selbst zugibt, daß sie „verbraucht“ waren. Auch die Tatsache, daß Klepper sich zwar gern von ihm über die Personalsituation informieren ließ, nicht aber bereit war, Belehrungen darüber zu empfangen, wie er mit der Bürokratie umzugehen habe, braucht nicht gegen Klepper zu sprechen. Die Zweifel, die Mende an Kleppers Fleiß sät, sind als unterschwellige Verdächtigung zu werten, da sie angesichts des in so kurzer Zeit zu bewältigenden Programms kaum eine reale Grundlage haben konnten. Daß Klepper sich mehr für die große Linie der Wirtschafts- und Finanzpolitik als für Einzelentscheidungen, wie die Mende beschäftigende Sanierung der Oberschlesischen Hüttenwerke, interessierte, trifft sicher zu. Interessant ist, daß Mendes Ausführungen die häufigen Kontakte Kleppers mit Karl Höltermann, dem stellvertretenden Führer des „Reichsbanners“, und Walter Stennes von der „Schwarzen Front“ und deren Unterstützung durch einen Dispositionsfonds des Finanzministeriums bestätigen, wenn Mende dies auch als charakterliches Defizit ausgelegt wissen will: „In Zuständen wie den damaligen ließen sich Opportunisten oft in merkwürdige Verhältnisse

\footnotetext{
32 Severing, Lebensweg, Bd. II, S. 309.

${ }^{33}$ BAK, R 45 III/65, zitiert bei Schulz, Brüning, S. 588.

${ }^{34}$ Schulz, Brüning, S. 588 und $589 \mathrm{ff}$.

${ }^{35}$ Brecht, Bd. II, S. $119 \mathrm{f}$.

${ }^{36}$ Dietrich Mende, „Erinnerungen", unveröffentlicht, eine Kopie des Klepper betreffenden Teils der Erinnerungen in: KNL.
} 
ein.“ Nicht wissend, daß Klepper sich ganz bewußt „einließ“, um den Widerstand gegen die Bedrohung durch die Nationalsozialisten zu organisieren ${ }^{37}$. Auf der gleichen Unkenntnis beruhte Mendes Unterstellung, es sei „gewiß [...] Opportunismus [gewesen], der Klepper verleitete, sich mit dem Amtsgehilfen Blume [einem NSDAP-Mitglied] zwei Stunden lang zu unterhalten", nachdem Klepper zufällig Zeuge von dessen Auseinandersetzung mit einem dem Kommunismus zugeneigten Pförtner geworden war. Das war nicht Opportunismus, sondern klare Überlegung, hinter der vermutlich drei Absichten gestanden haben: politischen Streit in seinem Hause zu schlichten, der Versuch, den NSDAP-Mann im Sinne der Republik zu beeinflussen und ihm Informationen über die NSDAP zu entlocken.

Diese Beispiele zeigen erneut, wie Klepper sich Verdächtigungen aussetzte, weil er keine Scheu hatte, mit Leuten der verschiedensten politischen Couleur zu sprechen. Zweifel an der Unbefangenheit von Mendes Urteil kommen schließlich auch auf, wenn man sich seine Kronzeugen betrachtet, die sein negatives Urteil über Klepper bestätigen. $\mathrm{Zu} \mathrm{Kleppers} \mathrm{„schärfsten} \mathrm{Kritikern“} \mathrm{gehörten} \mathrm{nicht} \mathrm{etwa} \mathrm{der} \mathrm{Staatssekretär} \mathrm{Frank}$ Schleusener oder der einflußreiche Ministerialdirektor Arnold Brecht, die ständig mit Klepper zusammenarbeiteten, von Mende aber nicht als Kritiker erwähnt werden, sondern Leute wie der Ministerialrat Friedrich Landfried, der laut Weichmann „zusammen mit Herrn Neumann derjenige [war], der im Komplott des Papenschen Staatsstreichs die führende Rolle hatte“. Als Landfried bei seinem Tode als „Vorbild der Pflichterfüllung und Treue“ gerühmt wurde, fand Weichmann, daß das „doch etwas zu weit" gehe, und fragte Klepper, als Landfrieds „letzten Chef, ob man in dieser Angelegenheit etwas tun solle“. Klepper hatte zwar abgewinkt, „man sollte ihn jetzt ruhen lassen“, aber hinzugefügt: „Wahrscheinlich war es ein Fehler von mir, daß ich ihn nicht rechtzeitig aus dem Amt entfernt habe. “38 Eines macht Mendes Niederschrift allerdings klar, Klepper fand im Finanzministerium bei der alten Beamtenschaft, die ihrem Chef HöpkerAschoff nachtrauerte und Klepper als „Usurpator" 39 betrachtete, kein so großes Wohlwollen und keinen solchen Respekt wie bei seiner Preußenkasse ${ }^{40}$.

Das Urteil in der Presse war deutlich politisch motiviert; während die Kommentare der liberalen und Linkspresse in etwa dem Urteil Brechts entsprachen, stützte die Rechtspresse sich eher auf Verdächtigungen und nahm Klepper zum Anlaß, gegen ,das System' zu wettern, eine Ouverture zu der sich bis 1933 stetig steigernden Diffamierungskampagne. Zur Illustration einige Ausschnitte: In der Landtagsdebatte vom 16. Dezember 1931, in der der Mißtrauensantrag gegen Klepper auf der Tagesordnung stand, wurde Klepper „als Vertrauensmann dieses Systems, das wir für das größte Un-

\footnotetext{
${ }^{37}$ Vgl. weiter unten Kleppers Versuch, den Widerstand gegen Papens Staatsstreich zu organisieren.

38 Weichmann an Klepper, 5. 1. 1953 und Klepper an Weichmann, 6. 1. 1953, K/Kor.

${ }^{39}$ Mende beruft sich auf "die beiden Amtsgehilfen, die ausschließlich beim Minister Dienst taten und ihn als Usurpator betrachteten"; sie, so berichtet Mende weiter und gibt damit Einblick in die Atmosphäre des Ministeriums, „unterrichteten mich, aber auch andere, die weniger diskret waren als ich, über Kleppers Besucher".

40 Otto Lauplicher, später Generalbevollmächtigter der Firma Otto Wolff, schrieb: „Herr Klepper war als Präsident der Preußischen Zentralgenossenschaftskasse viele Jahre hindurch mein Chef. Ich habe deshalb im Rahmen dieses Instituts Gelegenheit gehabt zu sehen, mit welcher Energie und Sachkunde Herr Klepper die schwierigsten Probleme anpackte und zu einer sinnvollen Lösung führte" (Akte Beileidsschreiben, KNL, 17. 5. 1957).
} 
glück des preußisch-deutschen Volkes halten“41, tituliert. Der DNVP-Abgeordnete Hans v. Rohr, der den Antrag begründete, bezog sich in seiner Rede, die eine einzige Kette von Beleidigungen und Unterstellungen enthielt, auf ein Zitat von Heinrich v. Treitschke, nämlich „daß ein gerechtes Schicksal eine morsche Staatsgewalt immer zu zwingen pflegt, am Rande ibres Grabes alle Gebrechen vor aller Welt sinnfällig noch einmal zu offenbaren", und er wandte dieses Zitat auf Klepper an, indem er seine Rede dramatisch mit den Sätzen beschloß: „Wenn Sie übermorgen Herrn Klepper bestätigen, so zeigt uns das mit aller Klarheit, daß Ihr System unter dem Wort Treitschkes steht. Machen Sie nur so weiter! Behalten Sie Ihren Klepper. Wir lassen Ihnen Ihr System und werden es noch stoßen, damit es in dem schon offenen Grabe versinkt. " ${ }^{2}$ Der Tag fragte polemisch, ob der neue „Vertrauensmann Brauns“ wohl „der richtige Sparfinanzminister für Preußen sein“ werde, während die Deutsche Zeitung die Ernennung Kleppers als „Gegenstoß gegen die Berufung Schlanges“ wertete, er sei „der Finanzminister derselben Sozialdemokratie, deren Ziel die Zerschlagung des östlichen ,reaktionären' Grundbesitzes“ sei. Die Berliner Börsenzeitung, die ihn ebenfalls als „erklärten Feind des Großgrundbesitzes“ bezeichnete, unterstellte ihm, daß er sein vorheriges Amt nicht unter sachlichem, sondern unter dem Gesichtspunkt verwaltet habe, „die Gunst der sozialdemokratischen Freunde und die Anwartschaft auf einen hohen Posten in der marxistischen Verwaltungshierarchie" zu erwerben ${ }^{43}$.

Die liberale Presse reagierte dagegen positiv: Das Berliner Tageblatt vom 8 . November 1931 betrachtete Kleppers Ernennung unter dem Gesichtspunkt der kritischen Situation „der nächsten Monate“ und der dafür notwendigen „besonderen Härte des Willens“, die ihm zuerkannt wurde. "Sein Eintritt in das preußische Kabinett ist in jedem Falle ein Vorteil, weil in ihm eine lebendige Kraft hinzukommt, die gerade in diesen Monaten wertvoll sein kann. “44 Auch die Vossische Zeitung, die seine Ernennung „einen guten Griff“ nannte, bescheinigte ihm „ungewöhnliches wirtschaftliches Verständnis, eine lebendige Initiative, starke Energie und Geschicklichkeit“ und eine schon bei der Lösung der bisherigen Aufgaben notwendige „Rigorosität und Unbeugsamkeit“ gegenüber jeglichen Interessenten, die ihn von seiner Linie abzudrängen versuchten ${ }^{45}$. Ähnlich äußerte sich der Vorwärts: „Der preußische Ministerpräsident hat sich durch die Berufung Kleppers die Mitarbeit eines sehr energischen finanz- und bankpolitisch erfahrenen und vor allem von Interessen unabhängigen Ministers gesichert."46 Auch von der falschen Seite bekam Klepper Beifall. In Goebbels' Der Angriff wurde Klepper als „Mann mit den rücksichtslosen Ellenbogen und dem sozialdemokratischen Herzen“ bezeichnet. Aus seiner unmittelbarer Umgebung heiße es, daß jetzt „an Stelle eines Finanztheoretikers ein Finanzpraktiker trete, an die Stelle des Finanzverwalters der Finanzpolitiker", einer, „der die Einnahmen unter dem Gesichtspunkt ,des politisch Notwendigen“ verwenden werde, ein Bankmann, der von der Überzeugung ausgehe, daß Geld wirt-

${ }_{41}$ Oscar Maretzky (DNVP), PrLT, 264. Sitzung, 16. 12. 1931, Sp. 23185.

${ }^{42}$ Ebenda, Sp. 23155-23171, 23171 (Hervorhebung im Original).

${ }^{43}$ BAP, 25.01, Deutsche Reichsbank, Nr. 3559, Bl. 194 ff. und DGBkA, ND-P.Z., 7. Jg. , Nr. 261, 9. 11. 1931, Bl. $5 \mathrm{ff}$.

44 DGBkA, ND-P.Z., 7. Jg., Nr. 261, 9. 11. 1931, Bl. 6.

${ }^{45}$ Ebenda, Bl. 7. Es werden noch zahlreiche andere Zeitungen zitiert, außerdem befinden sich Kommentare zur Ernennung im BAK, NL-Zarnow, Bl. 65 ff. und in BAP, 25.01, 3559, Bl. 194 ff. ${ }^{46}$ BAP, 62 DFA 3, 17632, Bl. 118. 
schaften, arbeiten und sich vermehren müsse“47. Jedenfalls schienen sich alle mit dem Vorwärts einig darin zu sein, daß „die Unabbängigkeit und Selbständigkeit Kleppers, besonders den großagrarischen Sonderinteressen gegenüber, dem neuen Finanzminister frühzeitig deutschnationalen $\mathrm{Haß}$ eingetragen" habe ${ }^{48}$.

Die meisten Kommentatoren sahen Kleppers Ernennung zum preußischen Finanzminister im Zusammenhang mit der Auseinandersetzung zwischen Preußen und Reich ${ }^{49}$. $\mathrm{Da}$ Brüning in dieser Auseinandersetzung die Hauptrolle auf der Seite des Reiches spielte, wurde Klepper notgedrungen zu seinem Gegenspieler. Für Brüning war die Ernennung Kleppers eine „Katastrophe“, zumal er sich gerade noch der Verwirklichung seiner Reichsreformpläne so nahe geglaubt hatte. Schrittweise wollte er die Reichsreform über die Zusammenlegung erst des preußischen und des Reichsfinanzministeriums, dann der beiden Landwirtschaftsministerien und schließlich der beiden Justizministerien erreichen, um damit vordergründig Geld einzusparen, hintergründig aber den Einfluß des Reiches zu stärken und den mißliebigen Minister Klepper und den „unmöglichen" Heinrich Steiger zu beseitigen ${ }^{50}$.

Diese Pläne durchkreuzte Klepper, der genau durchschaut hatte, daß Brüning „durch finanziellen Druck auf die Länder eine Reichsreform erzwingen " 51 wollte, indem er versuchte, Preußen finanziell so weit zu sanieren und stark genug zu machen, „um sich dauernd von jeder wie auch immer gearteten Reichsregierung fernzuhalten" $" 52$. Klepper tat dies, obwohl er eine Reichsreform befürwortete, und lehnte damit zugleich die Kompromißbereitschaft Brünings, mit den rechten antirepublikanischen Kräften zusammenzuarbeiten, strikt $a b^{53}$. Brüning, der von Hindenburg abhängig war ${ }^{54}$ und "mit Hilfe einer Reichsverweserschaft Hindenburgs nach einer Volksabstimmung die konstitutionelle Monarchie als Schutzschirm demokratischen Verfassungslebens" eingeführt wis-

${ }^{47}$ Ebenda, Bl. 116, Der Angriff Nr. 19, 12.11. 1931 (Hervorhebung im Original).

${ }^{48}$ Ebenda, Bl. 118 (Hervorhebung im Original). Vgl. auch Frankfurter Zeitung, 8. 11. 1931.

${ }^{49} \mathrm{Vgl}$. u. a.: NL-Zarnow, Bl. 68, eine nicht gekennzeichnete Stellungnahme vom 11.11. 1931 aus dem PrLT: „Die Ernennung Kleppers zum preußischen Finanzminister ist vielleicht sogar eine Verstärkung des Gegensatzes von Preußen gegen das Reich und seinen neuen Osthilfeminister Schlange-Schöningen“, ein Gegensatz, der wie oben nachgewiesen wurde, gar nicht so groß war wie vermutet.

${ }^{50}$ Brüning, Memoiren, S. 483 und 515. Luther erwähnt Pläne für ein mögliches „Preußisch-deutsches Konzentrationskabinett“" im Sommer 1931 (S. 167). Schäffer berichtet unter dem 9. 11. 1931, daß Brüning die Preußenkasse gerne früher schon stärker beeinflußt und Klepper entzogen hätte (Bd. 15, S. 1003).

51 Brüning, Memoiren, S. 515.

52 Brüning schreibt dazu in seinen Memoiren, S. 582: „Ich hatte Äußerungen von Klepper gehört in dem Sinne, die preußische Regierung sei finanziell stark genug, um sich dauernd von jeder wie auch immer gearteten Reichsregierung fernzuhalten. Sie würden mit der Schupo dann schon etwaige Absichten der Reichswehr zurückweisen." Vgl. Schulze, Braun, S. 704 f. Mommsen, Beamtenschaft, in: VfZ 21 (1973), S. 162: „Indessen entzog sich Preußen der insgeheim vorbereiteten ,kalten' Reichsreform, indem es die von Reichs wegen verfügten Einsparungsmaßnahmen mit größter Energie vorantrieb. Dies erklärt die scharfe Kritik, die Brüning später an dem preußischen Finanzminister Klepper [...] geübt hat, zumal seine Absicht gescheitert war, das preußische Finanzministerium in Personalunion mit dem Reich durch Dietrich verwalten zu lassen."

${ }^{53}$ Vgl. G. Schwarz, Th. Wolff, S. 239.

${ }^{54}$ Vgl. u. a. Muth, Zum Sturz und Becker, Brüning, in: GWU 17 (1966), S. 215. 
sen wollte ${ }^{55}$, konnte unmöglich für Klepper sein, den er bei den Verhandlungen über die Osthilfe bereits als Hemmnis empfunden hatte, und, schlimmer noch, dem „schwer beizukommen war". Die Ablehnung Kleppers durch Brüning gipfelte in dem sogar noch in seinen Memoiren fixierten Urteil, daß „die nunmehr unvermeidliche Ernennung Kleppers zum preußischen Finanzminister einer der schwersten Fehler war, der in der ganzen Politik in den letzten zehn Jahren begangen worden war". Abgesehen von den bereits skizzierten Überlegungen und Plänen Brünings findet sich keine Begründung für ein derart scharfes Urteil, im Gegenteil: Im nächsten Satz berichtet Brüning: „Klepper ging mit außerordentlicher Energie an seine Aufgabe."

Angesichts einer derartigen Übertreibung muß man sich also fragen, was Brüning zu diesem Urteil bewogen haben mag, zumal er andererseits sehr viel von Kleppers Fähigkeiten hielt ${ }^{56}$ und beide zumindest grundsätzlich für die Erhaltung der Demokratie eintraten? Es ist wichtig, diese Frage zu erwägen, weil Brüning mit seinem negativen Urteil einen ganz entscheidenden Einfluß auf die allgemeine historische Urteilsbildung über Klepper gehabt hat ${ }^{57}$.

Gewiß waren beide höchst unterschiedliche Naturen. Wenn sie auch das Fronterlebnis als Soldaten im Ersten Weltkrieg verband, so verfügten sie im übrigen über durchaus gegensätzliche Erfahrungen. Klepper kam aus einer protestantischen Kaufmanns- und Juristenfamilie und war stolz auf seine hugenottische Herkunft, Brüning war westfälischer Katholik; Klepper war Vater von vier Kindern, während Brüning als Junggeselle lebte. Klepper galt als entschlossener Kämpfer, Brüning als „Zögerer" 58 . Kleppers sehr unorthodoxe, ja zuweilen unberechenbare Art erweckte ständig Brünings chronisches Mißtrauen, das er ohnehin "gegen jedermann, den er nicht seit langer Zeit bestens kannte", hegte und das "nur sehr schwer zu überwinden" war ${ }^{59}$. Klepper gegenüber ging er sogar soweit, daß er Braun im Frühahr 1932 davon in Kenntnis setzte, er wolle „Klepper demnächst wegen Landesverrates verhaften lassen“, weil er „die Kreise der Reichspolitik“ durch seine eigenständigen Verhandlungen mit den Franzosen über An-

55 Brüning, Memoiren, S. 373 und 378: „Stets betrachtete ich mich als Treuhänder des Reichspräsidenten; ibn wollte ich als Staatsoberhaupt erbalten mit dem Ziel, die friedliche Wiedereinfübrung der Monarchie vor seinem Ableben zu ermöglichen. Das war der Angelpunkt meiner ganzen Politik." Diese Pläne werden vielfach bezeugt, u. a. auch von Luther (S. 127) und Görlitz, Hindenburg (S. 346). Görlitz zitiert Brünings Vorlesungen vor der Harvard-Universität. Vgl. auch Schulze, Braun (S. 627 f.): „Sein politisches Weltbild, vom Fronterlebnis und der scharf antimarxistischen Frontstellung des Christlichen Gewerkschaftsbundes geprägt, war konservativ, ja monarchistisch, jedenfalls antiliberal und antisozialistisch.“

${ }^{56}$ Brüning, Memoiren, S. 481 ff.: „Niemand konnte seine außerordentlichen Fähigkeiten bestreiten."

57 Vgl. u. a. Faust, Geschichte, S. 573, der sich befleißigt, die negativen Urteile zu bündeln, und besonders Brünings Urteil, ohne dieses zu hinterfragen, so zitiert, daß der Leser den Eindruck gewinnt, Kleppers Ernennung zum preußischen Finanzminister sei tatsächlich als eine Katastrophe angesehen worden, was, wie oben gezeigt werden konnte, nicht den Tatsachen entspricht.

${ }^{58}$ Schlange-Schöningen, Am Tage, S. 50. Schlange schreibt über Brüning: „[...] seine ungewöhnliche Klugheir, die ihn auch die Gefahren jeder Aktion sofort begreifen ließ. In dem ihm eigenen, fast übergewissenhaften Abwägen des Für und Wider gingen nicht nur Minuten, sondern manchmal Tage und Wochen verloren, die leider keine Ewigkeit zurückbrachte."

${ }^{59}$ Luther, S. 129: „Was unsere rein menschliche Beziehung angeht, so stand unserem Näherkommen zunächst ein Charakterzug Brünings entgegen, der viele seiner engsten Mitarbeiter verstimmte oder mit Bedauern erfüllte [...] sein eigenes Mißtrauen gegen jedermann." Vgl. auch Dokumentation von Broszat, zu Briefen Brünings an Sollmann, VfZ 22 (1974), S. $458 \mathrm{ff}$. 
leihen störe ${ }^{60}$. Klepper hatte in der Tat gute Kontakte zu Frankreich, wie noch zu zeigen sein wird. André François-Poncet, der französische Botschafter in Berlin, kannte Klepper persönlich und berichtete zum Beispiel über Kleppers Ernennung zum Finanzminister nach Paris ${ }^{61}$.

Wenn sich auch beide über die kritische Lage im klaren waren, so hatten sie unterschiedliche Vorstellungen, sowohl von der Zeit, die ihnen blieb, die Krise zu bewältigen, wie von dem Weg dorthin. Klepper war offensichtlich davon überzeugt, daß nur noch sehr wenig Zeit blieb und rasch gehandelt werden müsse. Brünings Taktik ging dahin, die Konferenz für die endgültige Lösung der Reparationsfrage unbeschadet zu erreichen und möglichst nichts zu tun, was irgendwie Mißtrauen im Ausland erregen könnte. Für Brüning hatte die Außenpolitik, speziell die Lösung der Reparationsfrage, entschieden Vorrang ${ }^{62}$, während Klepper die Lösung der sozialen, wirtschaftlichen und vor allem agrarpolitischen Probleme für vordringlich hielt, um ein Anwachsen des Extremismus zu verhindern und die Gesellschaft im Innern zu befrieden. Die Frage: Sollte man in einer wirtschaftlich und politisch kritischen Situation aktiv und rasch auch unbequeme Reformen durchführen und damit allen der Demokratie gegenüber positiv eingestellten Kräften zeigen, daß es vorangeht und die Krise bewältigt werden kann, oder sollte man abwarten, nichts Unpopuläres tun und hoffen, daß die extremen Parteien dadurch weniger Zulauf bekämen, wurde von beiden gegensätzlich beantwortet. Brüning, der eher der zweiten Alternative zuneigte, hatte für Kleppers Haltung keinerlei Verständnis und charakterisierte sie folglich mit Worten wie „Ressentiment" , "Quertreiberei“, „mangelnder Weitblick“, das Fehlen von „politischem Instinkt, Geduld und verständnisvollem Eingehen" auf konservative Schichten wie die Landwirte und schließlich mit mangelnder „Einsicht, daß eine Regierung sich nicht unnötig unpopulär machen darf“63. Ja, er ging sogar soweit, Klepper niedere Motive zu unterstellen und ihm eine Zusammenarbeit mit den Nationalsozialisten zuzutrauen ${ }^{64}$. Es ist erstaunlich, daß dieses negative Urteil Brünings so stark ins Gewicht fiel, obwohl Kleppers Einschätzung der Lage und sein ent-

${ }^{60}$ Schäffer, Bd. 19, 4. 3. 1932, S. 318. Brüning beklagte sich gegenüber Schäffer, daß François-Poncet "ganz ähnliche Argumente [benutze], wie sie Klepper immer gebraucht. Ich habe den Verdacht, daß da ein Zusammenhang mit der Französischen Botschaft besteht." Ferner Schulze, Braun, S. 706 f.: „Brüning, der auch dort noch Kabalen und Intrigen gegen sich witterte, wo schlichte politische Ungeschicklichkeit vorlag, konnte es nicht verwinden, daß Klepper auf eigene Faust versuchte, das preußische Haushaltsdefizit durch französische Anleihen zu finanzieren; dahinter sah Brüning eine Verschwörung gegen seine Reparationspolitik."

${ }_{61} \mathrm{AD}$, Relations Commerciales 1500, Ambassade De France à Berlin, 12./19. 11. 1931.

62 Winkler, Weimar, S. 443. Luther begründete die Pläne für eine Reichsreform im Sinne Brünings damit, daß "dies auf die Kreditfrage im Ausland starke beruhigende Wirkung haben werde“ (S. 167). Vgl. auch Becker, Brüning, S. 207: „Es verstand sich für Brüning wie für die Mehrzahl der deutschen Parteien von selbst, nach der Niederlage des Reiches im Ersten Weltkrieg die deutsche Politik unter dem beherrschenden Primat der Außenpolitik, das hieß unter dem Primat der Revisionspolitik, zu sehen“, sowie Köhler, VfZ 17 (1969), S. 276, Holtferich, S. 628 f. und Schulz, Brüning, besonders S. $674 \mathrm{ff}$.

63 Brüning, Memoiren, S. 481 ff. Wie die Verhandlungen mit den Genossenschaften gezeigt haben, war Klepper durchaus in der Lage, sich sogar mit dem ultrarechten Reichslandbund zu einigen.

${ }^{64}$ Brüning gegenüber Schäffer, als dieser ihn am 7.6. 1932 nach seiner Meinung über die „preußische Sache" befragte: „Ich traue Hirtsiefer nicht. Wenn sich ein Mensch dieser Art erst mal an einen solchen Lebensstil gewöhnt hat, dann tut er alles, um ihn aufrecht zu erhalten. Ich bin überzeugt, daß er schon eine Rückversicherung bei den Nazis genommen hat. Das Gleiche habe ich auch von Klepper gehört und halte es für wahr" (Bd. 21, S. 570). 
sprechendes Handeln von der Geschichte eher bestätigt worden ist als das Brünings ${ }^{65}$. Dies läßt sich einmal durch die Tatsache erklären, daß Brüning viel bekannter war als Klepper und nach dem Zweiten Weltkrieg Memoiren veröffentlicht hat, und zum anderen dadurch, daß sein negatives Urteil scheinbar bestätigt wurde durch die Angriffe der DNVP in der Presse und im Untersuchungsausschuß des preußischen Landtags, Angriffe, bei denen sich kaum jemand mehr die Mühe machte, sie auf ihren Wahrheitsgehalt hin zu untersuchen. Die Begründung für das harte Urteil Brünings liegt jedenfalls einmal in Brünings eigenem Charakter, der ihn durch sein Mißtrauen zu krassen Fehlbeurteilungen verführte, und zum anderen in der Tatsache, daß Brüning sich durch Klepper bei der Verwirklichung seiner Reichsreformpläne und der Realisierung seiner außenpolitischen Ziele gestört fühlte.

\section{Verteidigung der Unabhängigkeit Preußens gegenüber dem Reich}

Kleppers Ernennung zum preußischen Finanzminister wurde offensichtlich sowohl von Kommentatoren wie von beteiligten Politikern im Zusammenhang mit der Frage nach der Erhaltung oder der Zerschlagung des „Systems“ gesehen. Da Preußen nunmehr mit seiner noch regierenden Weimarer Koalition das „System“ verkörperte, ging es um die Erhaltung oder die Beseitigung Preußens. Auch Klepper selbst sah seine Ernennung in diesem Zusammenhang. „Weil wir wissen, daß es um das Ganze geht, gehen wir auf das Ganze.“ Es gehe um die „Zusammenfassung aller Kräfte des Willens in der Richtung auf ein Ziel, nämlich die Macht"66. Da die Auseinandersetzungen zwischen Preußen und Reich genau zu dieser Zeit kulminierten und bevorzugt in Kleppers Kompetenzbereich, der Finanz- und der Agrarpolitik, ausgetragen wurden, fiel ihm notgedrungen eine gewisse Schlüsselrolle in dieser Endphase der Republik zu.

In diesem Zusammenhang müssen auch Kleppers finanzpolitische Maßnahmen gesehen und beurteilt werden und erst in zweiter Linie unter allgemeinen finanzwirtschaftlichen Gesichtspunkten. Klepper stellte seine Finanzpolitik vom November 1931 bis zum Juli 1932 primär unter das politische Ziel, Preußen zu erhalten und das „internationale Vertrauen zu einer friedlichen wirtschaftlichen Entwicklung herzustel-

${ }^{65}$ Selbst Zeitgenossen aus dem konservativen Lager bestätigen Kleppers Diagnose. Schlange-Schöningen klagt in einem Brief an Hindenburg vom 27.5. 1932, daß seine eigenen Standesgenossen „,wiederum die Zeichen der Zeit nicht begreifen wollen, so fürchte ich, sie graben sich selbst ihr Grab, und eine stürmische Entwicklung wird über sie hinweggehen'“, zitiert bei Muth, Zum Sturz, S. $557 \mathrm{f}$.

${ }^{66}$ GSTAM, VNL-K, Nr. 176, S. 1-30, S. 2, Klepper: Wahlrede gehalten in Kiel am 19. 4. 1932, ein paar Tage vor den preußischen Landtagswahlen am 24. 4. 1932, deren Wahlergebnis (s.u.) seine Sorge bestätigte. Erwähnt wird die Rede auch in: GSTAM, Rep. $151 \mathrm{HB}$, Nr. 39, weil sie durch eine Klage des Finanzministers gegen die beiden Hugenberg-Blätter Berliner Lokalanzeiger und Der Tag, die die Rede falsch wiedergegeben hatten, ein gerichtliches Nachspiel hatte. Dieser gerichtliche Streit, der von einer widerlichen Pressekampagne begleitet wurde, führte zu einem endlosen Austausch von gegnerischen Schriftsätzen und zu Verhandlungen, die groteskerweise erst am 3. Mai 1933, als Klepper und Braun längst im Exil waren, eingestellt wurde, wofür der Anwalt vom preußischen Staatsministerium 532,04 RM forderte. 
len“67. Erstes Gebot dieser Politik war zwar Sparen, denn die preußischen Kassen waren leer, aber Klepper verband seine Sparpolitik von Beginn mit einem Reformprogramm, das einerseits das Sparen unterstützen und andererseits den demokratischen Staat stabilisieren sollte.

Anhand seiner Reden vor dem preußischen Landtag und dem Staatsrat, anhand seiner beiden Rundfunkansprachen im Dezember 1931 und Frühsommer 1932 und seiner Wahlreden ${ }^{68}$ lassen sich folgende Grundlagen für seine Politik ermitteln: Erstens die aus dem Studium der Wirtschaftsgeschichte gewonnene Einsicht, daß „eine grundsätzliche Grenzziehung zwischen der öffentlichen Finanzpolitik und der allgemeinen Wirtschaftspolitik notwendig" sei69, denn weder die wirtschaftliche Krise noch die Konjunktur werden von der staatlichen Finanz- beziehungsweise der Steuerpolitik gemacht, diese kann höchstens stützend oder störend eingreifen. Zweitens die Erkenntnis, daß die Nationalwirtschaften sich nicht mehr als isolierte Gebilde betrachten können und schon gar nicht versuchen sollten, nach Autarkie zu streben, weil die nationale von der internationalen Konjunktur abhängig ist „und der Sinn der modernen wirtschaftlichen Entwicklung in einer Erleichterung des zwischenstaatlichen Güteraustausches, nicht aber in seiner Hemmung besteht"70. Ergänzend dazu sagte er im Frühjahr 1932 in seiner Kieler Wahlrede: „Die Dinge liegen hart und eindeutig so, daß es entweder gelingt, die große politische Verständigung der Völker, in deren Mittelpunkt Deutschland und Frankreich stehen, herbeizuführen, oder alles das, was wir unter der modernen Wirtschaft verstehen, wird zusammenbrechen."71

Drittens erforderten, so meinte Klepper, die sich verändernden wirtschaftlichen, technischen und sozialen Bedingungen Reformen, die der Staat durch Abbau von Subventionen, zum Beispiel in der Landwirtschaft, durch „die Anpassung des allgemeinen Verwaltungsapparates an die verminderte Leistungsfähigkeit des Staates“, also durch eine Verwaltungsreform ${ }^{72}$, und durch die Anpassung der Arbeitszeit an die veränderten technischen Bedingungen erreichen kann. Klepper setzte sich für Arbeitszeitverkürzung mit dem Ziel der 40-Stunden-Woche ein, weil er dadurch „1 Million Arbeitslose in den Produktionsprozeß zurückzuführen“ und damit die Gemeinden zu entlasten hoffte ${ }^{73}$. Parallel dazu müsse „der Weg der Beschaffung neuer Arbeit beschritten werden“. „Volkswirtschaftlich rentable Arbeitsmöglichkeiten“ aber ergaben sich für Klepper aus „der

\footnotetext{
67 Klepper, Kieler Rede, S. 16.

${ }^{68}$ Seine beiden Reden im PrLT wurden am 15/17. 3. 1932 anläßlich der Einbringung des Haushaltes für 1932 (281./283. Sitzung, Sp. 24571-24582; Sp. 24725-24748) und am 16. 6. 1932 anläßlich der 2. preußischen Sparnotverordnung (9. Sitzung, Sp. 545-553) gehalten. Vgl. außerdem: Rede vor dem PrStR (GSTAM, Rep. 151 HB, Nr. 531, Bl. 107 ff.) in der Sitzung des Haupt- und Gemeindeausschusses des Staatsrates vom 21. 1. 1932 (GSTAM, Rep. 151 HB, Nr. 563/1, Reden des Finanzministers im PrLT, Handakte 1932) und die Rundfunkansprachen vom 23.12. 1931 und vom 10. 6. 1932 (die letztere in VNL-K, beide im Rundfunkarchiv in Frankfurt/M.).

${ }^{69} \operatorname{PrLT}$, 281. Sitzung, 15.3. 1932, Sp. 24580.

70 Ebenda, Sp. 24582 und 9. Sitzung, 16. 6. 1932, Sp. 551: „Von der Erkenntnis, daß nur durch eine internationale Wirtschaftsverständigung die Krisenwirkung behoben und die Konjunktur hervorgehoben werden kann, ist bisher in den Kundbarmachungen der Reichsregierung nichts zu erfahren."

${ }_{71}$ Kieler Rede, S. $16 f$.

72 PrLT, 281. Sitzung, 15. 3. 1932, Sp. 24580.

${ }^{73}$ Kieler Rede, S. 21. Am 16. 6. 1932 spricht er im PrLT (9. Sitzung) über die Verminderung der Arbeitslosen und damit der staatlichen Sozialausgaben (Sp. 552).
} 
Durchführung der Agrarreform im deutschen Osten“, durch vermehrte Ansiedlung „bäuerlicher Familienbetriebe“, die sich als „der krisenfesteste Teil der Landwirtschaft" erwiesen hätten. Im Gefolge der Bauern würden dort auch Handwerker, Kaufleute und Arbeiter neue Arbeitsmöglichkeiten finden ${ }^{74}$. Viertens sah Klepper in einer Stärkung der „Selbstverwaltungskörper" auf allen möglichen Gebieten, zum Beispiel auch auf dem Gebiet der Kulturpolitik, das heißt im Abbau von Staat zugunsten gesellschaftlicher Initiativen, nicht nur eine Möglichkeit, staatliche Gelder einzusparen, sondern auch die Demokratie von unten zu stärken ${ }^{75}$.

Die praktischen Konsequenzen, die Klepper aus seinem Reformprogramm zog, waren einmal eine eiserne Sparpolitik, die in erster Linie darauf achtete, den Haushalt "echt" auszugleichen, das heißt nicht mehr auszugeben, als man einnahm, und zum anderen Reformen, die die Kürzung von Ausgaben ermöglichten ${ }^{76}$. Seine strikte Forderung nach einem ausgeglichenen Haushalt, gegen die man hätte einwenden können, daß unter bestimmten Bedingungen Mehrausgaben von seiten des Staates zu rechtfertigen gewesen wären, begründete Klepper zwar in der Öffentlichkeit mit volkswirtschaftlichen Argumenten, aber dahinter standen politische Überlegungen. Vor dem Landtag sagte er, wenn das Finanzsystem durch eine wirtschaftliche Krisenlage ins Schwanken gerate, die Einnahmen den Ausgaben nicht mehr entsprächen, dann gerate die Regierung unter den Druck einer starken politischen und sozialen Dynamik und komme aus dem „Bedürfnis nach Populariät“ heraus in Versuchung, „durch eine illegitime Geldschöpfung die Zahlungsfähigkeit aufrechtzuerhalten“, wodurch „,erhebliche Erschütterungen für Wirtschaft und Währung heraufbeschworen werden können"77. So gehe es allein darum, „eine Gefährdung von Währung und Wirtschaft zu vermeiden“, um „die Zeit bis zur wirtschaftlichen Wende lebensfähig zu überstehen“, und er fügte hinzu, „diese Überzeugung gibt auch einer bewußt sozial-fortschrittlich eingestellten Regierung wie der preußischen Staatsregierung die innere Berechtigung zu der Härte, die die augenblickliche Finanzpolitik leider kennzeichnen muß"78.

Nachdem Klepper in der Staatsratssitzung drei Tage nach seiner Ernennung zum Finanzminister, am 10. November 1931, feierlich begrüßt und zum Mitglied des Reichsrates ernannt worden war ${ }^{79}$, legte er bereits eine Woche später einen Gesetzentwurf für das Haushaltsjahr 1932 vor $^{80}$. Preußens Kassen waren leer, das Defizit für Ende November lag bei 54 Millionen RM, zu dem ein Fehlbetrag von rund 450 Millionen aus den beiden vorherigen Haushaltsjahren gerechnet werden mußte. Was lag näher, als beim Reich betteln zu gehen? Wie aus einem Aktenvermerk Kleppers hervorgeht ${ }^{81}$, fand bereits am 17. November eine Sitzung bei Reichskanzler Brüning statt. Klepper berichtet: Nach-

\footnotetext{
${ }^{74}$ Kieler Rede, S. $21 \mathrm{ff}$.

75 PrLT, 281. Sitzung, 15. 3. 1932, Sp. 24577/80. Vgl. auch Kleppers Behandlung der Theater (s.u.) und die Stärkung der Genossenschaften durch ihre Rationalisierung.

76 PrLT, 281. Sitzung, 15. 3. 1932, Sp. 24576.

77 Ebenda, Sp. 24579. PrLT und 9. Sitzung, 16. 6. 1932, Sp. 546.

${ }^{78}$ PrLT, 281. Sitzung, Sp. 24582.

79 GSTAM, Rep. 90a, Bd. 177, Bl. 158 und GSTAB, I. HA, Rep. 90, Annex A, Nr. 39, Bl. 68. VNLK, Nr. 187/88, Akte Briefe des Vaters: Telegramm an den frischgebackenen Finanzminister: „Gott mit Dir, tausend Grüße Eltern".

${ }^{80}$ GSTAB, Rep. 90, Nr. 39, Bl. 160, Vorlage vom 17. 11. 1931.

${ }^{81}$ GSTAM, VNL-K, Nr. 171.
} 
dem er Brüning die Kassenlage dargelegt und der Hoffnung Ausdruck verliehen habe, am 20. November die fälligen Gehaltszahlungen leisten zu können, ohne allerdings eine Deckungsmöglichkeit - weder durch Einnahmen noch durch Überbrückungskredite zu sehen, habe Brüning gemeint, die Sparmöglichkeiten seien noch nicht ausgeschöpft, zum Beispiel seien weitere Gehaltskürzungen möglich. Das habe er ohne „vorherige Durchführung einer allgemeinen Senkung der Lebenshaltungskosten“ abgelehnt, worauf Brüning geantwortet habe, ,wirtschaftspolitische Maßnahmen der angedeuteten Art würden keine momentane Wirkung haben“. Außerdem müsse er fordern, daß der preuBische Etat zur Zeit nicht veröffentlicht werden solle. Klepper „erschien im Gegenteil eine volle Publizität der Staatsfinanzen eine politische Notwendigkeit“. Brüning habe dann eine nochmalige Besprechung in acht Tagen vorgeschlagen, zu der Klepper einen genauen Etatentwurf mitzubringen versprach. Zwei Tage nach dieser Besprechung, in der Brüning ausdrücklich um Stillschweigen gebeten hatte, erschien im Demokratischen Pressedienst eine aus Quellen der Reichsregierung stammende Presseveröffentlichung über die Gestaltung des preußischen Etats!82

Wie die nächste Besprechung von Braun und Klepper mit Brüning am 23. November $1931^{83}$ verlief, hat der ebenfalls anwesende Staatssekretär im Reichsfinanzministerium, Hans Schäffer, überliefert. Seine Aufzeichnungen sollen hier ausführlich wiedergegeben werden, weil sie nicht nur die Trostlosigkeit der Situation widerspiegeln, sondern auch Einblick in die Verhandlungsweise Kleppers und seine zu Brüning konträre Politik gewähren ${ }^{84}$. Dies festzuhalten, ist auch deshalb wichtig, weil Gerhard Schulz kürzlich die alten Vorurteile gegen Klepper aus der einseitigen Sicht von Brüning und Severing wiederholt hat. Klepper sei „nicht nur ein Vertreter preußischer Interessen " 85 , wie auch immer "preußische Interessen" zu definieren sein mögen, er sei einer, der auf zwei Schultern zu tragen scheine. Als Beleg zitiert Schulz Brünings oben bereits erwähnten Ausspruch, daß Klepper „schwer beizukommen“ sei, und zieht daraus den Schluß: „Er [Brüning] verdächtigte ihn also einer Art doppelten Spiels. “ Das aber macht auch für Schulz „nur dann einen Sinn [...], wenn Klepper konkurrierenden Intentionen ausge-

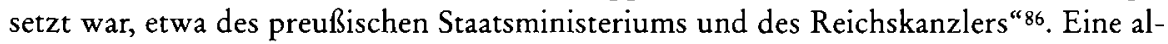

82 Ebenda, Brief Klepper an Braun, vom 19.11. 1931.

${ }^{83}$ AdR-Brüning, Nr. 566: Vermerk des Staatssekretärs Pünder über eine Besprechung des RK mit dem PrMP und dem PrFM am 23. 11. 1931. Klepper beziffert das Kassendefizit für November auf 54, für Dezember auf 76, für Januar auf 48, für Februar auf 47 und für März auf 51 Millionen RM. Vgl. außerdem PrLT, 281. Sitzung, 15. 3. 1932, Sp. 24572.

${ }^{84}$ Schäffer, Bd. 15, S. 1072 ff., 23. 11. 1931. Zu bedenken ist natürlich, daß Schäffer die Ansicht des Reiches vertritt. Er berichtet über sich selbst in der dritten Person folgendes: „Der Kanzler leitet die Ausschußsitzung des Wirtschaftsbeirates am 10.11. 1931 ein. [...] Schäffer ist überhaupt nicht der Auffassung, daß jetzt der Zeitpunkt ist, an dem die Länder an das Reich Anforderungen zu stellen haben, sondern daß an jeder Stelle so gespart werden muß, daß man mit den vorhandenen Mitteln auskommt. Die Pläne von Klepper, einen Defizit-Haushalt auszuweisen, um das Reich zur Unterstützung einer bestimmten Politik zu bringen, lehnt Schäffer ab. Es soll vielmehr gemeinsam vom Reich und den Ländern nach Ersparnismöglichkeiten gesucht werden.“

85 Schulz, Brüning, S. 745.

${ }^{86}$ Ebenda, in diesen Zusammenhang gehört auch der von Hagen Schulze (S. 796) geäußerte Verdacht, Klepper habe Beziehungen zum Deuxième Bureau gehabt. Diese irrige Auffassung läßt sich durch Kleppers Freundschaft zu Degon (s.u.) erklären. Degon arbeitete als Kenner Deutschlands als Übersetzer für das Deuxième Bureau, allerdings erst ab 1939. 
ternative Deutung, die Brünings Aussage ${ }^{87}$ auch nahelegt hätte, nämlich daß Klepper alles getan hat, um Preußen als demokratisches Bollwerk gegen das Reich zu erhalten, bis die Demokratie-Krise im Reich überwunden war, und daß dazu an erster Stelle die finanzielle Unabhängigkeit Preußens vom Reich gehörte, wird nicht angeboten, obwohl Schulz' Darstellung der Finanzverhandlungen zwischen Preußen und Reich Kleppers Rolle bereits sehr viel stärker berücksichtigt, als andere Autoren es getan haben.

Nun also zu Schäffers Bericht von der Sitzung am 23. November 1931: „Klepper: Preußen braucht in den nächsten Tagen einen Betrag von 56 Millionen, außerdem bis zum Ultimo Dezember weitere 76 Millionen, bis zum Ultimo März 32 Millionen, im ganzen 300 Millionen als Kassenmittel. Ob wir sie geben können? Es ist eine Situation vorhanden, daß Preußen sich nicht mehr retten kann. Im Abstreichen von Ausgaben hat es alles getan. Einnahmeerhöhungen hat ihm das Reich unmöglich gemacht. Damit hat es die Verpflichtung übernommen, ihm jetzt auch beizuspringen. Ich [Schäffer]: Es ist aber völlig unmöglich. Woher sollen wir die Beträge nehmen? Wir haben Mühe, selber durchzukommen. Klepper: Einen solchen Fall konnte man voraussagen. Auf diesen mußte das Reich gerüstet sein. Ich: Seit wann? Klepper: Aus den Zeiten der reichlichen Einnahmen. Ich: Die flossen den Ländern und Gemeinden genauso zu. Im Gegenteil, deren Steuern nahmen noch mehr zu. Hier hätte man die Reserven bilden sollen. Klepper: Ich halte aber die ganze Wirtschaftspolitik für falsch. Man sollte nicht die Einkommen senken und damit wieder das Wirtschafts- und Steuervolumen vermindern. Brüning: Glauben Sie, daß wir allein in der Welt eine der allgemeinen Einstellung entgegenlaufende Politik machen können und noch dazu in einem Augenblick, in dem wir vor Verhandlungen stehen, bei denen die Gefahr besteht, daß die anderen, für die Sparsamkeit als absolutes Ziel gilt, uns Verschwendung vorwerfen?" Nun schaltete Braun sich ein und unterstützte Klepper, so könne man die Wirtschaftspolitik nicht machen und Preußen, das 3/5 des Reichsgebietes umfasse, nicht allein lassen und schließlich habe Bayern 120 Millionen für seine Post, Preußen aber nichts für seine Eisenbahnen bekommen $^{88}$. Dieser exemplarische Ausschnitt aus Schäffers Tagebuch illustriert bei aller Verkürzung die Notlage Preußens, die Kompromißlosigkeit der Reichspolitik, die klar ihre Prioritäten in der Außenpolitik hatte, sowie Brauns und Kleppers Versuche, der Reichspolitik die Ziele Preußens entgegenzusetzen.

Die Verhandlungen waren zunächst ergebnislos, und auch bei dem Gespräch zwischen Schäffer und Klepper unter vier Augen kam nichts heraus. Klepper gab immerhin $\mathrm{zu}$, „wenn ich nicht von vornherein überzeugt gewesen wäre, daß Sie auch nichts haben, hätte ich ganz anders auf Sie gedrückt“. Er wiederholte, daß "die ganze Außenpolitik und die ganze Wirtschaftspolitik geändert werden“ müsse und daß „auch die Agrarpolitik schuld" sei. Obwohl Schäffer es für aussichtslos hielt, Auslandsanleihen zu bekom-

${ }^{87}$ Brüning, Memoiren, S. 482: „Klepper war [...] schwer beizukommen [...], weil er in Besprechungen mit der Reichsregierung klug und sachlich war, aber nachher insgeheim die preußischen Ressorts anders beeinflußte, wobei er durch seinen Appell an die Partikularinstinkte auch die Unterstützung hoher preußischer Beamter fand, die an sich der deutschnationalen Partei angehörten."

${ }^{88}$ Ebenda, S. 1073. RFM Schwerin v. Krosigk bestätigte Schäffer gegenüber am 8. 2. 1932, daß das Reich Preußen „tatsächlich schlecht behandelt" habe, im Gegensatz zu Württemberg und Bayern (Bd. 17, S. 183). 
men, meinte Klepper, französische Anleihen besorgen zu können ${ }^{89}$. Schulz kommentiert dieses Gespräch mit den Worten, Klepper habe sich „als ein Mann von begrenzter Kompetenz auf seinem schwierigen neuen Fachgebiet“" erwiesen, ein hartes Urteil, das er durch eine begrenzte Vermutung zu begründen weiß, nämlich durch Kleppers, wie er meint, „unangemessenen Hoffnungen auf Auslandskredite“90.

Tatsächlich aber hatte Klepper berechtigten Grund, auf französische Anleihen zu hoffen, schon seit 1930 pflegte er Kontakt mit der Caisse Nationale Du Crédit Agricole (CNCA) in Paris. Im Sommer 1931 hatte er mit Mitarbeitern der Preußenkasse eine sechswöchige Reise durch Holland, Belgien, Frankreich und die Türkei gemacht und überall die landwirtschaftlichen Kreditbanken besucht. Auf dieser Reise begleitete ihn auch Jean Degon, der ihm später das Leben rettete, als französischer Dolmetscher. Degon war Anfang 1931 als deutschsprechender und an Deutschland interessierter Franzose nach Berlin gekommen und hatte Kontakt zu Klepper aufgenommen, da dieser einen Französischlehrer suchte. Um Degon stets in seiner Nähe zu haben, stellte Klepper Degon kurzerhand als Volontär bei der Preußenkasse ein, was Degon immerhin so sehr beeinflußt hat, daß er nach seiner Rückkehr nach Paris zur Caisse Nationale Du Crédit Agricole (CNCA) ging. Seine spätere Frau Madeleine Landy-Degon hat ein Buch über den Crédit Agricole geschrieben, das sich, wie sie sagt und wie es im Vorwort des Buches vermerkt ist, stark auf die Ideen Kleppers stützte ${ }^{91}$.

Noch als Präsident der Preußenkasse hatte Klepper Ende Oktober 1931 eine Serie von Besprechungen mit dem französischen Landwirtschaftsminister André Tardieu, dem Sous-Sécrétaire d'Etat de l'Economie Nationale, Gignoux, und dem Direktor des Crédit Agricole, Louis Tardy, den Klepper schon von früher her kannte. Mit allen sprach er über eine notwendige Zusammenarbeit zwischen Deutschland und Frankreich ${ }^{92}$. Wie sich aus den Papieren Tardieus in den Archives de France ergibt, hatte Tardieu eine ähnliche Auffassung von landwirtschaftlichen Reformen wie Klepper und beklagte die Getreideüberproduktion sowie den weltweiten Preisverfall ${ }^{93}$.

${ }^{89}$ Ebenda, Bd. 15, S. 1073 f., 23. 11. 1931.

${ }^{90}$ Schulz, Brüning, S. $598 \mathrm{f}$.

${ }^{91}$ Die Verfasserin hatte im Sommer 1992 die Möglichkeit, sowohl mit Jean Degon, der heute in Cannes lebt, und mit Madeleine Landy-Degon, die immer noch auf der kleinen Farm bei Quillan im Dep. Aude, auf der Klepper 1941/42 Zuflucht fand, lebt, ausführlich zu sprechen. Degon berichtete, daß Klepper auf jener Reise 1931 jeden Tag mit Berlin telephoniert habe und am Tage seiner Rückkehr die große Bankenkrise ausgebrochen sei, d. h. die Reise fand Juni/Juli statt. Die Kontakte mit dem Crédit Agricole werden bestätigt durch VNL-K, Nr. 157 und Nr. 160. Vgl. auch Bosséno, Madeleine, in: Le Magazine Du Groupe CNCA, 30 (Mars 1993), S. 17 (der erneuerte Kontakt zwischen dem Crédit Agricole und Madame Landy-Degon ergab sich aus meinen Recherchen).

92 VNL-K, Nr. 160, Konferenz vom 31. 10. 1931, vgl. dazu Briefwechsel zwischen Etienne Metzger und Klepper, 7. 10.1931 bis 4. 1. 1932. Der Besuch Kleppers bei Landwirtschaftsminister Tardieu und der CNCA sowie der diesbezügliche Kontakt mit François-Poncet werden durch ein Protokoll vom 20. 11. 1931 aus dem Archiv der CNCA, das jetzt erst wieder aufgebaut wird, bestätigt. Leider müssen die meisten Unterlagen aus der Zeit vor dem Kriege als verschollen gelten.

${ }_{93}$ C.A.R.A.N., Papiers Tardieu, 324 AP, 65. In dem gleichen Karton befindet sich eine Mappe mit der Aufschrift: "Prêts à l'Allemagne" (Anleihen an Deutschland), in der sich aber nur ein Zettel mit Daten (Juli/August 1931) und Ausschnitte aus der Parlamentsdebatte vom 26. 6. 1931 befinden. 
Das Programm der Zusammenarbeit, das Klepper vorschlug ${ }^{94}$ und das auf großes Interesse stieß, konzentrierte sich vor allem auf zwei Ziele: „1) eine finanzielle Verbindung zwischen den beiden Instituten“, CNCA und P.Z., und „2) eine gemeinsame Tätigkeit beider Institute zur Verwirklichung von Getreideeinkäufen auf den europäischen Märkten, zwecks Gesundung des Getreidemarktes durch richtige Verwendung und Verteilung der Getreideüberschüsse, in Verbindung mit Vorteilen für die Industrien beider Länder“. Voraussetzung für die Zusammenarbeit war ein gegenseitiges Sich-Bekanntmachen der Institute. Entsprechend bereitete Klepper eine Serie von sechs Konferenzen zwischen den Vertretern der Preußenkasse und der CNCA vor, in denen über deutschfranzösische Zusammenarbeit auf dem Gebiet des Agrar- und Kreditwesens verhandelt wurde $^{95}$. Da es sehr schwer sein würde, gemeinsame Getreideeinkäufe bei den ostdeutschen Landwirten durchzusetzen, drang Klepper auf eine Geste der Franzosen in Form eines französischen Darlehens an die Preußenkasse, wobei er ausdrücklich betonte, daß die Preußenkasse „finanziell auf völlig gesunden Füßen“ stehe. Es gehe, so sagte er zu Tardieu, tatsächlich nur um die Geste, die Höhe des Darlehens sei ohne Belang und im übrigen bringe es den Franzosen wegen der höher liegenden deutschen Zinsen sogar Vorteile. Klepper sah die Zusammenarbeit zwischen der CNCA und der P.Z. in dem größeren Zusammenhang deutsch-französischer Zusammenarbeit, die „auf landwirtschaftlichem Gebiet noch nie versucht und auf industriellem Gebiet so schwierig“ in die Wege zu leiten sei ${ }^{96}$. Es ist anzunehmen, daß Klepper, der immer wieder die Notwendigkeit einer Eingliederung der deutschen Wirtschaft in die Weltwirtschaft betonte und dafür die deutsch-französische Zusammenarbeit als unbedingte Voraussetzung ansah, mit der offiziellen Geste der französischen Darlehen einen symbolischen Anfang schaffen und Preußen durch diese Zusammenarbeit mit Frankreich vom Reich zusätzlich unabhängig machen wollte.

Sowohl Tardieu wie Tardy gaben ihre positiven Eindrücke von den Gesprächen an den französischen Botschafter, André François-Poncet, nach Berlin weiter, verbunden mit der Bitte, den Gedankenaustausch fortzusetzen. François-Poncet hat regelmäßig über Kleppers Finanzpolitik und die Osthilfe nach Paris berichtet ${ }^{97}$; insofern lag Brüning mit seiner Meinung über eine Verbindung Kleppers zum französischen Botschafter nicht falsch, zumal François-Poncet mit Harry Graf Kessler, in dessen Haus auch Klepper verkehrte, befreundet war. Daß Brüning sich über ein derart eigenständiges Vorgehen Kleppers ärgerte, zumal er davon überzeugt war, daß die Franzosen nur gegen politische Zugeständnisse seitens der Deutschen Anleihen vergeben würden ${ }^{98}$, kann man aus Brünings Sicht verstehen. Allerdings könnte man auch genausogut andersherum argumentieren: Brüning hätte diese mehr inoffiziellen, auf persönlicher und auf Landesebene

\footnotetext{
94 GSTAM, VNL-K, Nr. 157, Protokoll der 5. Konferenz, 9. 11. 1931, Bl. 107.

${ }^{95}$ VNL-K, Nr. 160.

96 VNL-K, Nr. 157, Bl. 13 und 108. Zu welchem Ergebnis die Verhandlungen geführt haben, ist leider aus den unvollständigen Akten nicht zu ersehen.

${ }^{77} \mathrm{AE} / \mathrm{F}, \mathrm{B} 31467$ ff., $\mathrm{F}^{30} 536 \mathrm{ff}$. und 470, $\mathrm{F}^{30}$ 539, Berichte François-Poncets vom 24. 12. 1931, 5. 1. 1932, 16. 3. 1932. Die in den Archives du Ministère Des Affaires Étrangères (AD) eingesehenen Berichte der französischen Botschaft aus Berlin über die wirtschaftliche Situation Deutschlands aus den Jahren 1930-1933 (Z Europe 1930-40, situation économique de l'Allemagne 1930-1931/ 761 und 1932-1933/762) bestätigen die Urteile der liberalen deutschen Presse und spiegeln insofern eine bestimmte liberale wirtschaftspolitische Einstellung wider.

98 Vgl. Brünings Gespräch mit Schäffer vom 4. 3. 1932, Bd. 19, S. 317 ff.
} 
laufenden Kontakte auch begrüßen und nutzen können, weil die Zusammenarbeit besonders mit Frankreich auf Reichsebene zu dem Zeitpunkt noch ausgesprochen schwierig war ${ }^{99}$, aber dazu war Brüning wohl nicht der geeignete Mann und sein Mißtrauen gegenüber Klepper zu groß.

Klepper verhandelte weiter mit dem Reich und versuchte Schritt für Schritt, Möglichkeiten zu finden, seinen Haushalt über die Runden zu bringen. Es war, wie Schulze anmerkt, „ein Kreislauf von Bittgängen, Drohungen und Erpressungen [...] in Gang gekommen" 100 . Schon einen Tag nach der Besprechung Brauns und Kleppers mit Brüning am 23. November erreichte Preußen in Verhandlungen mit Reichsbankpräsident Hans Luther die Zusage, daß „5 Millionen für diesen Ultimo von der Reichsbank weiter gestundet" werden würden. Dafür wollte Klepper am 10. Dezember seinen Etat vorlegen, wobei er allerdings Gehaltskürzungen unter das Niveau des Reiches strikt ablehnte ${ }^{101}$. Ende des Monats berichtete Braun dem Reichskanzler nochmals über die im Kabinett beratene Lage der preußischen Staatsfinanzen und darüber, daß „die noch vorhandenen Steuerquellen restlos ausgeschöpft" sowie die halben Dezembergehälter sichergestellt worden seien. Braun endete seinen Brief mit der versteckten Drohung: Falls „die erforderliche Hilfestellung “ nicht gegeben werde, „würde die preußische Staatsregierung sich gezwungen sehen, alsbald der Öffentlichkeit über die Zuspitzung der Kassenlage und über die Gründe ihrer Entwicklung vollen Aufschluß zu geben“102.

Daraufhin fand am 2. Dezember eine Besprechung mit dem Reichskanzler statt, bei der Klepper die preußischen Absichten zur Abdeckung des Etats darlegte ${ }^{103}$. Und zwar sollten „die Personalausgaben um 100 Millionen und die Sachausgaben um 113 Millionen“ gesenkt werden, dafür müßten „70 Amtsgerichte und 56 Kreise eingespart“, die „Staatstheater mit Ausnahme der großen Oper"104 und auch „Akademien“ geschlossen werden. Zu den so eingesparten 213 Millionen sollten noch „90 Millionen“ „aus der erhöhten Umsatzsteuer" und 100 Millionen aus der noch einzuführenden Schlachtsteuer gewonnen werden, so daß Preußen über einen Betrag von 400 Millionen verfügen könne, der noch durch einen „Bewegungskredit von 200 Millionen“ aufzustocken sei. „Im gegenwärtigen Augenblick brauche Preußen sofort 35 Millionen.“

Die preußische Regierung hatte erreicht, was sie wollte, die Dinge kamen in Gang, und die Reichsregierung begriff, daß sie etwas tun mußte, zumal sie aus wahltaktischen Gründen vor einer Schlachtsteuer und der auch von Klepper erwähnten möglichen Margarinesteuer zurückschreckte. Zunächst wurde die Hilfe der Reichsbank bei der Beschaffung der 35 Millionen zugesagt. Dazu bemerkt Schäffer in seinem Tagebuch: „Der Kanzler drückt über die Braunsche Regierung auf die Sozialdemokratie, den Reichstag

99 Vgl. die seit Anfang des Jahres verstärkt anlaufenden taktischen Manöver zur Lösung der Reparationsfrage, zur Vertagung der Lausanner Konferenz und zur Abrüstungskonferenz, dargelegt bei: Schulz, Brüning, S. $683 \mathrm{ff}$. und $696 \mathrm{ff}$.

100 Schulze, Braun, S. 712.

101 Schäffer, Bd. 15, 24. 11. 1931, Bl. $1082 \mathrm{f}$.

102 AdR-Brüning, Nr. 575: Der PrMP an den RK, 28. 11. 1931. Der Entwurf des Briefes stammt von Klepper und wurde in der Kabinettssitzung beraten (VNL-K, Nr. 171, Bl. 15 ff.). Vgl. ebenda: Entwurf eines Schreibens Brauns an Brüning, 27. 11. 1931.

${ }^{103}$ AdR-Brüning, Nr. 581.

${ }^{104}$ Engelmann, S. 35, berichtet von einem Vorschlag Kleppers, „das hohe Subventionen kostende staatliche Schauspielhaus zu schließen und auf die Reinhardt-Bühnen, die dann keine Hilfe mehr brauchen würden, die Rechte und Pflichten eines Staatstheaters zu übertragen" (S. 38). 
nicht einzuberufen. "105 Wie es in Wirklichkeit in der angeblich leeren Reichskasse aussah und wie recht Klepper mit seinen Forderungen hatte, verdeutlicht die folgende Notiz über ein Gespräch Schäffers mit Reichsbankvizepräsident Fritz Dreyse: „Ich sage ihm, daß unsere Kasse um 70 Millionen besser stehe, als wir gerechnet hatten. Es müsse aber geheim bleiben. Ich glaubte, daß wir jetzt mit einem Betrag von 80 Millionen wohl über den Dezember-Ultimo hinwegkommen. Ich rechne Dreyse die Sache vor. Dreyse zeigt sich durchaus geneigt, in diesem Umfang durch Finanzierung der Betriebskredite entgegenzukommen." 106

Am folgenden Tag konferierten die Finanzminister der Länder, und Klepper bemühte sich um ein gemeinsames Vorgehen der Länder, um die Wahrung ihrer Eigenverantwortlichkeit gegenüber dem Reich und um eine Verbesserung der Leistungsfähigkeit der Staatsbanken, damit sie mit den Privatbanken konkurrieren könnten, wozu man sich „die besten Leute“ mit entsprechend hoher Bezahlung holen müsse ${ }^{107}$. Klepper versuchte den Bürokratien marktwirtschaftliches Denken beizubringen. Die finanzielle Lage der Länder war unterschiedlich, Schäffer meinte, „daß die süddeutschen Länder durchkommen werden. Preußen will seine Sache mit brutalem Ruck in Ordnung bringen." Entsprechend wurde Klepper von allen Seiten unter Druck gesetzt. Selbst der Preußenkasse, die er laut Treviranus immer noch genauso wie früher regierte, wollte man an den Kragen. Die Zinsen sollten gesenkt und eine neue, der Reichsregierung angenehme Leitung bestellt werden ${ }^{108}$.

Am 16. Dezember mußte Klepper einen Runderlaß zur „vorläufigen Durchsetzung der dritten Gehaltskürzungsverordnung bei Beamten und Lehrpersonen“ veröffentlichen ${ }^{109}$, was er zunächst abgelehnt hatte und nun gewiß nicht gerne tat. Schließlich fand am gleichen Tag im preußischen Landtag eine Debatte über einen Mißtrauensantrag gegen Klepper statt. Die Begründung für den Antrag stammte aus der Zeit seiner Tätigkeit bei der Domänenbank und der Preußenkasse und war in etwa identisch mit der für die Einsetzung eines Untersuchungsausschusses zur „Geschäftsgebarung Kleppers als Preußenkassenpräsident“. Die Deutschnationalen warnten in bewegten Worten vor dem „System Klepper“, mit dem die „alten, in Ehren ergrauten Minister noch ihr blaues Wunder" erleben würden, und griffen Klepper auf unsachliche Weise an. Die Debatte schloß mit einem auf Klepper gemünzten Vers, der recht bezeichnend ist:

${ }^{105}$ Schäffer, Bd. 16, 2. 12. 1931, S. 1106.

106 Ebenda, vgl. auch Schulz, Brüning, S. 696: „Das Jahr 1931 hatte Deutschland den größten AuBenhandelsaktivsaldo der Nachkriegszeit gebracht (2 778 Millionen RM); trotz der umfänglichen Gold- und Devisenabflüsse ergab sich am Ende auch hier ein Aktivsaldo von 1706 Millionen RM.“

107 Ebenda, Bd. 16, 3. 12. 1931, S. 1110 f.: „Alle Etats müssen aufgestellt werden, und sie müssen ausgeglichen sein."

${ }^{108}$ Ebenda, 4. 12. 1931, S. 1118 und 1133, Brüning sagt: „Die Zustände in der Preußenkasse haben uns sehr geschädigt. “ Luther erwidert: „Die Preußenkasse ist nur von innen her zu behandeln.“ Robert Weismann meint: „Die Preußenkasse ist pleite und muß daher die Bedingungen schluken."

109 HAStK, 902, 46,2, 2. Bd., Bl. 659 (ebenda, Bl. 661-666: Abdruck des preußischen Besoldungsblattes). 

„Die über Nacht sich umgestellt
Die sich zu jedem Staat bekennen,
Das sind die Praktiker der Welt
Man könnte sie auch anders nennen."110

„Der Praktiker der Welt" wird vielleicht sogar geschmunzelt haben, als er diese Verse hörte, man hatte ihn während der Debatte dazugeholt, und er hatte ein paar Mal dazwischengerufen: „Das ist unwahr!“ Der Mißtrauensantrag wurde mit 217 gegen 177 abgelehnt ${ }^{111}$, eine solide parlamentarische Basis für sein schwieriges Vorhaben, die Staatsfinanzen zu sanieren!

Parallel zu den Verhandlungen mit dem Reich liefen Kleppers Verhandlungen mit Reichsbankpräsident Luther. Im Januar 1932 konnte Klepper ihm mitteilen, daß der voraussichtliche Fehlbetrag für 1932 etwa 150 Millionen betragen werde und durch eine Fortsetzung der Verwaltungsreform weiter zurückgeschraubt werden könne. Die letzten 100 Millionen könnten durch eine Schlachtsteuer oder einen Überbrückungskredit der Reichsbank beschafft werden, was Luther ablehnte und statt dessen nach der Schuldentilgung Preußens fragte. Klepper antwortet kategorisch: „Erst ausgeglichener Etat, dann Schuldentilgung. " 112 Schon zwei Tage vor Weihnachten hatte erneut eine Besprechung mit Brüning über die preußische Finanzlage stattgefunden, und Klepper pokerte mit Hilfe der gefürchteten und auch von ihm keineswegs geliebten Schlachtsteuer ${ }^{113}$ um die Eisenbahnabfindung ${ }^{114}$ durch das Reich, doch ohne Erfolg. Das Jahr näherte sich dem Ende, Preußen hatte sich gegenüber einem Bankenkonsortium, dem auch die Reichsbank angehörte, verpflichtet, seinen Staatshaushalt bis zum Jahresende klar auszugleichen, wenn ihm dafür ein Überbrückungskredit von 50-60 Millionen RM gewährt werden sollte ${ }^{115}$.

So wurde schließlich ohne die Hilfe des Reiches am Tag darauf die sogenannte Sparnotverordnung ${ }^{116}$ erlassen, mit der Klepper notgedrungen das schaffte, "was sämtliche preußischen Innenminister seit 13 Jahren nicht fertiggebracht hatten"117, nämlich eine Verwaltungsreform einzuleiten, die Brüning sogar als „die größte der letzten

110 PrLT, 264. Sitzung, 16. 12. 1931, v. Rohr (DNVP), Sp. 23156 und Werner Kaufhold (DNVP), Sp. 23207. Der Vers stammt von Bogislav v. Selchow. Vgl. außerdem Kap. über Untersuchungsausschuß (s.u.).

111 GSTAM, Rep. 169 D, Nr. 33, Bd. II, Bl. 434f. PrLT, 266. Sitzung, 18. 12. 1931, Sp. 23387.

112 Ebenda, VNL-K, Nr. 171, Briefwechsel zwischen Klepper und Luther vom 16. 1. 1932 (K. an L.), 19.1. (L. an K.) und 29.1. (K. an L.), Bl. 6 ff. Außerdem schrieb Klepper am 19.11. 1931 (B1. 9 f.) wegen der schwierigen Kassenlage an Dietrich und sandte die Kopien jeweils an Braun und Hirtsiefer (Bl. $12 \mathrm{f}$.).

${ }^{113}$ AdR-Brüning, Nr. 613. Engelmann, S. 35. Die Vorlage für eine Schlachtsteuer lag seit Anfang Dezember 1931 im Entwurf vor und war Anfang Januar 1932 voll ausgearbeitet (VNL-K, Nr. 153).

114 Nach dem Staatsvertrag vom 30. 4. 1920 (RGBl. 1920, S. 773) hatte Preußen durch die Abgabe seiner Staatsbahnen an das Reich Anspruch auf eine Eisenbahnabfindung.

115 AdR-Brüning, Nr. 613. Vermerk von Ministerialrat Vogels vom 21. 12. 1931 (Anm. 3, S. 2129).

116 PrGslg. Nr. 54 vom 23. 12. 1931, S. 293 ff. Die „Dietramszeller Notverordnung“ des RP vom 24. 8. 1931 ermöglichte den Erlaß von Notverordnungen durch die Länder. Zu Verfahren und Legitimation der preußischen Notverordnungspolitik vgl. Ehni, S. $217 \mathrm{ff}$.

117 Schulze, Braun, S. 713. Horkenbach (Hrsg.), II, S. 398 ff., Weichmann in Vossische Zeitung Nr. 603, 23. 12. 1931. 
100 Jahre" 118 bezeichnete, wobei der Grund für das Lob gewiß weniger die Bewunderung für Klepper war, als die geheime Freude, seine Pläne ein Stückchen mehr verwirklicht zu sehen. Doch auch diese Freude kann nicht ganz rein gewesen sein, denn er hielt sie „bei größter Hochachtung [...] für die sachliche Arbeit Kleppers [...] zu diesem Zeitpunkt [...] für politisch falsch“, und zwar keineswegs nur, wie es zunächst scheinen mochte, wegen der bevorstehenden Wahlen, sondern weil er sehr wohl verstanden hatte, daß Klepper daran arbeitete, „die erdrückende Abhängigkeit Preußens vom finanziellen Wohlwollen des Reichskanzlers zu mildern"119 und damit Brüning das finanzielle Druckmittel aus der Hand zu nehmen, mit dem er die Preußen „im Laufe des Sommers zu zwingen [versucht hatte], aus ihrer Notlage heraus freiwillig Polizei und Justiz dem Reiche anzubieten" 120 .

So ergab sich für Braun wie für Klepper die widersprüchliche Zielsetzung, für die finanzielle Unabhängigkeit Preußens kämpfen und Maßnahmen ergreifen zu müssen, die ihnen selbst bei den Wahlen schaden würden. Obwohl sie beide im Prinzip nicht gegen eine Neuorganisation der Verwaltung von Preußen und Reich waren ${ }^{121}$, stemmten sie sich schließlich gegen diese Absichten des Kanzlers, weil sie weder „dieses an Erpressung grenzende Vorgehen " 122 dulden noch den demokratischen Absichten der Reichspolitik trauen konnten. Bei Klepper war offenbar das Mißtrauen gegen Brüning und die Energie, mit der er für die Unabhängigkeit Preußens zu kämpfen bereit war, noch größer als bei Braun. Während Braun in Ascona Urlaub machte ${ }^{123}$, nutzte Klepper die Weihnachtstage, um erneut einen Haushaltsplan aufzustellen und an dem Entwurf einer großen Verwaltungsreform weiterzuarbeiten.

Sein Haushaltsdeckungsplan passierte in Abwesenheit von Braun, der ihn „nie hätte passieren lassen "124, das preußische Kabinett und wurde am Dreikönigstage dem Reichskanzler im Beisein von Schäffer vorgelegt ${ }^{125}$. In dieser Sitzung zeigten sich sowohl Brüning wie Klepper durchaus kooperativ, und die Art, wie Klepper argumentierte und den „Druck“ der miserablen Kassenlage fast begrüßte, „um solche an sich unbeliebten Maßnahmen annehmbar zu machen“, beweist die von Engelmann erwähnte „sportliche Freude", kritische Situationen mit Kampfgeist und Phantasie zu bewältigen ${ }^{126}$. Die Verwaltungsreform sollte mit der Zusammenlegung der drei Ministerien für Handel, Wohlfahrt und Landwirtschaft, die sich alle einen eigenen Apparat geschaffen hätten, fortgesetzt werden; ferner müßten die Oberpräsidenten mit den Regierungspräsidenten zusammengelegt und die Kreise vielfach vereinheitlicht werden. „Der Kanzler“, so berichtet Schäffer, „mißt dieser Verwaltungsreform die größte Bedeutung bei, er könne sich vorstellen, daß sie eine solche Erleichterung für die bedrückten Gemüter der Menschen bedeute, daß sie auf den Ausgang der preußischen Wahlen einen sehr günstigen Einfluß haben würde.“ Klepper, voller Optimismus, „hofft, sie sogar parlamentarisch durchzu-

\footnotetext{
118 Brüning, S. 485.

119 Schulze, Braun, S. 713.

120 Brüning, S. 515. Vgl. auch Schäffer, 7. 6. 1932, Bd. 21, S. 563 f.

121 U.a. Schulze, Braun, S. 714.

122 Braun an Severing, 21. 1. 1932, in AdsD, Bonn, NL-Severing/53.

${ }^{123}$ Schulze, S. 712.

${ }^{124}$ Severing an Braun 21.1. 1932 (NL-Severing/53).

${ }^{125}$ Schäffer, Bd. 17, 6. 1. 1932, S. $24 \mathrm{ff}$.

126 Engelmann, S. 35.
} 
bringen. Die Sozialdemokraten würde er herumbekommen, ebenso die Staatspartei. Die Schwierigkeit läge beim Zentrum“127, woraufhin Brüning lakonisch meinte: „Das preußische Zentrum kann man doch zwingen.“ Der Kanzler drängte: „Bis wann könnten dann die Dinge beschlossen sein?"Klepper schätzte, daß noch 14 Tage zur Ausarbeitung benötigt würden und „die Dinge in den Ressorts besprochen“ werden müßten, bevor „der Versuch einer parlamentarischen Erledigung gemacht" werde. „Ende Februar, Anfang März könnten sie in der preußischen Gesetzessammlung stehen. "Brüning fragte nach Ersparnissen in der Justiz; Klepper erwiderte, daß die Justiz bereits mit Minus arbeite wegen der zahlreichen „Armensachen“ und der entsprechend hohen Gebühren für Anwälte, aber er zeigte sich sogar geneigt, „die Justiz an das Reich abzutreten, wenn auch die anderen Staaten es tun“, wobei Klepper diese Übertragung im Sinne einer vom Reich und Preußen gemeinsam durchgeführten „Vereinfachung“ der Justizverwaltung und der Gerichtsverfassung meinte ${ }^{128}$ und nicht im Sinne einer einfachen Unterstellung des preußischen Justizministeriums unter das des Reiches, was aber Brünings heimlichen Absichten entsprochen hätte. Dabei war er sich allerdings darüber im klaren, daß ein solches Vorhaben allenfalls von den norddeutschen, niemals aber von den süddeutschen Ländern gebilligt worden wäre. Ohnehin hätte keines der Länder ohne ein verfassungsänderndes Gesetz zugestimmt. Brüning, der Klepper an diesem Dreikönigstag, laut Schäffer, als erstaunlich kooperativ empfand, bohrte noch einmal wegen der Schlachtsteuer, sie doch „vor der Wahl nicht zu erwähnen“, worauf Klepper „nur sehr ungern" einging ${ }^{129}$.

Wenn man Brünings und Kleppers Argumentation vergleicht, so fällt auf, daß Brüning vor allem die Wirkung der geplanten Maßnahmen auf die Wähler im Auge hatte, die er notfalls auch zu täuschen bereit war, während er auf seine eigenen Parteigenossen glaubte Zwang ausüben zu können. Klepper dagegen hoffte, die Wähler von der Richtigkeit der Maßnahmen überzeugen zu können, und vertraute darauf, daß ehrliche Darlegung der Notlage bei der Bevölkerung auf Einsicht stoßen würde ${ }^{130}$. So betonte er in seiner Kieler Rede, daß die Lage „ernster ist, als vielfach angenommen“ und daß dies auch noch nach den Wahlen anhalten werde, dennoch nutze es nichts, sich „einer mutlosen Stimmung hinzugeben. Die politischen Chancen dieser Zeit hat auch nicht der, der am unanständigsten auftritt, sondern der, der die sachliche Lösung aufzeigt und durchführt." Vielleicht entsprach diese Haltung in einer von politischer Demagogie beherrschten Zeit nicht mehr der Realität, vielleicht wurden die leiseren Töne nicht mehr gehört. Wenn man seine Rundfunkansprachen heute hört, so klingen sie zwar von der Sache her überzeugend, aber sie setzen voraus, daß man in etwa wußte, worum es ging, daß man bereit war, Opfer auf sich zu nehmen, und vor allem daß man die Republik bejahte. Wer tat das?

${ }^{127}$ Schäffer, Bd. 17, 6. 1. 1932, S. 25. Zwei der betroffenen Minister gehörten dem Zentrum an, Heinrich Hirtsiefer und Heinrich Steiger.

${ }^{128}$ Klepper dazu in der Besprechung mit Brüning vom 5. 2. 1932 (AdR-Brüning, Nr. 660). Vgl. die ungenaue Angabe bei Schulz, Brüning, S. 599 und die zu diesem Zeitpunkt unzutreffende Bemerkung: „Das Ende der starken Stellung Preußens und seines Ministerpräsidenten war besiegelt."

129 Schäffer, Bd. 17, 6. 1. 1932, S. 26.

130 Kieler Rede, S. 4. Vgl. auch die Rundfunkansprachen. 
Nachdem Klepper im Januar bei Braun in Bad Gastein gewesen war, um ihn über den Gang der Verhandlungen und Brünings Vorgehen in Sachen Reichspräsidentenwahl zu informieren ${ }^{131}$, ging das Tauziehen zwischen Preußen und Reich weiter ${ }^{132}$. Am 19. Februar 1932 kam es dann endlich zu einer Kompromißlösung im Finanzkonflikt Preußen - Reich ${ }^{133}$. Brüning hatte scheinbar aus lauter Sorge vor den Auswirkungen der Schlachtsteuer eingelenkt ${ }^{134}$ und zugesagt, im Laufe des Jahres 1932100 Millionen RM an Preußen zu zahlen, davon 50 Millionen bis Mitte des Jahres. Dafür sollten die preußische Landesrentenbank, die Siedlungsgesellschaften und die preußischen Anteile an der deutschen Siedlungsbank auf das Reich übertragen werden, ein logischer Schritt „nach dem Rückzug Preußens aus der Siedlungs- und Osthilfe“ "135. Doch steckte dahinter mehr, nämlich der alte Plan Brünings ${ }^{136}$, der sich laut Schulze in einer vor der Öffentlichkeit geheimgehaltenen Verpflichtung der preußischen Regierung niedergeschlagen haben soll: „Bis spätestens 30. September 1932 eine Verwaltungsreform in Preußen durchzuführen und darüber hinaus sofort mit dem Reich Verhandlungen über eine gemeinsame Reform der Reichs- und preußischen Verwaltung einzuleiten“. Damit hätte, so fährt Schulze fort, Brüning sich „die Zustimmung des preußischen Kabinetts für eine zukünftige verstärkte Einflußnahme des Reiches auf die preußischen Verhältnisse erkauft, das Ziel, das er mit seiner restriktiven Finanzpolitik gegenüber Preußen verfolgt hatte, schien greifbar nahe und war von Braun und seinen Kabinettskollegen akzeptiert“ 137 worden. Brüning soll „im vertrauten Kreise“ geäußert haben: „Wenn die Wah-

131 Schulz zitiert einen Brief Brauns an Weismann vom 19. 1. 1931: „Als Klepper mir in Gastein mitteilte, was Brüning beabsichtigte (die Verlängerung der Amtszeit Hindenburgs ohne Wahl), sagte ich ihm gleich, bei der ganzen Sache wird doch nichts weiter herauskommen als ein erheblicher Prestigegewinn für Hitler", in: Politik und Wirtschaft, S. 1223. Zum Hindenburgmanöver vgl. Schulz, Brüning, S. $704 \mathrm{ff}$.

132 Siehe Verhandlungen am 1. 2. 1932: Das Reich bot an, Anteile an der Preußenkasse zu übernehmen, was Klepper natürlich mit dem Hinweis ablehnte, daß „entgegen anderslautenden Meinungen [...] die Preußenkasse auf absolut gesunden Füßen stehe“ (AdR-Brüning, Nr. 660). Vgl. auch Schäffer, Bd. 16, S. $1133 \mathrm{f}$.

${ }_{133}$ Vgl. Besprechung vom 5. 2. 1932 und die abschließende Besprechung vom 1. 3.1932 (AdR-Brüning, Nr. 689/90), zu der es zwei von einander abweichende Niederschriften gibt (s.u.).

${ }^{134}$ Schulze, Braun, S. 714. Sicher spielten auch seine Niederlage in der Reichspräsidentenaffäre und sein Angewiesensein auf die Sozialdemokraten sowie sein „Positionsverlust in der Außenpolitik" eine Rolle, vgl. S. $710 \mathrm{ff}$.

135 Ebenda und Vorwärts Nr. 69, 11. 2. 1932.

136 Brüning, S. 582.

${ }^{137}$ Schulze, Braun, S. 714 f., Schulze sagt, „dieser Beschluß wurde, damit er nicht ruchbar werde, nicht in einer Sitzung des preußischen Staatsministeriums, an der zahlreiche Beamte teilgenommen hätten, sondern in einer Ministersitzung gefaßt, in der neben den preußischen Ministern nur einige Staatssekretäre anwesend waren; das Protokoll der Sitzung schrieb Staatssekretär Weismann, es wurde mit dem - unüblichen - Vermerk, Streng vertraulich zu behandeln', versehen und im Panzerschrank verschlossen". Schulze zitiert GSTAB, I.HA, Rep. 90, Annex A/39, das Protokoll befindet sich auch unter dem Datum des 13. 2. 1932 (Weismann) neben einem anderen Protokoll über die Ministersitzung zur Verabschiedung des Etats am 12. 2. 1932 bei den Staatsministerialsitzungsprotokollen 1928-32, GSTAM, Rep. 90a, Bd. 181, Bl. 20 ff., und auch Schäffer erwähnt am 8.2. 1932 (Bd. 18, S. 184), daß „die Reichsbank der Einsetzung dieses Münzgewinnes nur zustimmen wird, wenn gleichzeitig klargestellt ist, $[\ldots]$ daß die Verwaltungsreform vorwärts kommt [und] ein Programm der Verwaltungsreform alsbald vom Reich und Preußen aufgestellt“ wird. So geheim kann die Verabredung nicht gewesen sein. 
len in Preußen schiefgehen, dann übernehme ich die preußischen Dinge auf das Reich.“"138

Wenn es auch richtig ist, hinter den Verhandlungen des Reiches einen Erpressungsversuch gegenüber Preußen zu vermuten, so scheint Schulzes Darstellung, daß das Reich sich die von „Braun und seinen Kabinettskollegen akzeptiert[e]“ Zusage zu einer Verwaltungsreform bis zum 30. September 1932 erkauft habe, so nicht zuzutreffen. Vielmehr fand am 1. März 1932 eine „abschließende Besprechung über die 100-MillionenHilfe statt, die seitens Preußens zur Ausbilanzierung seines Haushaltsplanes 1932 vom Reich erbeten" worden war. Zu dieser Sitzung, die offensichtlich nach dem Kompromiß vom 19. Februar noch einmal nötig geworden war, gibt es zwei voneinander abweichende Niederschriften, eine von Staatssekretär Pünder, eine von Klepper ${ }^{139}$.

Pünders Niederschrift enthält vage Feststellungen darüber, wann das Reich - auf jeden Fall erst nach der Reichspräsidentenwahl am 13. März 1932 - seinen Haushaltsplan abschließend beraten könne, und „nur bei Aufstellung eines solchen Gesamtplanes werde es möglich sein, die für Preußen vorgesehenen 100 Millionen in den Reichsetat einzustellen. Er [der Reichskanzler] erklärte hiermit aber in Übereinstimmung mit dem Reichsfinanzminister, daß in diesem Gesamtrahmen die für Preußen bestimmten 100 Millionen als Gegengabe für die preußischen Siedlungsanteile vorgesehen seien." Bezüglich des Zahlungstermins heißt es lediglich, „die preußischen Herren erklärten sich mit dieser Erklärung des Reichskanzlers einverstanden und hatten Verständnis dafür, daß angesichts der völlig ungeklärten politischen Lage über die Zahlungstermine noch nicht abschließend gesprochen werden könne“.

In Kleppers Niederschrift, die in: 1. Vereinbarungen, 2. Zahlungstermine unterteilt ist, heißt es: „Die preußische Staatsregierung liquidiert die preußische Landesrentenbank in der Weise, daß die Aktiven und Passiven auf die Deutsche Siedlungsbank (bis zum 1. April 1932) übertragen werden. Gleichzeitig erwirbt die Reichsregierung die preußische Beteiligung an der Deutschen Siedlungsbank und an den Siedlungsgesellschaften. Als Gegenleistung zahlt die Reichsregierung 100 Millionen, [die] im Laufe des preußischen Etatjahres 1932/33 nach noch zu treffender näherer Vereinbarung fällig" werden. „Die Reichsregierung wird sich bemühen, 50 Millionen Reichsmark vor dem 30. April 1932 zu zahlen."

Neben der wichtigen Frage der Zahlungstermine gab es einen weiteren strittigen und in beiden Niederschriften gänzlich unterschiedlich festgehaltenen Punkt, nämlich den der sogenannten „Landeskulturbehörden“. Dabei ging es um die Übernahme der bisher preußischen, mit der Siedlung betrauten Behörden auf das Reich. Dazu gab Pünder folgendes zu Protokoll: „Vorstehende Erklärung der Reichsregierung wurde in der heutigen Aussprache noch an eine zweite Voraussetzung geknüpft, deren Erfüllung auf preußischer Seite liege. Das Verlangen der Überführung der preußischen Kulturverwaltung in die Reichsverwaltung wolle er heute nicht ausdrücklich stellen, sondern sei damit ein-

${ }_{138}$ AdR-Brüning, Nr. 689/690. Schulze, Braun, S. 714, Anm. 441. Vgl. dazu Schulz, Brüning, S. 748, der die Interpretation der Ereignisse von $\mathrm{H}$. Schulze weitgehend übernimmt.

${ }^{139}$ AdR-Brüning, Nr. 689/690, „Einleitend erbat der preußische Ministerpräsident Klarheit über die Frage, da die preußische Staatsregierung ihre Etatberatungen abschließen und den Haushaltsplan alsbald dem Landtag vorlegen müsse." Pünders Niederschrift (S. 2343) und Kleppers Niederschrift (S. 4345). Beide Niederschriften befinden sich auch in: GSTAM, VNL-K, Nr. 171, Bl. $25 \mathrm{ff}$. 
verstanden, daß während des ersten Jahres zunächst praktische Erfahrungen gesammelt werden müßten. Durch Verhandlungen zwischen Reich und Preußen aufgrund der so gewonnenen Erfahrungen müsse aber sichergestellt werden, daß zum 1. April 1933, spätestens aber zum 1. Oktober 1933 die etwa erforderlich werdende Behörden-Umorganisation durchgeführt sei." ${ }^{140}$ Klepper notierte dagegen unter Punkt 3) zu dem Problem: „Der in früheren Verhandlungen erörterte Wunsch der Reichsregierung, die preußischen Siedlungsbehörden (Landeskulturbehörden) ganz oder teilweise zu übernehmen, oder ihnen den Charakter einer Auftragsverwaltung zu geben, wird zurückgestellt. Die preußische Staatsregierung sagt die nachdrückliche Unterstützung der von der Reichsregierung geplanten Förderung der Siedlungstätigkeit zu. “141

Braun sandte die von ihm unterschriebene Niederschrift Kleppers an den Reichskanzler mit einem von Klepper entworfenen Begleitschreiben, in dem er seinerseits bedauerte, dem Pünderschen „Vermerk nicht zustimmen zu können“, weil er „nicht die richtigen Verhandlungsergebnisse“ wiedergebe. Im einzelnen heißt es: „In der Besprechung kam eindeutig zum Ausdruck, daß der Übergang der preußischen Beteiligung an der Deutschen Siedlungsbank und den Siedlungsgesellschaften sowie der preußischen Landesrentenbank gegen Zahlung von 100 Millionen RM im Haushaltsjahr 1932/33 vereinbart war." Auch hinsichtlich der Behandlung der Siedlungsbehörden gebe der Vermerk das Verhandlungsergebnis nicht zutreffend wieder. „Der Herr Reichsarbeitsminister stellte seine Forderungen auf Übernahme der Siedlungsbehörden oder einzelner Beamter ausdrücklich zurück, wogegen Sie meine persönliche Zusage erbaten, gegenüber bürokratischen Hemmungen oder in aller sonst notwendigen Weise die von der Reichsregierung beabsichtigte Intensivierung der Siedlungstätigkeit zu fördern. "142

Die Tatsache, daß es zu keiner Einigung kam und Brüning es ausdrücklich ablehnte, Kleppers Niederschrift, die für das Reich bindende Festlegungen enthielt - anders hätten die Preußen auch niemals ihre Siedlungsanteile abgetreten -, zu unterzeichnen, und sich auch zu keiner weiteren Festlegung bereitfand ${ }^{143}$, entlarvte aus Sicht der preußischen Regierung zum einen die hinhaltende und Preußen zunehmend unter Druck set-

${ }^{140}$ Die vorstehende Erklärung wurde ausdrücklich auf Wunsch des Reichsarbeitsministers eingefügt, der diesen Text der Reichskanzlei mit Schreiben vom 3.3. 1932 übersandte (ebenda, S. 2344, Anm. 4). Das Datum 1. 10. 1933 stimmt ja mit dem von Schulze angegebenen 30.9. überein, nur nicht das Jahr, wobei man sagen muß, daß es kaum das Jahr 1932 gewesen sein kann, denn das hätte geheißen, daß a) nur ein halbes Jahr für eine doch sehr komplizierte Umorganisation zur Verfügung gestanden hätte, und b) daß das Reich unbedingt die 100 Millionen bis dahin hätte gezahlt haben müssen.

${ }^{141}$ Klepper, ebenda, S. 2345.

142 GSTAM, VNL-K, Nr. 171, Briefentwurf Kleppers an den RK vom 3. 3.1932 und seine Niederschrift über die Sitzung vom 1.1. 1932 (Bl. 35 ff.).

${ }^{143}$ AdR-Brüning, Nr. 689/690, Pünder an Weismann, 5. 3. 1932, S. 2344, Anm. 3: „Der Herr Reichskanzler sieht sich zu seinem Bedauern nicht in der Lage, dieses Protokoll des Herrn Min. Klepper zu unterzeichnen und zu billigen, zumal es ja verschiedene Formulierungen enthält, die, wie ich selber als Zeuge bestätigen muß, in unserer gemeinsamen Besprechung nicht einmal erwähnt, geschweige denn vereinbart worden sind. Über die in der Niederschrift [...] vom 1. d. Mts. enthaltenen Erklärungen hinaus sieht der Reichskanzler sich zu weiteren Festlegungen nicht in der Lage." Pünder selbst hatte Kleppers Protokoll in einem Schreiben an Schäffer vom 5. 3. 1932 als preußischen "Erpressungsversuch“ bezeichnet (AdR-Papen, Nr. 11, S. 25, Anm. 3). 
zende Politik des Reiches ${ }^{144}$ und erklärt zum anderen, warum Klepper begann, seine eigenen Wege bei der Haushaltsdeckung zu gehen. Im Etat vom 15. März, den er ausführlich im Landtag begründete, setzte er zwar noch die 100 Millionen des Reiches zur Dekkung des Defizits ein ${ }^{145}$ und vermied so die unbeliebte Schlachtsteuer, aber nach diesem Manöver war ihm klar, daß Preußen sich selber helfen mußte.

Im Hinblick auf die kommende Landtagswahl am 24. April gab Klepper Anfang des Monats eine Erklärung zur „Finanzpolitik im Dienst der Krisen-Bekämpfung“ an den amtlichen preußischen Pressedienst, um noch einmal zusammenzufassen, worum es der preußischen Regierung ging. Es wird, so erläuterte Klepper, bei den kommenden Landtagswahlen „eine maßgebliche Entscheidung in dem Kampf fallen, der um die Macht in Deutschland geführt wird und geführt werden muß“, denn trotz ,der dringend notwendigen inneren Beruhigung " müsse, vor allem auch dem Ausland gegenüber, klargestellt werden, „wer in Deutschland regiert“. Die Gruppen, die sich als , nationale Opposition“ bezeichneten, bewürben sich um die Regierungsgewalt, und zwar, indem sie allen alles versprächen, ohne aufzuzeigen, wie sie diese Versprechen einzulösen gedächten. Dagegen erfordere die Finanzpolitik der preußischen Regierung „große Opfer und weitgehende Entbehrungen. Sie bewahrt aber vor einem größeren Übel, nämlich dem Zusammenbruch der Staatsfinanzen und einer Gefährdung der Währung. "Sie sei „trotz aller Härte" „eine Politik von Ordnung und sozialer Gerechtigkeit“, aber „die Überwindung der Krise ist nicht etwas, was sich schicksalhaft nähert, sie muß vielmehr geschaffen werden“. Es sei ganz wichtig zu verstehen, daß die Völker inzwischen alle wirtschaftlich voneinander abhängig seien und daß deshalb eine enge wirtschaftliche Zusammenarbeit unter den Völkern „mit dem Ziel des freien Güteraustausches“ das Ziel der deutschen Politik sein müsse; die Voraussetzung dafür aber sei die Ordnung im eigenen Hause, dafür lohne es sich, mit Mut, Entschlossenheit und Verantwortungsbewußtsein zu kämpfen und bereit zu sein, „einen schweren und ernsten Weg“ zu gehen ${ }^{146}$.

Das Volk war nicht mehr bereit, diesen „schweren“ Weg zu gehen. Das Wahlergebnis, das der NSDAP die gleiche Stimmenzahl wie der bisherigen Weimarer Regierungskoalition beschert hatte ${ }^{147}$, zeigte, daß das Vertrauen in die Funktionsfähigkeit des parlamentarischen Regierungssystems erneut geschrumpft war und sich die Hoffnungen, die große wirtschaftliche und politische Krise bewältigen zu können, nun auch in Preußen auf die extremen Parteien verlagerten. Aufgrund der Änderung der Geschäftsordnung

144 Die hinhaltende Taktik des Reiches wird zusätzlich bestätigt durch die Notiz Schäffers über ein Telephongespräch mit Pünder am 7. 3. 1932 (Bd. 19, S. 330), in dem Schäffer sich über die „PreuBensache“ bei Pünder beschwerte und sagte, er wisse nicht, „woher wir die Mittel zur Deckung unseres Haushalts nehmen sollen“, worauf Pünder darauf hingewiesen habe, „daß keine Zusage zur Deckung von Kassenmitteln gemacht worden“ sei. Noch am 3.5. 1932 hieß es bei der Reichsministerbesprechung: „Ferner sei noch die Frage der Zahlungen an Preußen zu regeln. Hierüber werde er [der Reichsfinanzminister] mit dem preußischen Ministerpräsidenten und dem preußischen Fianzminister nochmals sprechen" (AdR-Brüning, Nr. 733).

145 PrLT, 281/283. Sitzung, Sp. $24571 \mathrm{ff}$. und 24575: „Im übrigen wurde das der Öffentlichkeit bekannte Abkommen zwischen Reichs- und Staatsregierung getroffen, auf Grund dessen die preuBischen Beteiligungen bei den Siedlungsfinanzierungsstellen gegen eine Ausgleichszahlung von 100 Millionen Reichsmark auf das Reich übergehen sollen."

146 VNL-K, Nr. 176, Amtlicher Preußischer Pressedienst, 13. 4. 1932.

${ }^{147}$ Ergebnis der Landtagswahl vom 24. 4. 1932: 162 NSDAP, 31 DNVP, 94 SPD, 67 Zentrum, 7 DVP, 2 DStP, 57 KPD und 4 für Splitterparteien. 
vom 12. April 1932148, durch die die Wahl des Ministerpräsidenten nur noch mit absoluter Mehrheit möglich war, blieb die Regierung als geschäftsführende Regierung weiter im Amt ${ }^{149}$. Daß Brüning „das gewaltige Anschwellen der Nationalsozialisten zum Teil auch [auf] die Klepperschen Finanzmaßnahmen“ zurückführte ${ }^{150}$, läßt eher auf seine Abneigung gegen Klepper als auf eine fundierte politische Analyse schließen, um so mehr als er selbst schon einen Monat später Opfer der vorwärtsdrängenden Rechten wurde.

Es scheint, daß Klepper mehr und mehr dazu überging, sich auf sich selbst zu verlassen, denn auch mit Brauns Kurs konnte er sich nicht mehr uneingeschränkt identifizieren ${ }^{151}$. Braun, der nach Schulze „seine Position und damit die seiner Regierung bereits vor den Preußenwahlen zu liquidieren begann“, war amtsmüde. Da er den Ausgang der Wahlen voraussah, steuerte er nun eindeutig den Kurs, „Brüning und Hindenburg, von denen er zu wissen glaubte, $d a ß$ auf sie beide in seinem Sinne Verlaß sei, nicht nur zu tolerieren, sondern im Rahmen des möglichen aktiv zu unterstützen und ihre Stellung zu stärken"152. Auf diesen Kurs wollte Klepper sich nicht so ohne weiteres festlegen lassen, wenn er auch nach außen loyal zur Regierung Braun stand. Laut Schäffer soll es nun mehrfach zu Differenzen zwischen Braun und Klepper gekommen sein ${ }^{153}$, die Braun allerdings in seinen Memoiren selbst nicht erwähnt. Klepper wollte offensichtlich nicht aufgeben und versuchte mit allen Mitteln die preußische Position in den Verhandlungen mit dem Reich zu halten, was, wie der damalige Staatssekretär im Reichsministerium für Finanzen, Lutz Graf Schwerin v. Krosigk, berichtet, auf wenig Gegenliebe stieß: „Immer wieder mußte ich mit den Preußen verhandeln, vor allem mit dem unzuverlässigen Minister Klepper. [...] Wir konnten Preußen nicht mehr durch Zuschüsse sanieren. Es mußte uns Vermögenswerte übereignen und ganze Verwaltungszweige abtreten. Jedesmal, wenn wir kurz vor dem Abschluß standen, kam irgend etwas dazwischen. Selbst der sonst in der Form so maßvolle Schäffer fiel Klepper gegenüber aus der Rolle, [...] [Klepper] betrieb stets eine ressentimentgeladene Politik. " ${ }^{54}$ Doch auch Braun war „nicht bereit, die Justiz abzugeben“.

Nachdem „die Sache zwischen dem Kanzler und Braun geplatzt“ war ${ }^{155}$, scheint Brüning versucht zu haben, einen Keil in das ohnehin nicht mehr ganz intakte preußische Kabinett zu treiben. Er ließ „Severing kommen und warnte ihn vor den Gedankengängen Kleppers und einer gewissen Clique in seinem Ministerium und im preußischen

148 PrLT, 285. Sitzung, Sp. $84891 \mathrm{ff}$.

149 Nach den verlorenen Wahlen erfolgte am 15.5. die Auflösung des PrLT und am 19.5. 1932 der Rücktritt des gesamten Staatsministeriums (GSTAM, Rep. 151 HB, Nr. 629, Bl. 15); ebenda unter gleichem Datum: Brief des Staatsekretärs des PrStM, Weismann, daß keiner auf der Ministerbank sitzen solle (PrLT, 4. WP, 1. Sitzung, Sp. 11932).

150 Brüning, S. 552.

151 Vgl. Tagesbericht des Reichsbankpräsidenten Luther vom 4. 5. 1932, abgedruckt in: Politik und Wirtschaft, 2. Teil, S. 1433.

152 Schulze, Braun, S. $715 \mathrm{f}$.

${ }^{153}$ Schäffer berichtet unter dem 3. 2. 1932 (Bd. 18, S. 165) von derartigen Differenzen einmal wegen der leidigen Schlachtsteuer und zum anderen wegen der Abneigung Kleppers, den Kassenfehlbetrag mit Hilfe der Reichsbank auszugleichen, weil man das „als inflatorische Maßnahme bezeichnen müsse“, was einen „absoluten Wendepunkt“, d. h. ein Abweichen von der bisherigen Politik bedeute.

154 Schwerin v. Krosigk, S. 101.

155 Schäffer notiert einen Bericht von Schwerin v. Krosigk, Bd. 18, 5. 2. 1932, S. 175. 
Staatsministerium“. Mit einem Hinweis auf die „Ideen des Reichspräsidenten“ entließ er Severing, „mehr konnte und wollte [er] ihm nicht sagen, um diesen ausgezeichneten Mann nicht völlig unsicher zu machen"156. Severing zeigte sich gegenüber derartigen Einflüsterungen offensichtlich nicht unempfindlich, verspürte er doch nach eigenen Aussagen von Beginn an eine Abneigung gegen Klepper ${ }^{157}$. Auch in seinem eigenen Ministerium gab es Spannungen; sein Staatssekretär Wilhelm Abegg war von Severings Qualitäten offensichtlich weniger überzeugt ${ }^{158}$ als von denen Kleppers, den er zu den „wenigen Männern und Energien dieser Zeit, wo die Geringwertigkeit und Halbheit Triumphe feiert", zählte ${ }^{159}$.

Diese innere Uneinigkeit einer ohnehin nur noch geschäftsführenden Regierung war keine ideale Voraussetzung, um den Kampf ums Überleben gemeinsam zu führen. Klepper, dessen parteiliche Ungebundenheit ihm in gewisser Weise auch einen größeren Spielraum ließ und ihn von wahltaktischen Rücksichten stärker befreite, scheint auf preußischer Seite der zäheste Verhandlungspartner gewesen zu sein. Seine Erfahrungen in den agarpolitischen Auseinandersetzungen mit den Genossenschaftlern, den Großagrariern und der Reichsregierung kamen ihm dabei zustatten. Im übrigen war seine Skepsis gegenüber dem Demokratieverständnis der Reichsregierung groß. Wie recht er damit hatte, sollte sich bald erweisen. Am 30. Mai 1932 wurde Brüning entlassen.

Wie sich aus einem Brief Kleppers an Braun vom Anfang Juni 1932 ergibt, wurden die nun folgenden Auseinandersetzungen mit der Regierung Papen entscheidend von Klepper beeinflußt. In diesem Brief versucht Klepper Braun davon zu überzeugen, daß es nicht nur unklug, sondern sinnlos sei, den von Braun entworfenen ausführlichen Brief über die Kassenlage Preußens an den Reichskanzler abzusenden. Der Briefentwurf Brauns vom 2. Juni hatte mit dem Satz begonnen: „Schon seit etwa einem Jahr habe ich unausgesetzt die Reichsregierung auf die immer bedrohlicher werdende Finanz- und Kassenlage des preußischen Staates schriftlich und mündlich hinweisen müssen." Braun hatte dann die finanzielle Lage im Detail dargelegt und darauf hingewiesen, daß, wenn das Reich seine Zusage zur Zahlung der 100 Millionen RM nicht einhalte, Preußen „die

${ }^{156}$ Brüning, Memoiren, S. 582. Vgl. dazu Schulze, Braun, S. 712 ff. und Schäffer, Bd. 21, 7. 6. 1932, S. $562 \mathrm{f}$.

${ }^{157}$ Zur Spannung zwischen Severing und Klepper vgl. u. a.: Bay, S. 121.

158 Teilweise enthüllte sich dies erst im nachhinein; vgl. Abeggs Briefe an Klepper im Frühjahr 1951, in denen er sich wenig positiv über Severing äußert. So schreibt Abegg am 19. 2. 1951 an Klepper über den Regierungspräsidenten im PrIM, Rudolf Diels, in dessen Entnazifizierungsverfahren Abegg als Zeuge geladen worden war und den er „einen erbärmlichen Zuträger von Papen“ nennt: „Ich habe den Eindruck, daß Diels und Sev.[ering] cine stille Gesellschaft auf Gegenseitigkeit bilden. Diels preist den einzigartigen Staatsmann, dem er eigentlich längst den Dolch in den Rücken gebohrt hatte, damit Severing den eidbrecherischen verlogenen Gesellen auch seinerseits schonen möge. " Dazu: v. Lindheim in: GWU 11 (1960), S. 157: Diels hatte das Gespräch zwischen Abegg und Ernst Torgler/Wilhelm Kasper (KPD) entstellt, im Sinne einer Verschwörung an Papen weitergegeben und damit einen Grund zum Eingreifen des Reiches in Preußen konstruiert. Neben Diels nennt v. Lindheim Ministerialrat Eduard Nobis als „Verräter" (S. 162). Abegg beruft sich in seinem Urteil auf Albert Grzesinski, der in seinen Lebenserinnerungen ,in schärfster Weise mit Severing “ abrechne. Dies wird durch Grzesinski, Lebensweg, Bl. 233 f. bestätigt: Laut Grzesinskis Aufzeichnungen (31. 8. 1932) von einem Mittagessen mit einem früheren Mitarbeiter Severings hat Severing sich wenig positiv über Grzesinski geäußert und sehr uninteressiert an Grzesinski gezeigt, das heißt dic Antipathie war wohl gegenseitig.

159 Abegg an Klepper 19.2. 1951 (K/Kor.). 
einschneidendsten Maßnahmen“ ergreifen müsse, „um nicht den Kredit Preußens und damit auch des Reiches zu zerstören" ${ }^{160}$.

Kleppers Hauptargument gegen die Absendung dieses ausführlichen Briefes war, daß in „der augenblicklichen Situation alles vermieden werden müsse, was den Anschein inflatorischer Maßnahmen auch nur andeuten könnte“, denn, so fuhr er fort, „wie ich aus einer zuverlässigen Quelle erfahren habe, sind die Absichten der Reichsregierung, einen Reichskommissar in Preußen einzusetzen, ernstlicher Natur. Da es meines Erachtens nicht angängig ist, die staatlichen Machtmittel vor oder während des kommenden Reichstagswahlkampfes aus der Hand zu geben, wird alles vermieden werden müssen, was die Handhabe zur Einsetzung eines Reichskommissars bieten würde. Eine solche Handhabe würde aber meines Erachtens der von Ihnen beabsichtigte Brief an die Reichsregierung darstellen, während andererseits die Aussicht, daß die Reichsregierung Preußen eine finanzielle Hilfestellung gibt, nach meiner Kenntnis der Dinge - es ist im Reich noch ein Defizit von über eine Milliarde zu decken - nicht vorhanden ist." Außerdem hatte Klepper bei der Reichsbank eine erneute Rediskontzusage für ein weiteres Jahr und einen Überbrückungskredit von 35 Millionen RM erreicht, unter der Voraussetzung, daß er einen ausgeglichenen Staatshaushalt vorlege. Deshalb schlug Klepper vor, den Brief nicht abzusenden und nur durch eine mündliche Rücksprache mit dem Reichfinanzminster festzustellen, ob das Reich zur Zahlung der 100 Millionen RM ganz oder teilweise bereit sei. Einen entsprechenden eigenen Briefentwurf, in dem nur ganz kurz die Bitte um eine Besprechung über die bereits zugesagten 100 Millionen geäußert wird, legte Klepper bei ${ }^{161}$. Er bat darum, alles in der Ministerbesprechung zu beraten.

Dies ist offensichtlich geschehen, und der kurze Brief wurde abgesandt, woraufhin es dann eine Woche später, am 7. Juni, zu der entscheidenden Besprechung der preußischen Regierung, vertreten durch Heinrich Hirtsiefer, der seit dem 4. Juni 1932 Braun vertrat $^{162}$, Klepper und Staatssekretär Frank Schleusener, mit dem neuen Kabinett Franz v. Papen kam ${ }^{163}$. Die Sitzung verlief, wie vorauszusehen, „völlig ergebnislos“164. „Die Bemühungen der neuen Reichsregierung [...], Preußen aufs Trockne zu setzen und damit Platz für einen Reichskommissar zu schaffen“, gingen weiter, aber, so fügt Pünder hinzu: „Die Herren der Reichsregierung waren überaus betroffen, als sie hörten, daß nun Preußen sich selber helfen werde. Morgen soll die neue preußische Notverordnung herauskommen. [...] Dann ist alles gedeckt für 1932, und das Reich hat keinerlei Einwirkungsmöglichkeiten. “165

160 GSTAM, VNL-K, Nr. 171.

161 Ebenda, Klepper an den preußischen Ministerpräsidenten Braun, 2. 6. 1932.

162 Vgl. die ausführliche Beschreibung der Endphase Preußens nach den verlorenen Wahlen im April von Schulze, Braun, S. 725 ff. und die "Flucht Brauns vor sich selbst“, S. $732 \mathrm{ff}$.; er hatte Hirtsiefer am 4. 6. 1932 zu seinem Stellvertreter ernannt und sich selbst beurlaubt.

${ }^{163}$ Reichsfinanzminister Graf Schwerin v. Krosigk und Innenminister Wilhelm Freiherr v. Gayl. Das Protokoll führte Ministerialdirektor Arthur Zarden (AdR-Papen, Nr. 11). Das Besprechungsprotokoll vom 7.6. 1932 befindet sich auch im VNL-K, Nr. 171, Bl. 56.

${ }^{164}$ Ebenda: Es wurde beschlossen, daß Preußen per Notverordnung einen eigenen Etatentwurf macht, außerdem wurde die Verabredung vom Anfang des Jahres zwischen RFM Dietrich und Klepper bestätigt, daß das Reich, das z.Zt. die 100 Millionen RM nicht zahlen könne, diese in 5 gleichen Jahresraten, beginnend mit dem 1. 4. 1933, zahlen solle. Schwerin v. Krosigk bestätigte diese Abmachung.

165 Pünder, S. $136 \mathrm{f}$. 
Tatsächlich legte Klepper noch am selben Abend dem Staatsministerium seinen Notverordnungsentwurf vor, der als "Pferdekur" vor allem wegen der umstrittenen

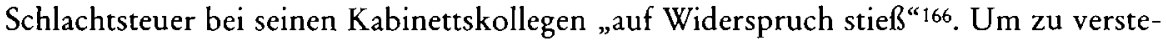
hen, welche massiven Widerstände Klepper zu überwinden hatte, sei hier ein Spiegel der Meinungen im Kabinett wiedergegeben: Handelsminister Walther Schreiber lehnte jede „Verantwortung für die Notverordnung" ab und war auch nicht bereit, sich an der Abstimmung zu beteiligen, kein Wunder, ging es doch unter anderem darum, seinen Ministersessel einzusparen ${ }^{167}$. Severing wollte zwar „für die Schlachtsteuer stimmen“, sah sich aber „aus sozialen und grundsätzlichen Erwägungen nicht in der Lage, der Kürzung der Dienst- und Versorgungsbezüge, sowie der Änderung der Hauszinssteuer zuzustimmen. Er werde jedoch im Hinblick auf die politische Gesamtlage zustimmende Beschlüsse des Staatsministeriums nicht zur Kabinettsfrage machen." Landwirtschaftsminister Heinrich Steiger lehnte zwar die Einführung der Schlachtsteuer ab, „weil erfahrungsgemäß die Landwirtschaft diese Steuer im wesentlichen trage, andererseits aber infolge der ungünstigen Viehpreise die bäuerliche Veredlungswirtschaft sich in größter Notlage befinde“, war aber für eine Kürzung der Dienstbezüge. Hirtsiefer setzte sich trotz schwerer Bedenken für die Schlachtsteuer, aber gegen eine Kürzung der Dienstbezüge ein. Schließlich gab Justizminister Hermann Schmidt zu bedenken, „daß er sich von der zwingenden finanziellen Notwendigkeit und der politischen Zweckmäßigkeit der Notverordnung nicht vollständig überzeugen könne und daß er auch verfassungsmäßige Zweifel habe. Er könne infolgedessen nicht positiv für den Erlaß der Verordnung stimmen." ${ }^{168}$ Daraufhin sei Klepper, wie er Engelmann später erzählt habe, „am Vorabend der dafür entscheidenden Kabinettssitzung bis spät in die Nacht hinein von Wohnung zu Wohnung seiner Kabinettskollegen gefahren [...] und [habe] sie einzeln von der Notwendigkeit, für die Steuer zu stimmen, überzeugt [...], was dann am nächsten Tag auch zu ihrer Annahme geführt habe“169.

Die Sparnotverordnung bedeutete tatsächlich auch eine Verwaltungsreform ${ }^{170}$. Liberale Zeitungen wie das Berliner Tageblatt lobten die "Zivilcourage“ der preußischen Regierung, sich unbeliebt zu machen, und erläuterten die „Zwickmühle“, in der die Regierung steckte: Hätte sie bis zur Zahlungsunfähigkeit gewartet, hätte das Reich mit dem Artikel 48 reagieren können, das heißt, im Grunde sei „das Reich schuld“, weil es die

${ }^{166}$ GSTAM, Rep. 151 HB, 632, Bl. 50, Staatsministerialsitzung am 7. 6. 1932, 17.30 Uhr, ebenso in: Rep. 90a, Bd. 181, Bl. 56 ff. (Staatsministerialsitzungsprotokoll vom 7. 6. 1932), abgedruckt bei Trumpp, S. 231 ff. Vgl. auch Schulze, Braun, S. 737.

${ }^{167}$ Sparnotverordnung von 1932 ist im VNL-K, Nr. 164 mit genauester Begründung jedes einzelnen Postens. Sie beinhaltet eine Verwaltungsreform, die Zusammenlegung von Behörden, Aufhebung des Ministeriums für Handel, Gewerbe und Volkswohlfahrt, Aufteilung auf andere Ministerien, Zusammenlegung von Provinzial-, Bezirks- und Kreisbehörden, Abbau des Personalbestandes, Kürzung der Gehälter, auch der Ministergehälter, Einsparungen bei der Rechtspflege.

168 Rep. $151 \mathrm{HB}, 632$, Bl. $50 \mathrm{ff}$.

${ }^{169}$ Ebenda, Bl. 53 f. Die „Verordnung zur Sicherung des Haushalts" vom 8. 6. 1932 (PrGslg. 1932, S. $199 \mathrm{ff}$.) verfügte u. a. eine Kürzung der Beamtenbezüge um $2^{1 / 2}$ beziehungsweise $5 \%$ (für Ledige und kinderlos Verheiratete in Form einer Zwangsersparnis), die Einführung einer Schlachtsteuer und die Umgestaltung der Hauszinssteuer. Vgl. Kleppers Ausführungen im PrLT, 16. 6. 1932, 9. Sitzung, Sp. 545-553 und Engelmann, S. 35.

170 GSTAM, VNL-K, Nr. 164. 
100 Millionen nicht gezahlt habe, dennoch sei die Lösung "nicht sehr elegant“, weil zu wenig dabei herauskomme und die ohnehin schon gerupften Beamten leiden müßten ${ }^{171}$.

Klepper begründete die Verordnung in einer Radioansprache mit der Notwendigkeit, die „völlige Unabhängigkeit Preußens sicherzustellen“, und machte kein Hehl aus seiner Sorge um die aktuelle politische Lage. Er sprach zu seinen Hörern von dem „Eindruck“, den er „empfinde“, „daß das deutsche Volk weiß, daß die nächste Zeit schwere Opfer von ihm fordern wird, daß es auf der anderen Seite aber den Wunsch hat, daß es über das, was geschehen soll, und wie die Dinge liegen, die Wahrheit hört und daß die Opfer, die ihm auferlegt werden, nicht umsonst gebracht werden“. Sodann erläuterte er die beschlossenen Maßnahmen im einzelnen und verwies im Zusammenhang mit der Schlachtsteuer auf Bayern, wo sie bereits seit längerer Zeit Geltung habe ${ }^{172}$. Eine Woche später begründete Klepper die harte Notverordnung vor dem preußischen Landtag ebenfalls mit der Notwendigkeit, „nunmehr den Weg der Selbsthilfe zu beschreiten und den Etat aus eigener Kraft auszugleichen, [...] weil es, wenn wir wirklich den Weg zu einer echten nationalen Konzentration finden wollen, (Zuruf der NSDAP: Den findet ihr nie!) unter allen Umständen notwendig ist, politisch, finanziell und wirtschaftlich die völlige Unabhängigkeit Preußens sicherzustellen“. Daß man diese Unabhängigkeit auch als „,hündische Unterwürfigkeit“ unter die „Diktaturregierung im Reich“ deuten konnte, beweist der direkt anschließende Kommentar des kommunistischen Abgeordneten Wilhelm Kasper. Klepper hatte seine Rede mit den Worten beendet: „So haben wir gehandelt, und so werden wir handeln, solange wir die Verantwortung tragen. Und ich nehme an, daß wir sie noch eine ganze Zeitlang tragen werden." ${ }^{173}$ Diese Prophezeiung sollte sich allerdings nicht erfüllen, wenn auch der Regierung Papen mit dieser Notverordnung zunächst einmal ein wichtiger Vorwand genommen worden war, in Preußen einen Reichskommissar einzusetzen ${ }^{174}$.

\section{Papens Staatsstreich und die Auflösung Preußens}

Ein knapper Monat blieb noch, bis Papen im Reichskabinett verkündete: „Bisher seien alle Maßnahmen der Reichsregierung, [einen Reicbskommissar in Preußen einzusetzen], durch die preußische Staatsregierung sabotiert worden “ 175 , doch nun müsse endlich „die Polizeigewalt [...] eine feste Staatsführung spüren“. Schleicher sekundierte, indem er „eine Endlösung mit Bezug auf die Beseitigung des Dualismus Reich - Preußen“ for-

171 BAK, NL-Zarnow, Bl. 70.

172 Rundfunkansprache vom 10.6. 1932 (DRA und VNL-K, Nr. 176).

${ }^{173} \operatorname{PrLT}, 16.6$. 1932, 9. Sitzung, Sp. 545-553, Sp. 553. Am 18. 6. legte Klepper den „Entwurf eines Gesetzes über die Feststellung des Haushaltsplans für das Rechnungsjahr 1932“ dem Landtag vor (PrLT-Drucksache Nr. 289, Bd. 764). Am 14.7. 1932 wurde es durch Notverordnung in Kraft gesetzt (PrGslg. 1932, S. 237).

${ }^{174}$ Bericht vom 10.6. 1932 über eine Besprechung der süddeutschen Ministerpräsidenten, Sitzung des Württembergischen Staatsministeriums (AdR-Papen, Nr. 10). Vgl. Besson, S. 398.

${ }^{175}$ Ministerbesprechung vom 11.7. 1932 (AdR-Papen, Nr. 57). Bay kommentiert Papens Aussage so: Sie „entbehrt jeder Berechtigung, es sei denn, sie bezog sich auf die preußische Notverordnung von Anfang Juni, die seinen Plan vereitelt hatte, durch Auslösung einer Finanzkrise einen Vorwand für die Einsetzung des Kommissars zu schaffen“ (S. 187). 
derte $^{176}$. Bei der Untersuchung der Ereignisse dieser wenigen Wochen zwischen der preußischen Sparnotverordnung vom 8. Juni und dem Papenschen Staatsstreich am 20. Juli 1932 soll hier nur auf die Rolle Kleppers eingegangen werden, von der Vogelsang

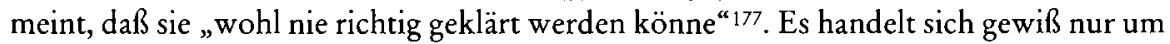
ein Detailproblem der Geschichte des Staatsstreiches, dessen Vorgeschichte, Ablauf und Nachwirkung in reicher wie kontroverser Vielfalt behandelt worden ist. Dennoch scheint die Frage nach Kleppers Verhalten nicht uninteressant zu sein, weil sich hinter ihr die weitergehende Frage verbirgt, ob es im Sommer 1932 noch zur Verteidigung der Republik fähige und entschlossene Demokraten gab oder ob, wie Hans Mommsen meint, „die Republik [...] spätestens seit dem Frühjahr 1932 keine Selbstverteidigungskräfte mehr $[\ldots]$ besaß“178.

Damit in engem Zusammenhang steht die Fragestellung, welche Chancen auf Erfolg eine kleine Minderheit hat, wenn sie Widerstand zu leisten versucht, und welcher Symbolwert einem solchen, in den Augen vieler von vornherein chancenlosen, Widerstand zukommt. Die letztere Frage wurde erst im Zusammenhang mit der Diskussion um den ,zweiten' 20. Juli, zwölf Jahre später, aktuell, einmal aus emotionalen Gründen, weil man jedes Symbol des Widerstandes gegen Hitler meinte brauchen zu müssen, und zum anderen, weil erst dann „endlich [...] mit jenem Legalitätsbedürfnis auch gegenüber offensichtlichem Rechtsmißbrauch gebrochen [wurde], das den Widerstand gegen den Papenputsch so entscheidend gelähmt hatte“. Bracher, der mehrfach auf diese "deutsche Fehltradition" 179 hingewiesen hat, ist einer der wenigen Historiker, der erkannt hat, was Klepper schon 1933 in bezug auf den 20. Juli 1932 schrieb: „Beseitigte man nämlich die preußische Regierung, ohne materiellen Widerstand zu finden, so werde das zu einer Depression innerhalb der republikanischen Kreise führen, also [...] der Rechten Auftrieb verleihen. Bei den zu erwartenden späteren Komplikationen stehe dann die Linke der kombinierten Macht von Reichswehr und Polizei gegenüber", deshalb sei jeder „Versuch eines Eingriffs in Preußen als Mißbrauch des Artikels 48 der Reichsverfassung, also als Staatsstreich zu behandeln, und also aufgrund der preußischen Verfassung der Ausnahmezustand zu verhängen "180. Mit dieser klaren Einschätzung des Vorgangs stimmte Klepper mit dem Urteil eines prominenten Zeitzeugen, des Staats- und Verfassungsrechtlers Otto Kirchheimer, überein, der die Vorgänge analysierte und schon vor der Urteilsverkündung des Staatsgerichtshofes zu dem Schluß kam: „Der Staatsstreich vom 20. Juli hat insoweit der gesamten Notverordnungspraxis einen ebenso gewaltsamen wie eindeutigen vorläufigen Abschluß gegeben, der mindestens den Vorzug unmißverständlicher Klarheit besitzt." "181 Für Bracher steht hinter diesem Problem die allgemeinere Frage nach der „Offenheit der Geschichte“. Das bedeute, daß zugleich mit der

\footnotetext{
176 Ebenda, Hauptinitiator dieser Politik war Innenminister Wilhelm v. Gayl.

177 Vogelsang, Reichswehr, S. 246.

178 Mommsen, Schatten, in: Bracher u. a. (Hrsg.), Weimar, S. 555, und Schulz, Brüning, S. 920 ff.

179 Bracher, Dualismus, in: Bracher u. a., Weimar, S. 547 und 544.

${ }^{180}$ Klepper, Erinnerung, S. 91 (Hervorhebung im Original). Vgl. Bracher, Dualismus, S. 546: „Der 20. Juli hat der Republik und dem Glauben nicht nur an ihre äußere, sondern vor allem an ihre innere Kraft an entscheidender Stelle das Rückgrat gebrochen. "Vgl. Grzesinski an Otto Wels, 2. 8. 1932, abgedruckt in: Matthias/Morsey, Ende der Parteien, Dok. Nr. 14, S. 226: „Der Ausgang des 20. Juli 1932 hat Nazis und Papenregierung zuversichtlich gemacht."

181 Kirchheimer, Verfassungslehre, S. 61. Zu Kirchheimer vgl. Luthardt/Söliner (Hrsg.), Verfassungsstaat.
} 
Frage nach den Chancen eines Widerstandes „die möglichen Konsequenzen“ des NichtEingreifens bedacht werden müßten. Das heißt konkret auf diesen Fall bezogen: Indem „jeder Versuch einer demonstrativen Bekundung des ungebrochenen Selbstbehauptungswillens der Demokratie auch gegen zeitweilig überlegene Gewaltaktionen“ unterblieb, wurde damit auch das „demokratische Selbstbewußtsein“ zerstört und den neuen Machthabern der Weg erleichtert ${ }^{182}$.

In diesem Sinne wußte Klepper, worum es in den nächsten Monaten gehen würde und was zu tun sei. Auch in der Öffentlichkeit hat er, wie die oben zitierte Rundfunkansprache vom 10. Juni und seine Kieler Rede zeigen, kein Hehl aus seiner Sorge um die aktuelle politische Lage gemacht. Es gilt also zu untersuchen, ob Klepper die politische und wirtschaftliche Situation im Sommer 1932 tatsächlich richtig eingeschätzt und versucht hat, den Staatsstreich zu verhindern, so wie er es später selbst dargelegt hat ${ }^{183}$. Neben der damit erneut aufgeworfenen Frage nach den Möglichkeiten eines Widerstandes im Juli 1932 geht es auch um die Glaubwürdigkeit Kleppers, die in der Literatur verschiedentlich angezweifelt wird.

Kleppers eigener Darstellung von 1933 und von 1947 folgend, soll schrittweise untersucht werden, ob sein tatsächliches Verhalten dem Dargestellten entsprach, beziehungsweise ob es durch andere Quellen bezeugt werden kann. Die erste Frage ist: Definierte Klepper seine eigene politische Position richtig, das heißt, stimmt die angeblich „nachträgliche" ${ }^{184}$ Definition mit seinem tatsächlichen Verhalten überein? Klepper zählte sich, im Gegensatz zu Severing und vielen anderen Politikern, zu denjenigen, die „erwarteten“, daß Hitler, wenn er erst einmal an die Macht käme, „durch massive Aufrüstung eine binnenwirtschaftliche Hochkonjunktur entfesseln und damit seine Macht so festigen [werde], daß es unmöglich sein werde, ihm in den Arm zu fallen, bevor das Unglück geschehen sei“, das heißt, er glaubte nicht, daß „die nationalsozialistische Bewegung, mit praktischer Verantwortung belastet, versagen werde“. Dic Konsequenz dieser Erkenntnis war für Klepper, „daß also der Gewalt mit Gewalt zu begegnen sei“, was bedeutete, daß die Demokratie verteidigt werden mußte, notfalls auch mit Waffen ${ }^{185}$. Daß Klepper diese Einstellung nicht erst im nachhinein, also 1947, entwickelt hat, läßt sich unschwer aus der Art seines bisher dargestellten politischen Handelns, das in seiner Emigrationszeit eine Fortsetzung unter anderen Bedingungen fand, entnehmen und wird durch seine

182 Bracher, Dualismus, S. 546.

${ }^{183}$ Kleppers Artikel, „Das Ende der Republik“, in: Die Gegenwart, 17/18, 30. 9. 1947, S. 19 ff. ist eine Antwort auf den zuerst erschienenen Artikel von Severing, „20. Juli 1932“, in: Die Gegenwart, 13/14 (1947), S. 14 ff. Vgl. auch die oben zitierten in Schweden erschienenen Artikel. Abegg nimmt in einem Brief an Klepper vom 4. 2. 1951 Stellung zu Kleppers Gegenwarts-Artikel: „Ihren Artikel über das Ende der Weimarer Republik habe ich natürlich mit größtem Interesse in der Gegenwart vom 30. 9. 1947 gelesen. Da fehlt aber noch ein Mittelstück, von dem Sie offenbar selber keine Kenntnis erhalten haben; ich würde Ihr Wissen gern gelegentlich ergänzen. [...] Natürlich ist Severings Standpunkt in der Verteidigung seiner völligen Passivität völlig unhaltbar" (K/Kor). Severing hat dann seinerseits noch einmal geantwortet mit dem Artikel: „Kräfte und Gegenkräfte“, in: Dic Gegenwart, 7/8, 1. 4. 1948, S. 17-19 und sein Schwiegersohn Walter Menzel, „Carl Severing und der 20. Juli 1932“, in: Die Gegenwart, 168, 8. 11. 1952, S. 734 .

${ }^{184}$ Bracher, Auflösung, S. 585: Klepper habe "nachträglich behauptet“".

${ }^{185}$ Klepper, Ende, S. 21. Vgl. Biewer (Hrsg.), Preußen: „Fehlurteile über die wirkliche Gefährlichkeit der NSDAP“, S. 106 f. Auch da stimmt Klepper mit Kirchheimer überein, vgl. Kirchheimer, Marxismus, S. 106. 
während der Endphase der Republik getroffenen Maßnahmen und gehaltenen Reden sowie seine unmittelbar nach der Machtergreifung geschriebenen Artikel bestätigt ${ }^{186}$. Außerdem gibt es eine Vielzahl von Zeitzeugen, die Kleppers Versuche, sich gegen die Gewalt zu wehren, bezeugen.

Schon als Präsident der Preußenkasse hatte er seit Dezember 1930 einen geheimen Sonderfonds zur „geistigen Bekämpfung des Nationalsozialismus" unterstützt, aus dem heraus der „Deutschlandbund“ gespeist wurde ${ }^{187}$. Arnold Brecht, der für diesen Bund verantwortlich war und unter dessen Namen auch das geheime Sonderkonto bei der preußischen Staatsbank (Seehandlung) lief, nannte diesen Bund eine „Gesinnungsgemeinschaft“. Klepper gehörte dazu, wofür er im späteren Untersuchungsausschuß von den Nationalsozialisten angeklagt worden ist ${ }^{188}$. Der Bund gab Informationsblätter heraus und veranstaltete Kundgebungen, er bestand bis August 1932189. Im Zusammenhang mit der späteren Überprüfung des Fonds durch die Oberrechnungskammer stellte Höpker-Aschoff die Frage nach der Legitimität der Verteidigung des Staatswesens als Parallele zur öffentlichen Propaganda des Nationalsozialismus. Er meinte, es sei wahrscheinlich falsch gewesen, die Propaganda für die Demokratie nicht öffentlich zu machen, was indirekt durch das Votum der Oberrechnungskammer vom 21. Juli 1933 [!] bestätigt wurde, dort heißt es nämlich: „Wir sind bei der Beurteilung der Zuverlässigkeit der ministeriellen Anordnung von dem Grundsatz ausgegangen, daß es der jeweiligen Regierung nicht verwehrt werden darf, diejenigen Maßnahmen zu treffen, die ihr zur Stützung ihrer Politik geeignet erscheinen, und daß die Verausgabung von Staatsmitteln für diese Zwecke an sich vertretbar ist. " 190

186 Vgl. auch sein 1933 im Exil, in Finnland gegebenes Interview sowie die Artikelserie, aber auch die späteren Artikel in: Die Zukunft, aus denen klar hervorgeht, daß man mit einem Hitler nicht verhandeln, sondern ihn nur bekämpfen kann.

${ }^{187}$ GSTAM, Rep. $151 \mathrm{HB}, \mathrm{Nr} .46$ : „Konto von Ministerialdirigent Brecht bei der preußischen Staatsbank zur Durchführung von Maßnahmen verwaltungspolitischer Reformen 1930-1933.“ Der Kontostand war 1930: 75 000, im Mai 1932: 170000 RM; Brecht gibt an, daß er ab 20.7. 1932 nicht mehr über das Konto verfügt habe (Bl. 11), es wurde dann von Gottfried BermannFischer verwaltet (Bl. 121 f.). Am 30. 3.1933 verlangt die Oberrechnungskammer Rechenschaft über die nie spezifizierten, stets von Klepper bestätigten Ausgaben, die u. a. die Unterstützung des Deutschlandbundes belegen (B1. 17). Ebenda, Bl. 60 ff.: Bericht über Entstehung und Zielsetzung des Sonderkontos. Dem Bericht sind Berichte von Brecht und Höpker-Aschoff angefügt. Vgl. auch S. $144 \mathrm{ff}$. Vgl. Brief Kleppers an Heinrich Lübke vom 20. 12. 1952: „Vermutlich wußten sie [die Nationalsozialisten] auch, daß wir, als ich noch Präsident der Preußenkasse war, über die von Ihnen geleitete Heimbank von der Preußenkasse aus Mittel an antifaschistische Organisationen geleitet hatten. [...] Ich erinnere mich genau, daß Sie der Preußenkasse ständig genauen Einblick in die Verwendung der zur Verfügung gestellten Mittel gewährt haben. Insbesondere haben Sie noch im Jahre 1932 einen eingehenden Bericht erstattet, und in einer anschlieBenden Besprechung, an der Sie, der inzwischen verstorbene Dircktor Siedersleben und ich teilnahmen, erklärten Siedersleben und ich unser Einverständnis mit allen von Ihnen getroffenen Maßnahmen" (K/Kor).

${ }^{188}$ Bermann-Fischer, S. 89 f.: Einige Gelder liefen auch über ein Konto des Verlegers, deshalb mußte er im April 1934 in der Verhandlung gegen Klepper als Zeuge in Moabit erscheinen, was für ihn äußerst gefährlich war.

189 Brecht, S. 145 ff. (Abdruck des Blattes S. 148).

190 Rep. 151 HB, Nr. 46, Bl. 155 ff., die Prüfung erfolgte durch den Notar Georg Pfuhl, nur die falsche Kontobezeichnung wurde gerügt. 
Ein weiterer Sonderfonds zum Schutze der Demokratie wurde im April 1932 von der preußischen Staatsregierung beschlossen, für den Klepper die Mittel bereitzustellen hatte und Carl Spiecker verantwortlich war ${ }^{191}$. Aus diesem Fonds wurde auf Betreiben Kleppers auch die "Schwarze Front“ ${ }^{192}$ unterstützt, weil sie als Gegner des Nationalsozialismus auftraten ${ }^{193}$. Auch Walter Stennes, der ursprünglich Nationalsozialist, von Hitler aber am 1. April 1931 wegen seiner Kritik an der Partei ausgeschlossen worden war, wurde durch den Fonds unterstützt ${ }^{194}$, weil er, wie Klepper für Stennes' Spruchkammerverfahren bekundete, „bei den Abwehrbestrebungen der damaligen preußischen Regierung [...] ebenso wertvolle wie für ihn persönlich riskante Dienste geleistet" hat, was auch von Spiecker bestätigt wurde ${ }^{195}$.

Die dritte Abwehrgruppe, zu der Klepper offensichtlich enge Kontakte hatte, war die „Eiserne Front", zu der sich am 16. Dezember 1931 das Reichsbanner Schwarz-RotGold ${ }^{196}$, die Gewerkschaften, die SPD und die Arbeitersportverbände zusammengeschlossen hatten. Hubertus Prinz zu Löwenstein berichtet von Gesprächen mit der preußischen Regierung über Abwehrpläne gegen eventuelle Maßnahmen der Reichsregierung, die von allen Ministern außer Severing und Braun - und „ohne sie konnte man nicht handeln“ - unterstützt worden seien; besonders Klepper habe dazu geraten, „eine Mobilmachung der ,Eisernen Front ' durchzusetzen“ ${ }^{6} 97$. Dies bestätigt auch der damals stellvertretende Gauvorsitzende des Reichsbanners für Berlin und Brandenburg, Wilhelm Nowack, der nach dem Kriege an Klepper schrieb: „Die Besprechungen sind mir so deutlich in Erinnerung geblieben, weil Sie - das konnte ich Ihnen schon damals sagen - der einzige aktive Minister der guten Weimarer Republik waren, der bereit war, die kämpferischen Abwehrmöglichkeiten des Reichsbanners in jeder Weise zu unterstützen. "198 Im Juni 1932 hielt Klepper eine Rede vor der Eisernen Front in Göttingen ${ }^{199}$.

191 Brecht, S. 143 f. Klepper an Innenminister des Landes NRW, Franz Meyers (IfZ, Walter Hammer-Archiv, Ed 106, Bd. 33 und K/Kor).

192 Otto Strasser erklärt den Namen in seinem Buch „Exil“, München 1958, so: „Wir waren die überall vorhandene, die schattenhafte, die geheime Front. Deshalb nannten wir uns, Schwarze Front"." Vgl. Grabe, Otto Strasser, Moreau, Nationalsozialismus von links, und Bartsch, Strasser.

${ }^{193}$ Klepper an Meyers: „Ich habe die erforderlichen Verhandlungen mit dem damaligen Beauftragten der Reichsregierung, Dr. Spiecker, geführt." Major a. D. Bruno Ernst Buchrucker sei namhaftes Mitglied der Schwarzen Front gewesen (K/Kor).

$194 \mathrm{Vgl}$. Mende, Erinnerungen.

195 Kleppers Aussage für das Anerkennungsverfahren von Stennes als Verfolgter des Naziregims, 18. 7. 1949. Der Regierungspräsident bestätigte im Bescheid vom 6. 3. 1954 zwar die Verfolgung durch die Nationalsozialisten bis zu seiner erzwungenen Auswanderung nach China, nachdem er von Mai bis September 1933 in Schutzhaft war, erkannte aber keine grundsätzliche Abkehr von der Ideologie des Nationalsozialismus an, was Klepper dagegen in einem Brief vom 9. 4. 1954 tat und sich auch zu einer diesbezüglichen Aussage vor dem Landgericht bereit erklärte (KNL).

196 Vgl. Mende, Erinnerungen, die dort erwähnten Kontakte zu Höltermann, seit Dezember 1932 hauptamtlicher Bundesführer des Reichsbanners Schwarz-Rot-Gold.

197 Prinz zu Löwenstein, S. 90 ff., dort zitiert er aus seinem unmittelbar nach der Machtergreifung geschriebenen Buch "The Tragedy of a Nation“, 1934. Liang (S. 171) bestätigt ein Treffen der Eisernen Front mit Severing und der SPD-Führung am 16. 7. 1932. Auch Brecht (S. 100) berichtet, $\mathrm{da}$ K Klepper die Arbeiter aufrufen wollte.

198 Nowack, nach dem Kriege Minister in Rheinland Pfalz, an Klepper, 3. 6. 1949 (K/Kor.).

${ }^{199}$ Der Hinweis findet sich in der Zivilklage gegen Braun in der Akte zur Kieler Rede (GSTAM, Rep. 151 HB, Nr. 39). 
Fazit ist, es gab durchaus Abwehrkräfte, und wenn man sie entschlossen zusammengefaßt und mit der preußischen Polizei200 koordiniert sowie durch einen Generalstreik unterstützt hätte, wäre die Abwehrfront zumindest so stark gewesen ${ }^{201}$, daß die Reichsregierung die Verantwortung für einen Bürgerkrieg hätte auf sich nehmen müssen. Hindenburg, der zwar für Papen, aber gegen Hitler war, hätte vor einem solchen sicher zurückgeschreckt. Grzesinski, der damals Polizeipräsident von Berlin war, sieht es in seinen Lebenserinnerungen als größtes Versäumnis an, daß es nicht gelungen sei, „die zur Abwehr in Frage kommenden Kräfte frübzeitig zu mobilisieren und Vorbereitungen zu treffen, die uns auch die Polizei in der Hand gelassen hätte". Die Ausführungen Grzesinskis werden oft, da nicht im Zusammenhang zitiert, schief wiedergegeben, deshalb soll hier die ganze der oben zitierten Stelle vorangehende Argumentation notiert werden: „Ich war wahrhaftig der letzte, der es auf ein Blutvergießen anlegte. Aber andrerseits widerstrebte es mir, vor der Kumpanei Papen-Bracht-Schleicher einschließlich Oskar v. Hindenburg so ohne weiters zurückzuweichen. Ich fühlte mich in dieser Stunde ganz besonders als Vertrauensmann nicht nur der Arbeiterschaft, sondern der ganzen republikanischen Bevölkerung. Aber nach der Einstellung, die Severing offenbar zu diesen Dingen hatte, gab ich es zunächst auf, das Gespräch fortzuführen. Ich rief daher: Wir können es doch aber auch nicht zu einem Blutvergießen kommen lassen. "202 Es ist unverständlich, daß auch heute noch behauptet wird, Grzesinski habe seine Abwehr erst im Nachhinein bekundet, obwohl seine Lebenserinnerungen von 1933 unter anderem von Winkler ausführlich zitiert werden ${ }^{203}$.

Gegen das Druckmittel eines Generalstreiks wird immer wieder das Argument der großen Arbeitslosenzahlen ins Feld geführt ${ }^{204}$, ein Problem, mit dem sich unter anderen Winkler überzeugend auseinandersetzt, ohne allerdings zu bedenken, daß der Generalstreik eine Sache von Stunden, allenfalls Tagen und nicht von Wochen gewesen wäre. Die sofortige "Lähmung des Verkehrs und des Nachrichtenwesens“205 hätte den raschen Einsatz der Truppen, von dessen Gefährlichkeit auch Grzesinski spricht ${ }^{206}$, erschwert oder zumindest hinausgezögert. Außerdem hätte ein solcher Aufruf für die Arbeiterschaft, die in ihrer Mehrzahl immer noch sozialdemokratisch gesonnen war, eine Fanalwirkung gehabt, „denn noch“, schreibt Bracher, „war es ja nicht eine brutale Diktatur,

${ }^{200}$ Die Frage, welchen Erfolg ein Eingreifen der Polizei gehabt hätte, ist ebenfalls bis ins einzelne diskutiert worden. Eine der neueren Abwägungen: Schulz, Preußenschlag. Vgl. auch v. Lindheim, S. 160 ff., Morsey, „Preußenschlag“, in: VfZ 9 (1961), und Ehni, S. 268 ff., der speziell auf Brauns und Severings Argumentation eingeht. Bracher, Bay u. a.

${ }^{201}$ Friedensburg, S. 211: „In der Polizei stand Severing ein wesentlich stärkeres und für innenpolitische Auseinandersetzungen geeigneteres Machtinstrument zur Verfügung, als es die Reichswehr in Berlin war und Reichsbanner und Gewerkschaften konnten das Mehrfache der Mannschaft aufbieten als die etwa zu mobilisierenden Reichsverbände." Damit wäre Hömigs Aussage, konkrete Planungen mit dem Reichsbanner etc. habe es nicht gegeben, widerlegt (S. 266). Im übrigen bestätigt Hömig den Widerstandswillen von Hirtsiefer und Klepper.

202 Grzesinski, Lebensweg, Bl. 291 ff., Bl. 296 (Hervorhebung im Original) und Bl. 293. „Ich beschloß aber, Widerstand zu leisten. Eine gewaltsame Abwehr kommt allerdings nicht mehr in Frage" (Bl. 302). Zur Rolle Grzesinskis vgl. Bay, S. 122 f.

${ }^{203}$ So Alexander in seiner kürzlich erschienenen Biographie über Severing, S. 204. Vgl. Winkler, Der Weg, S. $657 \mathrm{f}$.

${ }^{204}$ Winkler, Weimar, S. 501 f. Vgl. u. a. Bracher, Dualismus, S. 545.

${ }^{205}$ Friedensburg, S. 211.

206 Grzesinski, Lebensweg, Bl. $302 \mathrm{ff}$. 
gegen die man stand“. Und er folgert daraus, daß „das Verhalten der Führung der inneren Festigkeit und dem politischen Glauben der SPD-Anhänger einen Schlag versetzt [hat], der die Partei entscheidend lähmte und dann auch ihre weitere Passivität gegenüber der Hitlerschen Machtergreifung bis hin zu Auflösung bestimmte “207.

Unter diesem Blickwinkel betrachtet, gewinnt die Figur Kleppers eine gewisse Bedeutung. Sein Handicap, daß er keiner Partei angehörte, war allerdings groß, denn ihm fehlte die Hausmacht; dieser Nachteil konnte auch durch seine Kontakte zu den unterschiedlichsten Gruppen und Parteien nicht aufgewogen werden. Jedenfalls war er durch seine vielfältigen Beziehungen bestens informiert ${ }^{208}$, und man traute ihm Durchsetzungsvermögen $\mathrm{zu}$, auch diejenigen, die ihn ablehnten ${ }^{209}$. Kleppers Vorschlag, kurzfristig das Ressort mit Severing zu tauschen, er nennt es „einen Gedanken“, der im Laufe des Gespräches „aufgetauch"“ sei210, muß wohl in diesem Zusammenhang gesehen werden. Es ging nicht um die Usurpation eines Amtes, sondern darum, in dieser verfahrenen Situation die Autorisation, die allein der Innenminister besaß, für den Eventualfall in die Hände zu legen, die auch die Kraft hatten, die notwendigen Maßnahmen zu ergreifen. Hirtsiefer mußte Braun vertreten, sonst war kein anderer geeigneter Mann im preußischen Kabinett, der die Rolle des Innenministers vorübergehend hätte übernehmen können. Was von diesen Überlegungen ernsthaft erwogen wurde, läßt sich nachträglich nicht mehr beweisen, doch legte Severings Haltung, „keinen aktiven Widerstand zu leisten, sondern lediglich den Rechtsweg zu beschreiten“, eine Haltung, die Klepper be-

${ }^{207}$ Bracher, Dualismus, S. 546. Vgl. auch Friedensburg, S. $210 \mathrm{f}$.

208 Seine Behauptung, er sei schon Anfang Juli über die Absichten der Reichsregierung informiert gewesen und habe diese Information an Severing weitergegeben, trifft zu. Klepper an v. Lindheim, 14. 8. 1952: Zu der Besprechung mit Hirtsiefer und Severing habe er Stennes mitgebracht, damit dieser seine Information, „die er aus dem Reichswehrministerium“ hatte, selbst weitergibt, nämlich, daß „Papen nach Neudeck gefahren [sei], um sich von Hindenburg Vollmachten für einen Staatsstreich geben zu lassen “, er tat es „aus einer gewissen Affektion, die er mir gegenüber empfand" (K/Kor). Vgl. v. Lindheim, S. 160 (Stennes hat diese Aussage schriftlich bestätigt). Im übrigen sprach die Presse seit Wochen über die Möglichkeit eines Reichskommissars für Preußen. Vgl. Anlage preußischer Landtag, Nr. 1203, Sp. 98, in: NL-Höpker-Aschoff, BAK, 129, 15. Zeitzeugen: u. a. Grzesinski, Inside Germany, S. 154; Georg Bernhard, S. 295. Vgl. auch die von Bay, S. 118 zitierten Zeitungen. Morsey, Adenauer, in: Stehkämper (Hrsg.), S. 455, ebenda Ders., Adenauer als Präsident, S. 389. Der mögliche Reichskommissar war schon im Juni Thema der „Besprechung der Ministerpräsidenten und sonstigen Vertreter der Länder" vom 11. 6. 1932 (AdR-Papen, Nr. 18/19) und der „Besprechung mit den süddeutschen Staats- und Ministerpräsidenten beim Reichspräsidenten“ vom 12. 6. 1932 (Aufzeichnungen von Staatssekretär Otto Meissner, ebenda, Nr. 21), in der Hindenburg erklärte, „daß an die Einsetzung eines Reichskommissars zur Zeit gar nicht gedacht" sei. Schon einen Monat später, am 12. 7. 1932, unterschrieb er eine „Blanko“-Notverordnung, die die vom Reichskabinett tags zuvor beschlos sene "Einsetzung eines Reichskommissars in Preußen" ermöglichte (Ministerbesprechung vom 11. 7. 1932, ebenda, Nr. 57, S. 204 ff. mit vielen Anm.). Vgl. auch Ministerbesprechung vom 12. 7. 1932 (ebenda), es wurde vereinbart, Hirtsiefer, Severing und Klepper für den 20.7.1932 in die Reichskanzlei zu bitten, und Ministerbesprechung vom 16. 7. 1932 (ebenda, Nr. 63).

${ }^{209}$ Schäffer zitiert unter dem 7. 6. 1932 den Chefredakteur Julius Elbau von der Vossischen Zeitung, "Klepper und die Zentrumsleute" wollten "Preußen auf alle Fälle halten", und Klepper habe "geäußert, daß die Preußen den Reichskommissar, wenn er seine Tätigkeit aufnehmen wolle, einfach verhaften lassen" wollen (Bd. 21, S. 564).

210 Klepper, Ende, S. 20. 
kannt war ${ }^{211}$, solche Erwägungen ebenso nahe wie Grzesinskis kritische Äußerungen über die Fähigkeiten Severings ${ }^{212}$.

Um so erstaunlicher ist es allerdings, daß Klepper Severing gegenüber so loyal war. Hätte er gewußt, daß Severing bereits mit dem Gedanken eines Reichskommissars gespielt, ja diesen Papen sogar nahegelegt hatte, wie aus einer Aussage Max Reiners Schäffer gegenüber hervorgeht, wäre er gewiß weniger rücksichtsvoll gewesen. Severing hatte „durch Reiner [...] Papen darauf hinweisen lassen, daß der richtige Moment für die Einsetzung eines Reichskommissars der Augenblick wäre, in dem der preußische Landtag den Haushalt nicht annehme und infolgedessen ein finanzieller Notstand geschaffen sei. Severing hat auch angedeutet, daß im Falle der Bestallung eines Reichskommissars aus solchem Anlaß mit einem Generalstreik nicht zu rechnen sei." ${ }^{213}$ Auch Wilhelm Freiherr v. Gayl gegenüber habe Severing "die Übernahme der Polizei auf das Reich zu gegebener Zeit für eine verständliche und natürliche Maßnahme gehalten“214. Kurz nach dem 20. Juli hat Klepper dann Harry Graf Kessler gegenüber zugegeben, daß er und Hirtsiefer Severings Charakter wohl „überschätzt“ hätten²15. Da der Grundsatz „loyal und seriös in hervorragendem Grade Kleppers Haltung in der Opposition kennzeichnete“216, erwartete er dies auch von anderen.

Probleme warf auch die Frage auf, wie weit die süddeutschen Länder bereit sein würden, Preußen beizustehen. Nach Kleppers Aussage hat „auf Hirtsiefers Einladung eine Zusammenkunft der süddeutschen Ministerpräsidenten “ stattgefunden ${ }^{217}$, die auf den preußischen „Entschluß, dem etwaigen Versuch eines Staatsstreiches mit Gewalt entgegenzutreten, [...] eindeutig positiv" reagiert und bestimmte Vereinbarungen getroffen hätten ${ }^{218}$. Unter Zugrundelegung des Petersen-Berichts scheint es sich eher um einen „Eventualbeschluß“ gehandelt zu haben, das heißt, es ist kein formeller Beschluß gefaßt worden, wie Kleppers Formulierung das nahelegen könnte; das würde auch erklären, $\mathrm{da}$ der anwesende Severing nicht protestierte, ein von Lindheim zu Recht diskutiertes

${ }^{211}$ Klepper, Erinnerung, S. 91, Severing, Lebensweg, S. 347 (auch im SPD-Fraktionsvorstand wurde der bewaffnete Widerstand wegen der ungleich verteilten Machtverhältnisse abgelehnt). 212 Grzesinski, Lebensweg, Bl. 233 ff., S. 133: Bestätigt durch Brief Adenauers an Heinrich Kurth, 21. 7. 1948, in: Adenauer, Briefe, Bd. II, S. 281.

213 Schäffer, Bd. 21, S. 676, 22. 7. 1932.

214 Lindheim, S. 162 f. Vgl. auch Winkler, Der Weg, S. $630 \mathrm{f}$.

${ }^{215}$ Harry Graf Kessler, Tagebücher 1918-1937, S. 690 f.

216 Engelmann, S. 24 und 35.

217 Die Besprechung hat am 27.6. 1932 stattgefunden. Undatierte Aufzeichnung des Hamburger Bürgermeisters Carl Petersen (StAH, Senatskanzlei-Präsidialabteilung, 1932, A69). Vgl. AdRPapen, Nr. 57, S. 204 f., Anm. 4. Vgl. die unkritische Übernahme dieser Information durch Görlitz, Hindenburg, S. 379 f.: „Dieser Plan eines, heißen Staatsstreiches', von dem Hindenburg und Papen 1932 keine Kenntnis hatten, rechtfertigt jedoch bis zu einem gewissen Grade nachträglich den ,kalten Staatsstreich", den Papen durchführte“.

${ }^{218}$ Klepper, Das Ende, S. 20: „Es wurde vereinbart", im Notfall den „Ausnahmezustand“ in PreuBen zu verhängen, „das Reichsbanner zur Hilfspolizci $[z u]$ erklären und $[z u]$ bewaffnen, Hindenburg diskret $[z u]$ neutralisieren, die Reichsregierung“ sowie die „Führerclique der NSDAP $[z u]$ verhaften. Die Regicrungsgewalt im Reich sollte vorläufig cin aus den Ministerpräsidenten der fünf größten Länder zusammengesetztes Direktorium übernehmen." Vgl. auch Klepper an v. Lindheim, 9. 5. 1953, K/Kor. 
Problem ${ }^{219}$. Möglich, daß Klepper „die bekannte starke Abneigung der Süddeutschen gegen Preußen und aus politischen Gründen gegen die preußische Regierung Braun“ unterschätzt hat. Grzesinski äußert sich über die besagte Sitzung sarkastisch, sie sei nach dem Motto verlaufen: „Ich bitt Dich lieber Florian, verschon mein Haus, zünd' andere an“, und sei ausgegangen „wie das Hornberger Schießen“220. In Übereinstimmung mit Adenauer sollte Köln vorübergehend zum Amtssitz der preußischen Regierung gemacht sowiedie Staatskasse dorthin überführt werden, ein Plan, der von glaubwürdigen Zeitgenossen bestätigt wird 221 . Immerhin diente diese Konferenz vom 27. Juni wenig später dem Reichsinnenminster v. Gayl als Vorwand, um für einen Eingriff in Preußen zu werben, wobei er allerdings das Ergebnis der Ministerpräsidentenbesprechung herunterspielte und behauptete, daß sie „dank der besonnenen Haltung des [württembergischen] Staatspräsidenten Bolz [...] zu keinen positiven Ergebnissen geführt" habe ${ }^{222}$.

Die Frage nach der Ernsthaftigkeit des Widerstandswillens der Länder ist vielfach untersucht worden ${ }^{223}$ und kann hier nicht in allen Einzelheiten aufgerollt werden. Folgende gegensätzlichen Aspekte sollten bei ihrer Erörterung aber eine Rolle spielen: einerseits die Angst der Länder vor einem Übergriff des Reiches auf den eigenen Staat, andererseits die traditionelle Abneigung der süddeutschen Länder gegen das übermächtige Preußen; einerseits der auch von Preußen selbst propagierte Wille, den Dualismus Preußen - Reich zu überwinden, andererseits der Wunsch nach einer Reichsreform, die keinesfalls die bestehenden föderalistischen Strukturen verletzen durfte; schließlich die teilweise Abneigung einerseits gegen die ,rote' preußische, andererseits gegen die reaktionäre Reichs-Regierung. Wenn man die besonders bei Bay ${ }^{224}$ im Detail wiedergegebenen

219 Petersen: „Alle Vertreter der Länder erkannten nicht allein das Recht, sondern auch die Verpflichtung an, dem Reichspräsidenten rechtzeitig auch von Seiten der Länder die Gefahren zu schildern, die man voraussehe." Außerdem ist von Absprachen der nicht-nationalsozialistischen Länder gegenüber den Notverordnungen der Papen-Regierung die Rede. „Schließlich habe Hirtsiefer festgestellt, ,daß in den wesentlichen Punkten eine völlige Übereinstimmung bestehe, und ,unter Zustimmung sämtlicher erschienenen Länderregierungen“ vorgeschlagen, ,die Länderregierungen wieder zusammenzuberufen, wenn dafür ein aktueller Anlaß gegeben sei“" (v. Lindheim, S. 161). Vgl. besonders Besson, S. 291 ff. sowie die dort im Anhang abgedruckten Dokumente, ferner Bay.

220 Grzesinski, Lebensweg, Bl. 285.

${ }^{221}$ Stehkämper, S. 455. Diese und die obigen Pläne wurden bestätigt von Herbert Weichmann gegenüber Jürgen Bay, S. 121, Anm. 637, von Carl Spiecker gegenüber v. Lindheim, S. 160, Anm. 24. Vgl. auch Schwarz, Adenauer, S. 334 und Biewer, Adenauer, S. 120.

222 Ministerbesprechung vom 11. 7. 1932 (AdR-Papen, Nr. 57). Besson, S. 291 ff. Zur Rolle v. Gayls vgl. u. a. Winkler, Der Weg, S. 647 ff.

223 Vgl. Benz, Papens ,Preußenschlag', Dokumentation, in: VfZ 18 (1970), S. 320-338, und „Besprechung der Ministerpräsidenten und sonstigen Vertreter der Länder" vom 11.6.1932 (AdRPapen, Nr. 18). Dazu der „Bericht des Badischen Gesandten (Hermann Fecht) in Berlin über die Sitzung der Vereinigten Ausschüsse des Reichsrates", im Auszug abgedruckt in: Staat und NSDAP, S. 326 ff. „Besprechung mit den süddeutschen Staats- und Ministerpräsidenten beim Reichspräsidenten" vom 12. 6. 1932. Auszug von Staatssekretär Meissner (AdR-Papen, Nr. 21). Zur Haltung Bayerns vgl.: Vogelsang, Das Verhältnis Bayerns zum Reich, S. 460-488. „Denkschrift des Bayerischen Ministerpräsidenten Held zur Verfassungs- und Reichsreform", München 20. 8. 1932 (AdR-Papen, Nr. 108). Zur Haltung Württembergs vgl. Besson und „Besprechung mit den Staats- und Ministerpräsidenten der Länder in Stuttgart am 23.7. 1932" (AdRPapen, Nr. 83), sowie einen Bericht des RK über die Sitzung vom 23. 7. 1932, in: „Ministerbesprechung vom 25.7.“ (AdR-Papen, Nr. 85). Vgl. Bracher, Bay u. a.

${ }^{224}$ Bay, S. $79 \mathrm{ff} ., 135 \mathrm{ff} ., 170 \mathrm{ff}$. 
Vorgänge von der Berliner Konferenz am 27. Juni bis zur Aufnahme des Leipziger Urteils durch die Länder Ende Oktober 1932 aufmerksam verfolgt, so läßt sich eine ,abfallende ' Linie feststellen, im Sinne einer zunehmenden Distanzierung von Preußen zugunsten einer Hinwendung zu den eigenen Partikularinteressen. Die Bereitschaft, Preußen zu unterstützen ${ }^{225}$, die „Mainlinie“ nicht zur Trennlinie werden zu lassen ${ }^{226}$, und die im ganzen negative Beurteilung des Staatsstreichs durch die Länder waren als Basis einer möglichen gemeinsamen Opposition gegen die reaktionäre Reichspolitik sicher vorhanden, aber es fehlten eine klare Linie in der preußischen Politik, Informationen über „die Zuspitzung der Lage" 227 und in der akuten Krise eine klare Politik des Widerstandes unter preußischer Führung. So geschah nichts. Prinz Löwenstein, der in Abstimmung mit Klepper nach dem 20. Juli bei den Bayern, den Württembergern und den Hessen sondierte, traf am 25. Juli mit Abegg und Klepper zusammen, um zu beraten, „aber es war zu spät. Kurz danach traf ein Kurier der Bayrischen Staatsregierung ein: Man habe vergeblich gewartet, nun müsse man sich mit Papen verständigen." 228

Zu diskutieren bleibt die Frage, ob Klepper tatsächlich auch noch unmittelbar vor und während der Sitzung am 20. Juli beim Reichskanzler zum Widerstand entschlossen und bereit war. Bay kommt nach Abwägung aller bisher bekannten Quellen und vor allem einer genauen Untersuchung von Severings Argumenten zu dem Schluß: Die „Haltung Kleppers nach der Besprechung in der Reichskanzlei, als jeder Widerstand wegen des sofort von der Reichsregierung verhängten Ausnahmezustandes aussichtslos erschien, schließt nicht aus, daß Klepper vor und wäbrend der Besprechung versuchte, den Absichten Papens zuvorzukommen oder sie zu durchkreuzen"229. "Wenn jemand zum Widerstand entschlossen war, sofern die Umstände eine Chance geboten hätten, so waren es Klepper und Grzesinski“, schrieb Weichmann an Bay ${ }^{230}$. Zur Unterstützung dieser These, daß Kleppers Aussagen über den Verlauf des 20. Juli der Wahrheit entsprechen und er tatsächlich versucht hat, Widerstand zu leisten, sei hier noch einmal der Ablauf der Ereignisse um den 20. Juli durch drei Zeitzeugen dokumentiert ${ }^{231}$.

$225 \mathrm{Vgl}$. auch v. Lindheim, S. $160 \mathrm{f}$.

${ }^{226}$ Hoegner, Erinnerungen, S. 32: „Eine Spaltung des deutschen Volkes in zwei feindliche Lager, die Wiederaufreißung der Mainlinie, den blutigen Kampf zwischen Reichswehr und Landespolizei hätten die politischen Falschspieler im Reichskanzlerpalais dem alten Hindenburg kaum zuzumuten gewagt."

${ }^{227}$ Prinz Löwenstein, S. 95.

${ }^{228}$ Ebenda, S. $92 \mathrm{ff}$. „Voraussetzung für jede Aktion sei“, so die bayerische Regierung, „daß die preußischen Minister ihren Anspruch, ,Regierung zu sein', aufrechterhielten.“

229 Bay, S. 122, Anm. 641, S. 120 ff. (Hervorhebung im Original). Wie Prinz Löwenstein bezeugt (s.o.), hat Klepper auch noch nach dem 20.7. 1932 versucht, Widerstand zu leisten.

230 Weichmann in einem Brief v. 25. 12. 1972 an Bay: „Aber“, so fährt er fort, „schon bei Hirtsiefer bin ich mir aus der Kenntnis seiner Person, die ich im übrigen hoch schätze, nicht sicher, daß er inen aktiven, d. h. mit Gewalt verbundenen Widerstand inauguriert hätte" (StAH, 622-1-Weichmann, 102, Schriftwechsel zum Sturz der Regierung Braun). Die Aussage über Grzesinski wird durch seine eigenen Aufzeichnungen (s.o.) bestätigt.

231 Vgl. zum Ablauf des Tages: „Aufzeichnungen der Reichskanzlei über den Ablauf der Aktion gegen die preußische Staatsregierung am 20. 7. 1932“ (AdR-Papen, Nr. 73) und die übrigen Dokumente zum 20. Juli 1932 in AdR-Papen, Nr. 68-71. Morsey, „Preußenschlag“, S. 430 f. und Dierske in: Zeitschrift für Politik 3 (1970), S. 198 ff. 
„Es war wochenlang vorher schon durchgesickert, daß etwas von der Reichsregierung gegen Preußen geplant sei. Die preußische Polizei war mobilisiert worden. Die Leitung des Reichsbanners, Schwarz Rot-Gold' hielt ihre Mitglieder in Alarmbereitschaft. Die in der ,Eisernen Front' zusammengeschlossenen jungen Gewerkschaftler und Arbeitersportler waren darauf gefaßt, zur Verteidigung der Republik aufgerufen zu werden. ${ }^{232}$ Am 15. Juli schickte die Eiserne Front ein Telegramm an Reichskanzler Papen, in dem er gewarnt wird, „das Spiel mit dem Feuer fortzusetzen“. Das Telegramm erhielt erst einen Tag nach dem Staatsstreich, am 21. Juli, seinen Eingangsstempel im Innenministerium und wurde am 28. Juli abgelegt, von einem gewissenhaften Beamten mit dem Kommentar versehen: „durch Zeitereignisse überholt “233. „Drei Tage vor der faktischen Vertreibung war schon die Entscheidung gefallen, das Ministerium wußte, was geplant war. [...] Sie berieten. Aber nur Dr. Klepper, ein bürgerlicher Fachminister, kein Politiker, rief zum Widerstand. Er hatte einen Desperado, früheren Polizeihauptmann, SA-Führer, dann Rebell gegen Hitler ${ }^{234}$, mitgebracht. Der sollte eine Hundertschaft zur besonderen Verwendung [...] anführen, sollte verhaften, wer unbefugt das Ministerium betrat, wenn's nötig war, zum Gegenangriff übergehen, auch vor dem Reichsoberhaupt, in dessen Namen die Verfassung gebrochen wurde, nicht haltmachen. Das Ministerium folgte ihm nicht. Der Katholik Hirtsiefer unterstützte ihn. Die Sozialdemokraten resignierten." 235

„Klepper war am Vortage des Ereignisses auf einer Dienstreise, auf der ihm vertraulich mitgeteilt wurde, daß Papens Schritt gegenüber der preußischen Staatsregierung für den nächsten Tag zu erwarten sei. Er fuhr sofort nach Berlin zurück und benachrichtigte [...] Severing von der erhaltenen Information. “236 Dieser "wollte seinem Kollegen auch jetzt nicht glauben, daß die Reichsregierung in irgendeiner Weise gewaltsam gegen die preußische Regierung vorgehen würde“237. "Ein Blick in die Morgenpresse hätte Severing und Hirtsiefer, wenn sie Klepper nicht glaubten, über die kommenden Dinge aufklären müssen. Noch detaillierter als das Berliner Tageblatt berichtete nämlich die Vossische Zeitung auf Seite 1 unter der Überschrift: ,Neuer Ansturm gegen Preußen'."238

„Als dann am nächsten Tag Papens Aufforderung an die preußischen Minister erging, zu ihm in die Reichskanzlei zu kommen, konnte Klepper gerade noch Severings Zustimmung dazu erlangen, daß die preußischen Minister sich jeder Stellungnahme gegenüber Papen zunächst enthalten und zu interner Beratung zurückziehen würden, wenn Papens Eröffnungen den angesagten Eingriff bedeuten sollten." 239 Bei der von Klepper vorgeschlagenen Unterbrechung der Sitzung wäre es darum gegangen, sofort die Polizei zu alarmieren, die Ministerien zu schützen, das gesamte preußische Kabinett zusammenzu-

232 Bernhard, S. 295. Vgl. Benz/Geiss, 20. Juli 1932, S. 29 f. Zur Stärke dieser Abwehrkräfte vgl. v. Lindheim, S. 163.

${ }^{233}$ GSTAM, Rep. 77, Preußisches Ministerium des Inneren, Abt. II, Tit. 4043, Akte „Eiserne Front", Nr. 352, Bl. 106.

${ }^{234}$ Gemeint ist Stennes.

${ }^{235}$ Olden, Warum versagten die Marxisten? in: Loewy (Hrsg.), Exil, Bd. I, S. 80. Vgl. zur Einstellung der SPD: Ilsar, Hermann Badt. Ilsar zitiert viele Aussagen von Sozialdemokraten.

236 Engelmann, S. 35 f. Bestätigt u. a. durch Grzesinski: Severing war am 19. 7.1932 „von durchaus zuverlässiger Seite“ unterrichtet worden (Lebensweg, Bl. 289). Vgl. auch Feder, Tagebücher, S. $321 \mathrm{f}$.

237 Bernhard, S. 296.

238 Ebenda, Vossische Zeitung, Nr. 345, 20. 7. 1932.

${ }^{239}$ Engelmann, S. 36. 
rufen und andere bereits diskutierte Maßnahmen zu ergreifen. All das wäre vor der Alarmierung der Reichswehr geschehen und hätte durchaus Erfolg haben können. Das Erstaunen Papens und Schleichers über die erschreckend leichte Absetzung der preußischen Regierung ist bekannt. „Nachdem Papen - übrigens sichtlich erregt und mit schwankender Stimme, wie Klepper berichtete, - seine Erklärung abgegeben hatte, die praktisch auf die Amtsenthebung des preußischen Kabinetts durch Einsetzung eines Reichskommissars für Preußen hinauslief und somit einen verfassungswidrigen Staatsstreich darstellte, wartete Klepper einen Augenblick auf die vereinbarte Antwort Severings und ging, als sie auf sich warten ließ, zur Tür, um die entsprechende Haltung der preußischen Minister zu demonstrieren ${ }^{240}$. Als er sich vor Verlassen des Raums nach Severing umsah, hörte er ihn auf einen fragenden Blick von Papen gerade noch sagen, er habe, mit Klepper nichts zu bereden'." ${ }^{241}$ "Er [Severing] hat leider nicht die Zivilcourage aufgebracht, so, wie es seine Ministerkollegen wollten, sich aus der Sitzung zurückzuziehen und der preußischen Polizei den Befehl zu geben, die Minister und die Staatsgebäude zu schützen." ${ }^{242}$ "Die Sozialdemokraten resignierten" und reichten noch am selben Tag eine Klage beim Staatsgerichtshof ein ${ }^{243}$, während Papen am Abend in "seiner gut vorbereiteten Rundfunkrede“, an der er „kaum etwas zu ändern“ brauchte, „die Situation in Preußen und die Gründe für die getroffenen Maßnahmen“ dem Volke erläuterte ${ }^{244}$.

Die Frage, ob es Möglichkeiten zum Widerstand gegeben habe, muß trotz der immer wieder gemachten Einwände ${ }^{245}$ nach dem soeben Dargelegten bejaht werden. Das heißt, die von Bracher anfangs formulierte Frage nach der "Offenheit der Geschichte“ ist in Bezug auf den 20. Juli 1932 im Sinne Brachers, also im Sinne der „Alternativen“, zu beantworten ${ }^{246}$. „Für den demokratischen Gedanken in Deutschland wäre es von unabsehbarer Bedeutung gewesen, wenn die Weimarer Entwicklung nicht einen so schwächli-

${ }^{240}$ In der „Aufzeichnung des Staatsministers Severing“ (BAK, Kl. Erw. 337/1, Bl. 135-138) heißt es: „Finanzminister Klepper regte an, die preußischen Vertreter möchten zu einer kurzen Sonderbesprechung zusammentreten, um über eine gemeinschaftliche Erklärung zu beschließen. Der preußische Innenminister widersprach dem Vorschlag mit dem Bemerken, daß eine Besprechung seine Haltung nicht ändern werde." In der Aufzeichnung Hirtsiefers (ebenda) heißt es dagegen nur: „Nach einigen weiteren Ausführungen des Herrn Staatsministers Klepper betonte der RK [...].“

${ }^{241}$ Engelmann, S. 36. Vgl. Winkler, Der Weg, S. 658.

${ }^{242}$ Bernhard, S. 296. Grzesinski, S. 155. Severings eigene Beschreibung von seiner „bestellten“ Verhaftung in seinen Memoiren (S. 353) spricht für sich selbst. Weichmann schreibt an Bay, daß Severing im allgemeinen überschätzt worden sei. „Er war alles andere als ein starker Minister, und Braun gab sich darüber keinen Illusionen hin“, er habe Grzesinski nur ungern entlassen. Vgl. Grzesinskis "Aufzeichnungen zum Ausscheiden aus dem Innenministerium", in: Lebensweg, Bl. $233 \mathrm{ff}$.

${ }^{243}$ Olden, S. 80. „Die preuß. Staatsregierung an den RK“, 20. 7. 1932 (AdR-Papen, Nr. 71).

${ }^{244}$ Ilsar, S. $291 \mathrm{f}$.

${ }^{245}$ Vgl. u. a. Winkler, Staatskrise, besonders I. Kap.: „Entscheidung für den Präsidialstaat: Komplott der Machteliten oder Selbstpreisgabe einer Demokratie?“

246 Bracher, Dualismus, S. $546 \mathrm{f}$. Bracher setzt seine Ansicht, daß es Alternativen gab, in Gegensatz zu Schulze und Möller. Er zitiert zur Stützung seiner These: „Auch ein so behutsam konservativer Beurteiler wie Ulrich Scheuner stellt fest, ,die Unterstellung Preußens unter ein Regime der Kommissare am 20. Juli 1932 war nicht nur verfassungsrechtlich nicht zureichend begründet', sondern hat die ,Ausschaltung der demokratischen Kräfte in Preußen herbeigeführt und am Ausgang der Weimarer Republik die Kräfte des stärksten deutschen Staates paralysiert'." 
chen, ja kläglichen Abschluß gefunden hätte."247 Wo hätten Alternativen und Handlungsspielräume auf dem Gebiet der preußischen Politik gelegen? Der 20. Juli 1932 ist unter diesem Aspekt vielfach und kontrovers diskutiert worden, hier sollen nur die Alternativen zur Diskussion gestellt werden, die Klepper damals gesehen und - allerdings erfolglos - durchzusetzen versucht hat. Daß darüber hinaus viele weitere Faktoren eine Rolle gespielt haben, versteht sich von selbst; so die Reichspolitik, deren Anteil am Scheitern der preußischen Politik aufgrund der dargelegten agrar- und finanzpolitischen Verhandlungen nicht geleugnet werden kann, oder das enorme Anwachsen der NSDAP besonders im preußischen Landtag und im Reichstag.

Handlungsspielräume hätten erstens in einer klareren und entschlosseneren Führung durch die preußische Staatsregierung gelegen. Die betroffenen Mitglieder des preußischen Kabinetts waren alle überzeugte Demokraten, und doch reagierten sie unterschiedlich auf den Gewaltstreich. Severing, der als Innenminister eine Schlüsselposition innehatte, beugte sich der vermeintlichen Übermacht der Reichsorgane. Die tiefere Ursache dafür lag in seinem letztlich obrigkeitsstaatlichen, legalistischen Denken, das eher dem eines Verwaltungsbeamten als dem eines mit dem Umgang mit der Macht vertrauten Politikers entsprach. Klepper, ein bürgerlicher Politiker, ohne Verbindung zu einer Parteibasis, aber auch unbelastet von dem Handicap falsch verstandener Autoritätsgläubigkeit und eines damit verbundenen „latenten Unterlegenheitsgefühls“248, durchschaute das illegale Ränkespiel und erkannte klar, daß Demokratie in der Bedrohung nur durch Macht zu schützen war, Gewalt nur mit Gewalt beantwortet werden konnte; setzte man ihr keinen Widerstand entgegen, würde sie weiterwuchern und ungleich größeres Unheil anrichten ${ }^{249}$. Zweitens wäre eine längerfristige Vorbereitung aller Abwehrkräfte, die auf dem Boden der Republik standen, inklusive der Polizei und ihrer entsprechenden personellen Umstrukturierung machbar gewesen, wie unter anderem Grzesinski betont hat. Drittens hätten mehr Verbote gegen extremistische Organisationen aller Art und deren öffentliche Auftritte ausgesprochen werden können. Viertens wäre auch eine gezieltere Zusammenarbeit mit den Ländern gelungen, wenn Preußen klarer und geschickter geführt hätte.

Interessant ist, daß Kleppers Wille zum Widerstand gegen Papens Staatsstreich vielfach angezweifelt und als seine nachträgliche Interpretation der Fakten gedeutet wird ${ }^{250}$. So schreibt Alexander noch 1992: „Severings schärfste Kritiker wurden später Grzesinski, Klepper und Abegg. Sie erklärten jedoch erst später, sie hätten anders als Severing aktiv Widerstand leisten wollen. Ihre Taten und auch Worte in der damaligen Situation sprechen jedoch eine andere Sprache." Da diese Behauptungen von keinen Originalquel-

${ }^{247}$ Friedensburg, S. 211.

248 Aufschlußreich, wie Alexander mit diesem Problem, daß Severing sich von ganz unten hochgearbeitet hat, umgeht (S. 262): „Severing fühlte sich den Bürgerlichen überlegen, hatte er doch den Aufstieg aus eigener Kraft geschafft und nicht etwa aufgrund einer schon bei der Geburt eingenommenen gesellschaftlichen Position. [...] Mit dem Selbstbewußtsein verbunden ist jedoch [...] ein nie zu überwindender Minderwertigkeitskomplex, ein latentes Unterlegenheitsgefühl“, das ihn nicht nur dazu brachte, sich ständig rechtfertigen zu müssen, sondern ihn auch glauben ließ, „politisch motivierte Kritik entspräche persönlichen Motiven, greife ihn also als Menschen, nicht als Politiker an“.

249 Vgl. Kleppers Kieler Rede vom 19.4. 1932.

250 Vgl. auch Möller, S. 572. 
len belegt werden, zeigt sich hier einmal wieder, daß auch die Geschichtsschreibung alte Vorurteile tradiert.

Die Ursachen für eine derartige Geschichtsüberlieferung sind vielfältig und liegen nicht nur darin begründet, daß Kleppers gleichlautende Darstellungen aus dem Jahre 1933 unbekannt geblieben sind. Sie hängen auch mit der Wechselwirkung von historischer Persönlichkeit und Zeitgeist und deren Niederschlag in der Geschichtsschreibung zusammen ${ }^{251}$. Eine Ursache liegt darin, daß Klepper als parteiloser Neuling in der preußischen Regierung in der breiten Öffentlichkeit weniger bekannt war als der populäre Severing252. Folglich hatte auch Severings einseitige Darstellung der Ereignisse vom 20. Juli 1932, die er nach dem Kriege mit seinem Artikel in der Gegenwart eröffnete und dann in seinen Memoiren fortsetzte ${ }^{253}$, eine sehr viel stärkere Wirkung als Kleppers Gegendarstellung in dem gleichen Blatt, der keine Memoiren folgten, und auch als Grzesinskis vom August 1932 stammende, eher nüchterne Bilanz, die Alternativen durchaus offenläßt ${ }^{254}$. Wenn man die Briefe Severings an Braun und auch dessen Antwortbriefe aus den Jahren 1947/48 über die Artikelserie zum 20. Juli 1932 liest, muß man sich etwas wundern, wie erwachsene Männer jegliche Urteilskraft verlieren, wenn es um ihre eigene historische Rolle geht. Severing polemisiert gegen Klepper auf die unsachlichste Weise und zeigt sich erbost, daß die Zeitschrift Die Gegenwart einen neutralen und nicht seinen Standpunkt einzunehmen versucht. Obwohl er selbst den ersten Artikel geschrieben hat, unterstellt er Klepper, daß er „den Streit vom Zaun gebrochen“ habe, und er fordert Braun auf, Stellung zu nehmen ${ }^{255}$, was dieser ablehnt. Doch auch Braun, der sich früher positiv über Klepper geäußert und mit dem er im Exil sympathisierende Briefe gewechselt hat ${ }^{256}$, äußert sich nun abfällig über Klepper, sei es um seinem Freund Severing nach dem Munde zu reden, sei es aus seiner resignativen, pessimistischen Altersstimmung heraus.

Ähnlich wie Klepper selbst galten auch die Zeitzeugen, die Kleppers Absicht und seine Vorbereitung zum Widerstand bestätigten, allgemein als weniger glaubwürdig. Ihre Namen haben eben nur für einen kleineren Teil der deutschen Öffentlichkeit einen guten Klang, sind sie doch allesamt Querdenker und in ein Parteienschema nicht fest einordenbare Demokraten. Daß dieses Defizit sich auch in der Geschichtsschreibung widerspiegelt, ist wenig verwunderlich, denn dahinter steht ein grundsätzlicher Streit

251 Friedensburg (S. 96): u. a. habe auch „das schwächliche Ende der Weimarer Republik, als Severing am 30. Juni [gemeint: 20. Juli] vor Papen und Hindenburg kapitulierte, viel zur Verwirrung des Geschichtsbewußtseins in unserem Volke beigetragen".

252 Dem Urteil Winklers in einer Rezension zu Alexanders Biographie (Die Zeit, 12. 5. 1993), daß Severing keineswegs so negativ dargestellt werde, wie Alexander es behaupte, ist zuzustimmen.

${ }^{253}$ Severing begann die Debatte um den 20. Juli 1932 nach dem Kriege mit einer unter Pseudonym (Wilhelm Gerviens) veröffentlichten Schrift mit dem bezeichnenden Titel: „Der 20. Juli 32 in Wahrheit und Dichtung" (Bielefeld o.J. [1946]). Es folgten der oben erwähnte Artikel zum 20. Juli 1932 und die Antwort Kleppers.

${ }^{254}$ Grzesinski, Lebensweg, Bl. $291 \mathrm{ff} .:$ Es sei schließlich wegen der preußischen Wahlen, der politischen Differenzen zwischen der Preußischen und der Reichs-Regierung, der Tatsache, daß der demokratische Teil Preußens auf sich selbst gestellt war, und wegen des extremen Bedachtseins der süddeutschen Staaten auf ihre eigene Sicherheit zu spät gewesen. Vgl. auch Grzesinski an Kurt Glaser, 3. 1. 1944 (IfZ, ED 202, Slg Glaser, Bd. 3) und Stampfer, S. 631 f.

255 GSTAB, I.HA, Rep. 92, NL-Braun C/I, Nr. 276, Bl. 7 ff., 17. 2. 1948, BI. 19.

256 Braun an Klepper, Mai/Juni 1933, KNL, hrsg. von Schumacher, in: Das Parlament, Nr. 20-21, 21./28. 5. 1983. 
um die Frage des politischen Widerstandes, der in unserer Geschichte keine starke Tradition hat. Es scheint fast, als wirke im Falle des 20. Juli 1932 eine Art ,schlechtes Gewissen' nach, das diese wichtige verpaßte Chance als eine für den ,Realpolitiker' nie existente Möglichkeit, also ein für die Geschichtsschreibung zu vernachlässigender Aspekt, herunterzuspielen versucht. Deutlich wird diese Tendenz im Vergleich zu der historischen Aufarbeitung des parallelen Ereignisses, zwölf Jahre später. Im Unterschied zum 20. Juli 1932 ist Widerstand zwar trotz geringster Erfolgschancen tatsächlich ausgeübt worden, aber die Erfolgschancen spielen bei der historischen Bewertung meist eine untergeordnete Rolle. Als wichtig gilt der symbolische Charakter des Aufstandes; ein Bewertungsmaßstab, der für den 20. Juli 1932 nur von wenigen Historikern, meist in der Nachfolge von Bracher, angelegt wird.

Es ist ein aufschlußreiches Gespräch überliefert, das kurz nach diesem Tag zwischen Harry Graf Kessler, Klepper und Heinrich Mann über die Frage geführt worden ist, warum der Widerstand nicht gewagt worden sei. Die von Graf Kessler wiedergegebene Antwort Kleppers klingt recht arrogant, trifft aber wohl einen wesentlichen Punkt: „Severings Verhalten sei nur daraus zu erklären, daß er ein ,kleiner Mann', ein ,Proletarier" sei, der doch noch immer einen Heidenrespekt vor den ,Herren' habe und um Gottes willen nichts tun wolle, was Konventionen der Herrenkaste verletze. " Heinrich Mann habe Kleppers Ausführungen in gleicher Richtung ergänzt: „Die Sozis seien an der Verachtung des Geistes gescheitert; die Zurückdrängung der Intellektuellen und die Vorherrschaft der Gewerkschaften habe sich gerächt; um Widerstand zu leisten, hätte Severing der Intellekt gefehlt. “257

Acht Jahre später fand die Kritik der drei Gesprächspartner eine interessante Bestätigung durch den französischen Journalisten Robert d'Harcourt, der in einer der letzten Nummern der von Georg Bernhard herausgegebenen Exilzeitung Pariser Tageszeitung 258 im Januar 1940, als der Krieg schon in vollem Gange war, zum Untergang der Weimarer Republik Stellung nahm, indem er sich auf ein Jagderlebnis Brauns bezog, das kurz vorher in derselben Zeitung abgedruckt worden war. Auf einer „einsamen Pirsch“ in der Schorfheide, die auch Hindenburgs Jagdrevier war, habe er „einen starken Hirsch in einem Nachbarrevier“ ausgemacht, so erzählte Braun, „obwohl ich mich auf dem Bauche kriechend mühsam an das Rudel herangepirscht hatte und der Hirsch gut war, schoß ich ihn nicht, da die Vermutung in mir aufkam, den für Hindenburg bestimmten Hirsch vor mir zu haben, den ich nur aus der Beschreibung kannte, da ich mich in dem Revier des Reichspräsidenten möglichst wenig bewegte. Ohne das Wild zu stören, schlich ich mich davon. “259 D'Harcourt nutzte dieses Bild und schrieb: „Die Weimarer Republik ist nicht besiegt worden, sie hat abgedankt, bevor sie noch angegriffen wurde, besiegt durch das tiefe Gefühl ihrer eigenen Unwürdigkeit, das sie selbst empfand gegenüber Helm, Stiefel und Uniform und allem, was das preußische Herz höher schlagen läßt. [...] Wie Braun im Wald hat sie schweigend den Platz geräumt, auf dem Bauche kriechend. " 260

${ }^{257}$ Graf Kessler, S. 691.

258 BN, Paris, D141, Pariser Tageszeitung (PTZ). Die Zeitung, vormals Pariser Tageblatt, nannte sich so ab 12. 6. 1936, als es zu einem großen Krach zwischen dem Herausgeber Wladimir Poliakow und den Redakteuren (Chefredakteur: Georg Bernhard) gekommen war.

259 Ebenda, PTZ, 11. 1. 1940.

260 Ebenda, 7. 2. 1940. 
Hinter diesen Antworten steht das von Klepper in seiner Artikelserie „Der Umschwung " erläuterte Problem, daß die potentiell staatstragende Schicht, die Arbeiterund die Mittelschicht, keinen „revolutionären Trieb zur Macht“ entwickelt hätten²61 und damit der eigentlich mit dem 9. November 1918 aus der Macht verdrängten Schicht des Adels die Möglichkeit geschaffen habe, sich im Bündnis mit dem Großbürgertum, das die gleiche Verachtung für die Arbeiterklasse hegte wie der Adel, die tatsächliche Macht im Staat zu übernehmen.

Dieser Zusammenhang wird noch genauer erläutert durch eine Antwort, die Klepper Rudolf Olden gab, als dieser ihn nach den Gründen für das Versagen Severings befragte. Klepper habe gesagt: „Weil sie [die Sozialdemokraten] ein schlechtes Gewissen hatten." Olden erläutert diese zunächst etwas rätselhaft klingende Antwort so: „Man muß diesen Ausdruck richtig verstehen. Er ist ungemein charakteristisch für die seelische Verfassung der Sozialdemokraten. Er bedeutet nicht [...] das Bewußtsein eines Fehlers oder einer Schuld; eher das Gegenteil." Es ist das Fehlen des "guten Gewissens“, das Olden in seltenen Fällen als „die Gabe des Genies“, meist aber als „Folge entweder einer aristokratischen Tradition oder des religiösen Gefühls der höheren Berufung“ definiert. Da aber, so argumentiert er weiter, „die Sozialdemokraten auf jede religiöse Aufgabe verzichtet hatten, als sie ihr Programm aufgaben und sich entschlossen, schlecht und recht weiter zu regieren, wie es die kaiserliche Bürokratie vor ihnen getan hatte, [...] war ihr innerer Machtanspruch auf ein Minimum gesunken“. Dazu komme noch die bei den Deutschen „sehr geringe Begabung zur Regierung“, die selbst Bismarck an seiner eigenen „Junkerkaste“ kritisiert hatte, diese mangelnde „Sicherheit des Handelns, wo nicht ein unmittelbarer Befehl vorliege. [...] Da jede Klasse sich nach dem Vorbild der früher herrschenden bildet, woher sollten“ da, so fragt Olden, "die Provinzredakteure und Gewerkschaftssekretäre das Bewußtsein der Legitimität haben, das sie befähigte, den Staat in der Krise zu leiten?“ Da sich „unter der Fuchtel-Despotie der preußischen Könige“ keine „wirkliche Aristokratie mit ihren historischen Fähigkeiten" hatte herausbilden können und „da die Bourgeoisie ihre Herrschaft nie revolutionär begründet hatte, sondern beide Klassen sich nur zur gemeinsamen Ausbeutung des Landes unter dem Schutz der kaiserlichen Bürokratie zusammengefunden hatten, da die Geschichte des unglücklichen Volkes - mit der einzigen Ausnahme des Freiherrn vom Stein und seiner Freunde - kein Vorbild des Bürgerstolzes und des patriotischen Selbstbewußtseins bietet, wo hätten die Sozialdemokraten, nachdem sie die eigene Klasse preisgegeben hatten, auch nur ein aneiferndes Beispiel in so gefährdeter Lage finden können?“262

Hier ist von der anfangs skizzierten demokratischen Tradition die Rede, der Klepper sich auch zugehörig fühlte. Klepper hatte offensichtlich das von Olden angesprochene „Bewußtsein der Legitimität“, das ihm die Stärke zum Handeln gab, das ihn aber auch

${ }^{261}$ Klepper, Der Umschwung, S. 164.

262 Olden, S. 81 f. Olden fügt hinzu: „Das, was im heutigen Deutschland ,Führerprinzip genannt wird, ist nur ein Ausdruck desselben Mangels, es setzt aufgeblasene, polternde Knechte an die Stellen, die verantwortungsvollen Vollbürgern gebührten." Vgl. dazu: Anm. des Hrsg. von „Exil“: „Die Schrift [Oldens] ist eine der scharfsinnigsten Untersuchungen über das Versagen der Linksparteien, Sozialdemokraten und Kommunisten, in der Weimarer Republik. Klaus Mann betonte in seiner Rezension (Die Sammlung, Jg. 1, 1933/34, H. 8, S. 447), Rudolf Olden, der in keiner Partei organisiert war, vertrete die Ansicht, nicht der Marxismus habe versagt, sondern die Arbeiterparteien, die sich auf ihn zu berufen pflegten." 
für die einen verdächtig und für die anderen gefährlich machte. Weil es zu wenige seiner Art gab, konnten sie sich zum Schaden Deutschlands weder gegen die Verdächtigungen noch gegen die die Demokratie bedrohenden Gefahren durchsetzen. Dennoch ist es im Zusammenhang mit der Frage nach dem möglichen Widerstand am 20. Juli 1932 wichtig, sich klarzumachen, daß es Demokraten mit dem nötigen Selbstbewußtsein gegeben hat, die gegen das dort begonnene und erst 1945 beendete Unrecht zu kämpfen versucht haben, wenn sie auch erfolglos waren. Nicht die von Rohr gegen Klepper, als Vertreter des verhaßten Systems, vor dem preußischen Landtag beschworene Tradition Treitschkes $^{263}$ sollte für die Geschichtsschreibung prägend sein, sondern die Brachers, der sagt: „Leugnet man [...] die Chancen einer Verhinderung des endgültigen Machtverlusts der Weimarer Demokratie und verfällt einer bloßen De-facto-Darstellung und Begründung des Geschehens", so folgt man „einer fatalistischen, deterministischen Interpretation" historischer Vorgänge und stützt damit indirekt „eine deutsche Fehltradition [...], die 1932/33 die fast kampflose Überwältigung der gesamten Republik nach dem Vorgang Preußens ermöglicht hat" ${ }^{264}$.

\section{Diffamierung als Mittel der Politik: Das Ende Preußens und das Ende von Weimar}

„Klepper sagte die nationalsozialistische Katastrophe voraus, freilich ohne Umfang und Dauer des Einbruchs, der bevorstand, zu ahnen. “Die preußischen Minister waren de facto abgesetzt, sollten sich aber gemäß der Anordnung von Ministerpräsident Braun nur als „von der Amtsführung suspendiert“ betrachten und sich „bis zur Ausschreibung der nächsten Wahlen ,zur Verfügung halten“" 265 . Es ging ja keineswegs nur um die ,suspendierten preußischen Minister'; in deren Gefolge verloren teilweise noch am gleichen Tag, teilweise im Laufe des Jahres viele renommierte demokratische Staatssekretäre, Landräte, Polizeipräsidenten und Regierungsbeamte ihre Posten ${ }^{266}$. Symptomatisch für diese Maßnahmen war die Tatsache, daß die in „der Ära Klepper in das Präsidium der Preußenkasse einbezogenen, der Sozialdemokratie nahestehenden Mitglieder ihren Abschied“ erhielten. Zu ihnen gehörte Lauffer, „der immer als besonderer Vertrauensmann Kleppers gegolten hat, ferner Direktor Possel, der zur sozialdemokratischen Partei gehört und der Direktor Schaub, ein Vetter des früheren Präsidenten und preußischen Finanzministers" 267 .

Wie rechtlos die Situation Preußens bereits geworden war, zeigt die Tatsache, daß die alte ehrwürdige preußische Institution, die Preußenkasse, durch Notverordnung des Reichspräsidenten noch vor dem Urteil des Staatsgerichtshofes auf das Reich überführt wurde, ein von gewissen Kreisen zwar lang ersehnter, aber illegaler Vorgang, der eines

${ }^{263}$ Vgl. die oben zitierte Rede des DNVP-Abgeordneten von Rohr im PrLT, 264. Sitzung, 16. 12. 1931, Sp. 23155-23171, 23171.

${ }^{264}$ Bracher, Dualismus, S. $543 \mathrm{f}$.

265 Engelmann, S. 37.

${ }^{266}$ In der Anlage zu einem Brief Brauns an den Reichspräsidenten vom 7. 11. 1932 werden die entlassenen und versetzten Beamtem aufgezählt, allein 53 Landräte wurden in den einstweiligen Ruhestand versetzt (AdR-Papen, Nr. 196).

267 VNL-K, Nr. 191, Abschrift unter dem Datum des 30. 7. 1932. 
Staatsvertrages zwischen Preußen und dem Reich bedurft hätte, aber Preußen gab es faktisch eben nicht mehr! ${ }^{268}$ Dieser Tatbestand wird von Faust nicht kritisiert, dagegen fällt sein Urteil über Hans Helferich, den neuen Präsidenten der neuen ,Reichskasse‘, der er bis 1945 blieb, ausgesprochen positiv aus: „War unter der Ägide Kleppers eine eigene, aber umstrittene Agrarpolitik der Preußenkasse sichtbar geworden, so betrachtete Präsident Helferich es als seine Aufgabe, die wirtschaftlichen Bestrebungen des genossenschaftlichen Spitzeninstituts [...] mit den politischen Zielvorstellungen des Reiches und der Länder in Übereinstimmung zu bringen. Aus der Rückschau darf es als eine glückliche Fügung bezeichnet werden, daß in Präsident Helferich eine Persönlichkeit an die Spitze der Anstalt gestellt wurde, die politisch ungebunden, kühl, distanziert gegenüber den bewegten Ereignissen der Zeit, einzig ihre Aufgabe darin erblickte, Sachwalter für die wirtschaftlichen und sozialen Belange der Genossenschaften zu sein. "269

Für alle, aber besonders für so einen aktiven und nun doppelt enttäuschten Mann wie Klepper muß diese Zeit zwischen Juli 1932 und Januar 1933 schrecklich gewesen sein, eine Zeit „völliger Untätigkeit, zu der er in seiner Privatwohnung in Zehlendorf verurteilt war [und die ihn] von Woche zu Woche mehr bedrückte “270. Doch war es ja keineswegs ein echtes Nichtstun, wie die ständigen Sitzungen des Staatsministeriums, die meist in Hirtsiefers Privatwohnung oder im Ministersaal des Landtags stattfanden ${ }^{271}$, zeigen. Diese uneingestandene Sinnlosigkeit des eigenen Tuns, vom Taktgefühl und der Disziplin der Beamten abhängig zu sein, und diese beklemmende Mischung aus Protest und „Ruhe bewahren“, die sich in gelegentlichen Briefen an den Reichskanzler, den Reichspräsidenten oder den Staatsgerichtshof entlud ${ }^{272}$, ohne daß sie irgend etwas bewirkten, mußte auf die Dauer mürbe machen. Der folgende Schlußsatz aus einem Bericht Papens für den Reichspräsidenten charakterisiert diese peinliche Situation aufs trefflichste: „Im übrigen versage ich mir, auf die hie und da wenig verbindliche Wortfassung des Schreibens des Herrn Ministerpräsidenten [Braun] näher einzugehen. Ich führe sie auf eine gewiß verständliche Empfindlichkeit zurück. Das gemeinsame Bestreben muß aber die Er-

${ }^{268}$ Die für Klepper gewiß schmerzliche Umwandlung der alten Preußenkasse in die neue „Deutsche Zentralgenossenschaftskasse“ geschah am 21. 10. 1932 durch Notverordnung des Reichspräsidenten: Das Stammkapital wurde herabgesetzt, Preußen und Reich erhielten je gleiche Anteile von 42,5 Millionen RM, die restlichen 15,11 Millionen RM wurden auf die anderen Verbandskassen verteilt. Im Ausschuß saßen nur noch 3 Vertreter des PrStM und dagegen 12 vom Reich bestellte Vertreter (inkl. Reichsbankdirektor und Direktor der Rentenbankkreditanstalt), Bestellung der Präsidenten geschah durch das Reich. Begründung für die Verreichlichung der P.Z. war die angeblich notwendige Deckung der Genossenschaftsverluste, die in Wirklichkeit durch Großagrarierkredite entstanden waren (RGBl. 1932, I, Nr. 70, 25. 10. 1932 und RGBl. 1933, I, Nr. 148, 29. 9. 1933, GSTAB, Rep. 84a, 11150, Bl. 239). Vgl. Beiträge zur Bankgeschichte über Helferich (DG Bank), DGBkA, ND-P.Z., Nr. 242, 8. Jg., 16. und 17. 10. 1932; Krebs, S. 577.

${ }^{269}$ Faust, Zentralkasse, S. 46.

${ }^{270}$ Engelmann, S. 37.

271 GSTAM, Rep. $151 \mathrm{HB}, \mathrm{Nr} .631 / 2$, Staatsministerialsitzungsprotokolle 1932-33: 1. Sitzung am 30. 8. 1932, letzte am 15. 2. 1933, am 6. 2. 1933 ist Klepper noch ausdrücklich als anwesend vermerkt. Im August waren Ferien, Klepper hat, nach Aussage von Brecht, Braun in Ascona besucht (Brecht, S. 222 und Schulze, Braun, S. 758).

272 Vgl.: Brief Brauns an Hindenburg vom 7.11. 1932, in dem er sich bitter über "die seit dem 20. Juli vorgenommenen umfangreichen personellen Veränderungen" beschwert (AdR-Papen, Nr. 196). 
reichung geordneter, von politischen Prestigefragen unberührter Zusammenarbeit sein.“273

So wundert es auch nicht, daß das Urteil des Staatsgerichtshofs, das formal den Preußen recht gab274, nicht viel an dem bisherigen Schwebezustand änderte ${ }^{275}$ : Die Amtsräume blieben Klepper und anderen verschlossen ${ }^{276}$, und ein Schreiben Kleppers und Brauns an den Reichskanzler vom 17. Dezember 1932 mit der Bitte um Unterlagen für die Erstellung eines Haushaltsentwurfs, „der nach wie vor zur Kompetenz des preußischen Finanzministers" gehöre277, wurde von Schleicher am 23. Dezember $1932 \mathrm{mit}$ dem Bescheid beantwortet, daß ,allein derjenige, der die Geschäfte führe, nämlich Popitz, den Haushaltsplan erstellen könne“278. Ein reiner „Federkrieg“, wie Schleicher zu bemerken beliebte 279 .

In dieser Zeit der gedrückten Stimmung war für Klepper die Familie Rückhalt und Trost. In den Akten fand sich auf der Rückseite einer der Einladungen zur Staatsratssitzung 280 in ungelenker Kinderschrift ein Wunschzettel für Weihnachten: „Marzipanbrot, Schlittschuhstiefel, Stempelreiniger, Füllfederhalter, Sparschwein, weiß mit einem kleinen Mond, Ingrid“, Kleppers älteste Tochter, damals 11 Jahre alt. Das Weihnachtsfest hat sich als das letzte im eigenen Heim im nachhinein in Kleppers Erinnerung verklärt, in vielen Briefen erwähnt er es immer wieder wie ein verlorenes Paradies. Zum Neujahr kamen viele Glückwünsche für „ein hervorragendes Jahr 1933“ ins Haus, und ein früherer Mitarbeiter schrieb: „Möge das Jahr 1933 die Überwindung der Reaktion und damit Ellenbogenfreiheit für Ihre Betätigungsmöglichkeiten bringen!“"281 „Es war in dieser Zeit, daß von nationalsozialistischer Seite Fühler ausgestreckt wurden, die auf Kleppers Eintritt in eine kommende Naziregierung abzielten", berichtet Engelmann, er habe sich aber „auch durch die offizielle Ankündigung, daß er [sonst] als ,Staatsfeind" registriert werden würde", nicht beeinflussen lassen. Andererseits seien Versuche nicht ausgeblieben, „ihn für die Unterstützung linksoppositioneller Maßnahmen gegen Papen, Hugenberg und andere zu gewinnen“. Man habe ihm Unterlagen vorgelegt, „die Bilanzfälschungen im Hugenberg-Konzern bewiesen und von ihm publiziert werden sollten. Er ließ sie sorgfältig prüfen, lehnte aber eine Beteiligung an ihrer Publikation ab“, da dies in

${ }^{273}$ Entwurf, als Anlage 2 zur Besprechung vom 10.11. 1932 (AdR-Papen, Nr. 201).

${ }^{274} \mathrm{Vgl}$. die bereits mehrfach angeführte Literatur, vor allem Bay, S. $185 \mathrm{ff}$. und Ehni, S. $271 \mathrm{ff}$.

275 24. 11. 1932 Erlaß des PrStM's, Richtlinien über die Weiterführung der Geschäfte. Die Veröffentlichung des Erlasses wurde durch den RK verhindert und durch eine gegenteilige Erklärung ersetzt (GSTAM, Rep. 151 HB, Nr. 631/2, Staatsministerialsitzungsprotokolle 1932-33).

${ }^{276}$ Brecht, S. 236 und Entwurf, als Anlage 2 zur Besprechung vom 10. 11. 1932, Anweisung Papens. Vgl. Ilsar, S. 337.

${ }^{277}$ AdR-Schleicher, Nr. 28. Vgl. GSTAM, Rep. 151 HB, Nr. 631/2, Staatsministerialsitzungsprotokolle 1932-33.

${ }^{278}$ AdR-Schleicher, Nr. 37. 23. 12. 1932, Schleicher an Braun. Es ist nicht uninteressant, im Zusammenhang von Geschichtsüberlieferung festzustellen, daß am ehemaligen preußischen Finanzministerium in Berlin eine Gedenktafel für Johannes Popitz, den Reichskommissar, angebracht worden ist, nicht für seine legalen Vorgänger.

${ }^{279}$ Ebenda, Braun nahm die Formulierung in seinem Brief vom 4. 1. 1933 an den RK auf. Es ging noch einmal um den Haushaltsplan (AdR-Schleicher, Nr. 42).

${ }^{280}$ GSTAM, VNL-K, Nr. 170.

${ }^{281}$ Ebenda, Possel an Klepper. Der erste Wunsch in der Glückwunschmappe war von Erich Welter aus Frankfurt/M. Klepper hat alle Karten und Briefe beantwortet und ebenfalls versucht, Optimismus zu verbreiten. 
seinen Augen „ein völlig untaugliches Mittel sei, gegen die massive und skrupellose Macht Hugenbergs vorgehen zu wollen“282. Diese Einsicht zu gewinnen, dürfte ihm nicht schwer gefallen sein, denn er steckte selbst mitten in einem von der Hugenbergpresse angeheizten Untersuchungsverfahren.

Ein kurzer Blick auf das Untersuchungsrecht des preußischen Landtags, das auf dem Artikel 25 der preußischen Verfassung beruhte und im wesentlichen mit dem des Reiches übereinstimmte, zeigt, welche symptomatische Bedeutung neben anderen auch dem Klepperschen Untersuchungsverfahren zukam $^{283}$. Die Institution des Untersuchungsausschusses war ausgesprochen demokratisch. Mit ihm erhielt auch die parlamentarische Minderheit die Möglichkeit, die Arbeit der Regierung zu kontrollieren und auf sie sowie den gesamten Verwaltungsapparat Einfluß zu nehmen, denn es genügte 1/5 der gesetzlich festgelegten Zahl der Landtagsabgeordneten, um einen Untersuchungsausschuß einzurichten. Er hatte öffentlich zu tagen und verfügte insofern über eine relativ große Unabhängigkeit, als er dazu befugt war, Zeugen und Sachverständige notfalls auch zur Aussage unter Eid zu zwingen sowie Amtshilfe von Gerichten und Behörden anzufordern. Mit der Berichterstattung an das Plenum war die Arbeit des Ausschusses beendet. Also in der Theorie eine demokratische, potentiell das Ansehen des Parlaments stärkende Institution, in der Praxis allerdings eine gefährliche Waffe, die zu zerstörerischer Agitation genutzt werden konnte, und das um so mehr, als die Parteien noch ungeübt in parlamentarischer Praxis waren und die Bevölkerung in der Mehrheit indifferent oder gar feindlich der Republik gegenüberstand, einer Republik, die ohnehin von Anfang an mit starken politischen, wirtschaftlichen und psychologischen Belastungen zu

${ }^{282}$ Engelmann S. 38. Bestätigt durch Kleppers autorisierten Lebenslauf für seine USA-Reise 1954, ein Dr. Theo Habicht, ein Österreicher, der in der Frühzeit der NSDAP eine gewisse Rolle spielte, soll ihn gefragt haben. Vgl. auch Kersten, Klepper, und Schumacher, Kommentare zum "Umschwung", S. 150.

${ }^{283}$ Art. 34 der Reichsverfassung. Vgl. Steffani, S. 287 f.: Insgesamt sind im PrLT 55 Untersuchungsanträge ( 3 in der verfassungsgebenden Landesversammlung) eingegangen (allein 7 bezogen sich auf Klepper), 24 erzielten die Einsetzung eines Untersuchungsausschusses ( 2 bezogen sich auf Klepper), 13 weitere wurden bereits bestehenden Ausschüssen überwiesen, 18 teils abgelehnt, teils zurückgezogen (zum größten Teil KP-Anträge); von den 24 Ausschüssen wurden 14 von den rechtsoppositionellen Parteien erzwungen, 7 von den Regierungsparteien, die restlichen 3 von besonderen Kombinationen, ähnliche Verhältnisse wiesen die 13 überwiesenen Uranträge auf; 11 Untersuchungsanträgen der Regierungsparteien stehen 43 der Opposition gegenüber; bei der Untersuchung erfolgreich waren die Regierungsparteien in 10, die Rechtsopposition in 22 und die KPD - stets unter Mithilfe der SPD - in 4 Fällen. Zeitlich verteilen sich die Anträge folgendermaßen: In den 10 Jahren vom Januar 1921 - Januar 1931 sind 37 Anträge gestellt und 13 Ausschüsse eingesetzt worden, in den letzten beiden Jahren waren es 21 bzw. 11. Zur Begründung dieser „wachsenden Antragshäufung“ schreibt Steffani: „a) Eine zunehmend leichtfertige Handhabung des Untersuchungsinstituts [...]. b) Das skandalhungrige Sensationsverlangen der Parteiagitatoren während des entscheidenden Ringens um die Macht in den Krisenjahren 1931/ 32. c) Die tatsächlich zu konstatierende Häufung von Ereignissen, die eine parlamentarische Untersuchung angebracht scin ließen (besonders hinsichtlich der Vorgänge um und nach dem preußischen Staatsstreich Papens). Die meisten sowohl sachlich wie auch propagandistisch bedeutsamen Ausschüsse fallen in die ersten Jahre, während zwischen 1931 und 1933 lediglich der Untersuchungsausschuß ,Dr. Klepper' eine breitere öffentlich-wirksame und der Untersuchungsausschuß ,Preußische Polizei' [...] (,Reichstagsdurchsuchung') eine sachlich bedeutsamere Rolle gespielt" haben (S. 288 f.). 
ringen hatte. Welche Folgen die Diskrepanz zwischen Verfassungsnorm und Verfassungswirklichkeit für die Weimarer Republik und besonders für Preußen hatte, geht aus der ausgezeichneten Analyse Winfried Steffanis hervor. Der Autor kommt zu dem Ergebnis, daß, obwohl von Anfang an der politisch-propagandistische Effekt des Untersuchungsverfahrens gegenüber dem sachlichen im Vordergrund stand, erst mit dem Wahljahr 1928 die "lediglich zersetzende, zutiefst republikfeindliche Agitation“ der DNVP, der NSDAP und der KPD „mit konzentrierter, kompromißloser Kraft in die Periode einer rücksichtslosen Kampfansage an die Weimarer Republik und ihre Verteidiger" eintrat $^{284}$. Damit erlangten die Untersuchungsausschüsse eine zunehmende politische $\mathrm{Be}-$ deutung, trugen zur Aufheizung des politischen Klimas bei und schadeten dem Ansehen des Parlaments und damit der Demokratie sowie auch denjenigen ganz erheblich, die diese Demokratie zu verteidigen suchten.

Seit dem Sommer 1928 waren nicht weniger als 18 sogenannte „Kleine Anfragen“, "Interpellationen“ oder "Uranträge“ im preußischen Landtag gegen Klepper eingegangen ${ }^{285}$, und es drehte sich immer um Geld, das er als Präsident der Preußenkasse beziehungsweise als Finanzminister für preußische Belange ausgegeben hatte und dessen Verwendung er jeweils begründen konnte. Alle Fragen des parlamentrischen Untersuchungsausschusses konnten von Klepper und der preußischen Regierung, die ebenfalls vernommen wurde, aufgeklärt werden, ohne Klepper zu belasten.

Der Untersuchungsausschuß war auf Initiative der DNVP, mit Hilfe der nach den Wahlen erstarkten NSDAP, zustande gekommen, war mit 29 Abgeordneten besetzt und trat zum ersten Mal am 21. September 1932 zusammen. Nachgeprüft werden sollte zunächst „die Geschäftsgebarung des jetzigen Finanzministers Dr. Klepper bei der Pächterkreditbank und der Domänenbetriebsgesellschaft und die daraus entstandenen Folgen". Dieser Untersuchungsauftrag wurde am Tag nach dem ersten Zusammentreten des Ausschusses erweitert durch die Frage nach dem "Geschäftsgebaren der Preußenkasse, insbesondere unter der Leitung des früheren Dr. Klepper" und deren „Geschäftsbeziehungen“ zur Pächterkreditbank ${ }^{286}$. Da die DNVP die Mehrheit im Ausschuß hatte, stellte sie den Vorsitzenden, einen Dr. Walther Zubke, der nur deshalb nicht abgesetzt wurde, weil er den entsprechenden, von der KPD gestellten Antrag auf seine Absetzung

\footnotetext{
284 Steffani, S. 209.

285 Alle Klepper betreffenden parlamentarischen Anfragen und Untersuchungsausschüsse in: GSTAM, Rep. 169 D, Nr. 33, Bd. 2 und 3, sowie Drucksachen des PrLT: Nr. 2632, 2706, 3250, 62, 90, 7499, 7996. Zur Einordnung von Kleppers Ausschüssen in den Gesamtzusammenhang vgl. Steffani, S. 287 f. Am 10.6. 1929 war bereits der 20. Untersuchungsausschuß „Preußenkasse" (s.o.: Liquidation der Raiffeisenbank) eingesetzt worden und hätte mit der Vorlage des Berichts (162. Sitzung) am 9.5. 1930 sein Ende gefunden, wenn nicht 3 weitere Untersuchungsanträge der DNVP und der NSDAP an ihn überwiesen worden wären, obwohl sich viele Vorgänge auf die Zeit lange vor Kleppers Präsidentschaft bezogen (1914!). Die Berichte wurden im Laufe des Jahres 1931 vorgelegt, der Ausschuß, in dessen Tätigkeitsphase auch der Mißtrauensantrag gegen den Finanzminister (s.o.) fiel, endete mit der Legislaturperiode am 23. 4. 1932. Zur Vorgeschichte und zum 20. Untersuchungsausschuß vgl. Steffani, S. $210 \mathrm{ff}$.

286 Steffani, S. 270 f. Die Uranträge (Nr. 281) der DNVP (v. Winterfeld) und der NSDAP (Kube) vom 17.6. 1932 sorgten dafür, daß die Kampagne gegen Klepper nicht abriß und ein neuer Untersuchungsausschuß eingerichtet wurde. Er trat am 7.7.1932 erstmalig als 21. sogenannter ,Klepperausschuß` zusammen, wurde durch 2 Uranträge (Nr. 668, NSDAP) vom 26. 7. und (Nr. 874, v. Winterfeld, DNVP) vom 3. 9. erweitert und mündete schließlich am 13. 10. in das Untersuchungsverfahren gegen Klepper.
} 
gar nicht zur Abstimmung kommen ließ. Der Berichterstatter Lothar Steuer (Parteisekretär der DNVP) wurde dagegen wegen Parteilichkeit und Unwahrhaftigkeit der Berichterstattung von allen Seiten so sehr angegriffen, daß ihm das Fragerecht entzogen werden mußte ${ }^{287}$. Nachdem Steuer Klepper als den „Ivar Kreuger der preußischen Finanzen" verunglimpft hatte, weigerte Klepper sich, „mit einem solchen Herrn“ eine „Unterhaltung“ zu führen, im übrigen aber bekannte er sich „,voll und ganz zu dem, was er getan habe“, und übernahm „alle Verantwortung“288.

Welches waren die Fragen des Ausschusses, und welche Antworten gab Klepper und die hinter ihm stehende preußische Regierung? Die erste Untersuchungsfrage bezog sich auf den von Klepper über die Domänenbank gegebenen und nun verlorenen Kredit der Preußenkasse von ca. 175000 RM an den neuen Chefredakteur und Besitzer der Zeitschrift Magazin der Wirtschaft, Raffael Bernfeld, der inzwischen Konkurs gemacht habe ${ }^{289}$. Bis Ende 1929 hatte die Zeitschrift Leopold Schwarzschild gehört, und zu den Mitarbeitern zählten bedeutende Professoren wie Julius Hirsch, Werner Sombart, Carl Oppenheimer, Wilhelm Röpke, Alexander Rüstow und mehrere Staatsminister wie zum Beispiel Höpker-Aschoff 290 . Auch Klepper hatte dort einen grundlegenden agrarpolitischen Artikel veröffentlicht. Klepper leugnete den durch den Konkurs der Zeitschrift entstandenen Verlust nicht, nannte ihn äußerst ärgerlich, verwies aber zurecht darauf, $\mathrm{da}$ andere renommierte Bankinstitute von gleichem Verlust betroffen seien ${ }^{291}$. Im übrigen wies Klepper darauf hin, daß die Angaben des Untersuchungsausschusses zur Kreditvergabe durch die Preußenkasse nicht korrekt seien. Als Bernfeld im Oktober 1929 das Magazin der Wirtschaft von Leopold Schwarzschild übernommen habe, wurde ihm aufgrund der Bonität des Magazins und seines bisherigen Herausgebers ein auf drei Monate befristeter Kredit von etwa $130000 \mathrm{RM}$ zu 91/2\% Zinsen von der Domänenbetriebsgesellschaft, nicht von der Preußenkasse, eingeräumt. Die Laufzeit des Kredits begann am 10. Oktober 1929; eine eventuelle Prolongation wurde zwar in Aussicht gestellt, aber nicht fest vereinbart ${ }^{292}$. Am 10. Februar 1930 wurde die Rückzahlung des im Januar abgelaufenen Kredits angemahnt. Nach langwierigen Verhandlungen wurde der Kredit am 6. Oktober 1930 kurzfristig verlängert und durch einen zusätzlichen Kredit um 20000 RM aufgestockt ${ }^{293}$. Als sich im Frühjahr 1931 herausstellte, daß Bernfeld unseriös war, wurde mit allen Mitteln versucht, die Gesamtschuld zurückzufordern, was

${ }^{287}$ Ebenda, S. $272 \mathrm{f}$., und die im ND-P.Z. und im NL-Zarnow zitierten Presseberichte vom Sept./ Okt. 1932.

${ }^{288}$ Klepper in der Pressekonferenz vom 15. 10. 1932, vgl. u. a. Vossische Zeitung von 15. 10. 1932.

${ }^{289}$ GSTAM, Rep. 169, Nr. 33, Bd. 2 und 3. Vgl. außerdem die Berichte und Zeitungsausschnitte im ND-P.Z. und im NL-Zarnow.

${ }^{290}$ Sösemann, S. $51 \mathrm{f}$.

${ }^{291}$ Aufstellung der ebenfalls betroffenen Gläubiger in VNL-K, Nr. 151: Deutsche Bank- und Diskontgesellschaft: 50000 RM; Dresdner Bank: 20000 RM; Darmstädter- und National-Bank: 150000 RM; Deutsche Effekten- und Wechsel-Bank: 99000 RM; Deutsche Pächterkredit Bank: 164500 RM; Commerz- und Privat-Bank: 15000 RM. Zusammen ergab das einen Verlust von $498500 \mathrm{RM}$, dazu kamen sonstige Gläubiger per 28. 2. 31, Steuer und Sozialversicherung in Höhe von 13400 RM, Akzepte: 52600 RM, Gehälter: 9200 RM, Honorare: 23300 RM und schließlich noch Privatschulden in beträchtlicher Höhe an Dr. Bock: 162000 RM, Dr. Bloch: 5000 RM, Georg Bernhard: 5000 RM und an Ob[er]regierungsrat Nathan: 4000 RM, zusammen: $128700 \mathrm{RM}$.

${ }^{292}$ GSTAM, VNL-K, Nr. 151, Bl. 3 f.

${ }^{293}$ Ebenda, Bl. 7 und 10. 
mißlang ${ }^{294}$. Die Zeitschrift ging in Konkurs, und der Kredit wurde von der Domänenbetriebsgesellschaft abgeschrieben. Es handelte sich hier also um ein normales Kreditgeschäft, dessen Ausgang Klepper nicht zu verantworten hatte.

Bei der zweiten Untersuchungsfrage ging es ebenfalls um einen Kredit; in diesem Fall wurde Klepper vorgeworfen, daß er der Stadt Köln über die Deutsche Bank einen kurzfristigen Kredit von 12 Millionen RM verschafft habe und daß diese Gelder, die eigentlich den Genossenschaften zur Verfügung stehen müßten, nun schon seit $2^{1 / 2}$ Jahren ausstünden. Klepper wies darauf hin, daß Köln die zweitgrößte preußische Kommune und es üblich sei, eine solche zu unterstützen, wenn sie in Not gerate, im übrigen seien 10 Millionen RM ohnehin durch Forderungen der Deutschen Bank abgedeckt ${ }^{295}$. Der Briefwechsel zwischen Adenauer und Klepper sowie zwischen Preußenkasse und Deutscher Bank beweist, daß Klepper sich Adenauer und der Stadt Köln gegenüber sehr fair verhalten und seinen Kopf für eine Sache hingehalten hat, die eindeutig nicht die seine war296. Adenauer hatte sich über seinen Parteifreund Hirtsiefer am 25. Februar 1931 an Klepper gewandt und ihn um einen Kredit über 12 Millionen RM gebeten. Klepper hatte ganz klar geantwortet, daß „die Preußische Zentralgenossenschaftskasse keine Kommunalkredite geben“ könne, daß er Adenauer aber helfen wolle, „die Überbrükkung des Jahresultimo zu erleichtern“, indem er der Deutschen Bank und Diskontgesellschaft Wechsel in dem gewünschten Umfang verkaufen und den Erlös stehenlassen wolle ${ }^{297}$. Im Juni war dann die Frist abgelaufen und die Lage auf dem Geldmarkt so schlecht geworden, daß Klepper die baldige Rückzahlung des Kredites verlangen mußte ${ }^{298}$, was Adenauer als unmöglich ablehnte.

Wie groß Adenauers Notlage offensichtlich war, zeigt der Ton seines persönlich an Klepper gerichteten Briefes: „Ihr gefl. Schreiben vom 8. ds. Mts. hat mich in sehr große Bestürzung versetzt. Ich bitte Sie auf das dringendste, doch den Kredit zu verlängern. [...] Sie erweisen der Stadt Köln und mir persönlich einen außerordentlich großen Dienst, wenn Sie für die Verlängerung besorgt sein würden. " 299 Klepper, obwohl er ausdrücklich betonte, daß er seine Forderung aufrechterhaiten müsse, damit „die Preußenkasse in erster Linie ihrer eigentlichen Aufgabe gewachsen " bleibe, ließ sich dennoch auf eine Verlängerung des Wechsels bei der Deutschen Bank mit Vorbehalt ein ${ }^{300}$. Adenauer verstand „durchaus“ Kleppers „Erwägungen“, bekniete ihn aber dennoch: „Ich bin überzeugt, daß Sie der Stadt Köln helfen werden, soweit es irgend in Ihren Kräften steht. “301 Da die Deutsche Bank sich stur stellte und den Wechsel nicht zurückzahlen wollte, obwohl sie ihn, wie Klepper vorschlug, auf ihr Guthaben von 10 Millionen RM bei der Preußenkasse anrechnen lassen konnte, bevor die Stadt ihre Schulden getilgt

\footnotetext{
${ }^{294}$ Am 10. Juli 1931 belief sich die Schuld auf 169323 RM, ebenda, Bl. $30 \mathrm{ff}$.

295 Neben den oben zitierten Quellen vgl. HAStK, 902, 42, Bd. 1, Bl. 248 ff. (Staatsrat/Akten der $O B$ als Präsident des Staatsrates 1929-33).

296 GSTAM, VNL-K, Nr. 158.

297 Ebenda, Bl. $1 \mathrm{ff}$.

298 Ebenda, Bl. 6 f., Klepper an Adenauer, 8. 6. 1931.

299 Ebenda, Bl. 8, Adenauer an Klepper, 9.6. 1931.

300 Ebenda, Bl. 12, Klepper an Adenauer, 12.6. 1931.

${ }^{301}$ Ebenda, Bl. 15, Adenauer an Klcpper, 19.6. 1931. Vgl. dazu Adenauers Stellungnahme zu dem gegen ihn von den Nationalsozialisten angestrengten Dienstverfahren vom April 1933, Brief vom 17. 4. 1933 an Ministerialdirigent Adolf Müller, in: Adenauer im Dritten Reich, Nr. 66, S. $112 \mathrm{ff}$. Adenauer versucht seine eigene Rolle hier verständlicherweise herunterzuspielen.
} 
hätte ${ }^{302}$, wurden die Verhandlungen immer mühseliger und gelangten schließlich an die Öffentlichkeit. Klepper versuchte, Adenauer und die Stadt Köln zu verteidigen, indem er darauf hinwies, daß das Land Preußen sich schließlich verpflichtet fühle, seinen notleidenden Gemeinden unter die Arme zu greifen. Daß Köln aber gewaltig über seine Verhältnisse gelebt hatte, verschwieg er ${ }^{303}$, obwohl "die finanzpolitischen Maßnahmen“ des Oberbürgermeisters der Stadt schon von Stresemann und später vor allem von Brüning „aus nationaler Sicht zu Recht und scharf kritisiert“ worden waren ${ }^{304}$.

Auch die dritte Untersuchungsfrage hing mit Köln und der Zentrumspartei zusammen, es wurde Klepper vorgeworfen, er habe für mindestens 2 Millionen RM Aktien des Kölner Verlagshauses Görres gekauft, um damit die Kölnische Volkszeitung zu stützen. Auf die Frage, warum das Geschäft über die „Heimbank“ gelaufen und vertraulich behandelt worden sei, erwiderte Klepper „unter allgemeiner stürmischer Heiterkeit [...]: ,Damit es nicht bekannt wird“. " ${ }^{305}$ Hinter dieser Bemerkung steckte eine Anspielung auf die ebenfalls gerade bekannt gewordene Stützung der Zeitschrift Germania durch den Dispositionsfonds des Reichskanzlers v. Papen, der „persönlich" ein Aktienpaket dieser Zeitung besaß und daran interessiert war, der "Zeitung einen konservativen Einschlag“ zu geben ${ }^{306}$. Klepper wie auch Braun hielten die Stützung der Kölnischen Volkszeitung aus "staats- und grenzpolitischen Gründen " 307 für notwendig, und im übrigen sei schon vor dem Ersten Weltkrieg ein Zeitungsverlag, in dem Fall ein deutschnational eingestellter, von der preußischen Regierung unterstützt worden.

Um den gleichen Sachverhalt ging es bei Punkt vier der Untersuchung, der Unterstützung des sogenannten „Sonderkontos A“, durch das Parteien und andere Gruppierungen im Wahlkampf unterstützt worden seien. Auch das wurde von Klepper nicht geleugnet, sondern im Gegenteil mit einem Hinweis auf Bismarcks „Reptilienfonds" und den "Dispositionsfonds“ des Reichskanzlers als „staatspolitische Notwendigkeit“ bezeichnet.

302 Ebenda, Bl. 71 ff., Briefe vom 6. und 8. 2. 1932, Verhandlungspartner der Preußenkasse waren Werner Kehl und Anton Paul Brüning von der Deutschen Bank.

${ }^{303}$ Ebenda, Bl. 29-32: Unterlagen und genaue Angaben zur Finanzlage der Stadt Köln.

${ }^{304}$ Biewer, Adenauer, S. 112. Kritisiert wurde auch die Tatsache, daß für Adenauer als Vorsitzenden des Staatsrates eine 7-Zimmer-Wohnung in der Wilhelmstraße 64 mit Möbeln und Kunstgegenständen aus Schlössern ganz Deutschlands und auch mit modernen Geräten eingerichtet worden war und er diese kaum nutzte. Braun drängte Adenauer, der gar nicht so gerne in Berlin weilte, möglichst bald einzuziehen, damit die Tatsache seines mietfreien Wohnens in diesem erheblichen Luxus nicht allzusehr durch die Presse breitgetreten werde in diesen Zeiten des allgemeinen Sparens (HAStK, 902, 42,1, Bl. 671 ff., 817 ff.).

305 Vossische Zeitung, 18. 10. 1932 (NL-Zarnow).

306 Deutsche Allgemeine Zeitung (DAZ), 20. 10. 1932 (DGBkA).

307 Braun vor dem Untersuchungsausschuß am 20. 10. 1932, Münchner Post vom 20. 10. 1932 (NLZarnow). Steffani (S. 272) zitiert einen sehr aufschlußreichen Kommentar der DAZ vom 19. 10. 1932 (Morgenausgabe) zu Brauns Auftreten vor dem Untersuchungsausschuß: „Das Erscheinen des Ministerpräsidenten vor dem Ausschuß war Dr. Brauns erstes Auftreten in der Öffentlichkeit seit der Ausschaltung seines Kabinetts durch die Juli-Aktion des Reiches. Wirkte der Ministerpräsident zu Beginn seiner Aussage leidend und verstimmt, so zeigt er bei der polemischen Auseinandersetzung mit den Fragestellern überraschende Schlagfertigkeit, die sogar eine Anspielung auf den noch immer ausstehenden Ausgang des Leipziger Rechtsstreits nicht verschmähte." 
Die fünfte Frage richtete sich an Klepper persönlich und sollte auch den bereits im Zusammenhang mit dem 20. Juli ins Gerede geratenen Staatssekretär Wilhelm Abegg treffen. Es ging darum, daß die Preußenkasse auf Kleppers Veranlassung Abegg einen persönlichen Kredit von 17930 RM gewährt hatte, als im Sommer 1931 die Bank, bei der Abegg seine Gelder hatte, zusammengebrochen war. Abegg, der ursprünglich sehr vermögend gewesen war, hatte den Banken wegen Arbeitsüberlastung viel zu weitgehende Vollmachten gegeben, um sein Vermögen zu verwalten, und war nun Opfer des Bankenkrachs geworden ${ }^{308}$. Der Kredit war bereits am 6. September 1932 mit Zinsen zurückgezahlt worden, was sich klar aus den Akten ergab ${ }^{309}$. Klepper wies die Anklage energisch zurück und bezeichnete sie als das, was sie war, eine üble Propaganda und den Versuch, einen politischen Gegner zu diffamieren, selbst wenn er über jeden Verdacht erhaben sei. Klepper bewies hier, wie in dem gesamten Untersuchungsverfahren, die ihm von Engelmann und anderen Mitarbeitern immer wieder bescheinigte Bereitschaft, persönliche Verantwortung zu übernehmen, auch wenn das für ihn unangenehme Folgen hatte 310 .

Das Ausbleiben eines Untersuchungsberichtes diente den Nationalsozialisten nach dem 30. Januar 1933 als Vorwand, ein angeblich neues Strafverfahren zu eröffnen und einen Haftbefehl gegen Klepper zu erlassen, auf dessen Grundlage sie ihn um die halbe Welt jagten, indem sie ihn mit Auslieferungsbegehren verfolgten und ihm die Bürgerrechte aberkannten. Wenn auch viele sein Schicksal teilten, Strafverfahren von den Nationalsozialisten angehängt bekommen zu haben, so gibt es wohl kaum einen Politiker der demokratischen Mitte, der so durchgängig sowohl in der Weimarer wie in der Zeit des Nationalsozialismus bekämpft worden ist. Die Vossische Zeitung faßte die „wahren Gründe der Hetze“ gegen Klepper zusammen und legte damit zugleich Zeugnis darüber ab, was Klepper all die Jahre zu ertragen hatte: „Der Lärm, den die Rechte [...] erhebt, steht zum Anlaß in gar keinem Verhältnis, und der Haß, mit dem Klepper seit Jahren verfolgt wird, hat wahrhaftig andere Gründe. Klepper hat von jeher die Ansicht verfochten, daß die landwirtschaftliche Besitzverteilung in Deutschland ungesund sei, und er hat schon als Leiter der Domänenbank seine bauernfreundlichen Überzeugungen, soweit er es konnte, in die Praxis umgesetzt. Das war leichtsinnig; denn damit hat er sich die Kreise zum Feinde gemacht, die noch nie etwas vergessen haben. Der Ton, den sie angeben, wird nachgesprochen von allen Parteien und Organisationen, die zur Rechten gehören. So ist er einer der bestgehaßten Menschen in Preußen geworden. Er mußte nicht nur zu Fall, sondern auch zur Strecke gebracht werden" ${ }^{311}$, und zwar in enger Zusammenarbeit mit der NSDAP312.

Diese Kontinuität in der Diffamierung, erst durch die Deutschnationalen, dann durch die Nationalsozialisten, und die Identität in Inhalt und Art der Anklage hatten Folgen. Zum einen konnten sich die Deutschnationalen wie die Nationalsozialisten jeweils aufeinander berufen und sich so gegenseitig entlasten, und zum anderen, und das wiegt sehr

\footnotetext{
308 Vgl. VNL-K, Nr. 199, Brief vom 6. 9. 1932 an Schmidt (P.Z).

${ }^{309}$ Ebenda, Sicherungsvertrag der Preußenkasse mit Willy Abegg vom 5. 8. 1931 führt Gemälde und andere Wertgegenstände als Sicherheit für den Kredit auf.

310 Abegg schrieb Klepper am 19.2. 1951, daß er ihm für sein „großzügiges und rückhaltloses Eintreten für $[i h n] 1931$ zu dauerndem Dank verpflichtet" sei (K/Kor).

311 Überschrift: „Das Kesseltreiben gegen Klepper", Vossische Zeitung, 15. 10. 1932.

312 Vgl.: Mommsen, Die verspielte Freiheit, S. 458.
} 
viel schwerer, litt Kleppers guter Leumund, was von manchem, sogar noch nach dem Kriege, gerne auf üble Weise ausgenutzt wurde, wie der folgende Briefauszug des früheren DNVP- und späteren CDU-Mitgliedes Eduard Funcke an Adenauer bezeugt ${ }^{313}$. Funcke, der in der Weimarer Zeit nach eigener Aussage „Hauptschriftleiter der Magdeburger Tageszeitung, eines deutschnationalen Blattes, sowie Reichsredner der DNVP und des Stahlhelm und Mitglied der zentralen Berliner Pressestelle der DNVP“ war, also mit den Vorgängen aufs engste vertraut sein mußte, fragte am 20. Juli 1947 bei Adenauer an, ob es stimme, daß Klepper für die Besetzung einer Direktorenstelle im Zweizonenrat im Gespräch sei, und erbat „in Anbetracht der Wichtigkeit dieses Falls“ von Adenauer persönlich eine Antwort.

Seine in dem Brief geäußerten Bedenken gegen Klepper sollen wiedergegeben werden, weil diese Mischung aus Erinnerung und Vergessen, aus unterschwelliger Verdächtigung und vermeintlicher Ehrenhaftigkeit ehemaliger Antidemokraten auf das politische Klima der frühen Bundesrepublik weitergewirkt und gerade den Emigranten die Rückkehr oft so schwer gemacht hat. Funcke schrieb: „Soviel mir in Erinnerung geblieben ist, gab es mal vor 15 Jahren im preußischen Landtag einen Klepper-Skandal, und es wurde ein parlamentarischer Untersuchungsausschuß gegen Klepper eingesetzt. Es sollte sich damals wohl um erhebliche Geldsummen handeln, über deren Ausgabe oder Verbleib näheres festgestellt werden sollte. Leider weiß ich mich des Ergebnisses dieser Untersuchung nicht mehr zu entsinnen. [...] Es wäre mir lieb, über den Ausgang dieser Untersuchung unterrichtet zu werden. Sollte die Untersuchung gegen Klepper damals wirklich nicht zu Ende geführt worden sein, so müßte das $\mathrm{m}$. E. nachgeholt werden, denn es geht doch nicht an, daß irgend jemand, der, unter welchem Regime es auch sei, unter dem kaiserlichen, dem Weimarer oder dem Naziregime, Dreck am Stecken haben sollte, für die heutigen Verhältnisse gut genug sei, um einen derart exponierten Posten, wie ihn eine Direktorenstelle im Zweizonenamt darstellt, zu bekleiden, lediglich auf Grund der Tatsache, daß der betreffende Nichtmitglied oder Gegner der NSDAP gewesen ist. Die CDU müßte hier $m$. E. ganz besonders vorsichtig sein, wen Sie im politischen und öffentlichen Leben herausstellt. Deshalb ist es - auch für die Öffentlichkeit - notwendig, zu erfahren, ob man sich der angefochtenen und früher umstrittenen Persönlichkeit Kleppers soweit versichert hat, daß man sagen kann: ,Er hat eine fleckenlose, weiße Weste ! «314

Daß diese Art von versteckter Diffamierung kein Einzelfall ist, sondern sogar in der Wissenschaft Spuren hinterlassen hat, zeigt die Darstellung der Vorgänge bei Faust: Im letzten Absatz des der Tätigkeit Kleppers gewidmeten Kapitels heißt es: „Die Mehrheit des erwähnten Untersuchungsausschusses des preußischen Landtags forderte auf Antrag der Nationalsozialisten schon damals die Verhaftung Kleppers. Ende März 1933 wurde auf Antrag der Staatsanwaltschaft Berlin gegen Klepper die Voruntersuchung eröffnet. Dieser konnte sich seiner ihm nun ernsthaft drohenden Inhaftierung nur durch Flucht ins Ausland entziehen. Nach 14 Jahren dauernder Emigration, die ihn um die halbe Welt geführt hatte, 1947 nach Deutschland zurückgekehrt, hat er den Anschluß

${ }^{313}$ STBKAH, NL-Ad, Bl. 99: Dr. Eduard Funcke (Reinbek/Hbg.) an Oberbürgermeister a. D. Dr. Konrad Adenauer, 20.7. 1947 (Rechtschreibung und Zeichensetzung im Original).

${ }^{314}$ Adenauer antwortete am 8. 8. 1947: „Die Kandidatur Kleppers ist niemals in ernsthaften Kreisen erörtert worden" (ebenda, Bl. 96). 
an das neue politische Leben nicht mehr gefunden. " 315 Hier wird erstens eine Kontinuität vorgespiegelt, als habe es einen 30. Januar 1933 überhaupt nicht gegeben. Zweitens wird Kleppers Flucht, die im übrigen falsch, nämlich viel zu spät, datiert wird, in einer Weise mit dem Strafverfahren in Verbindung gebracht, als habe er fliehen müssen, um sich einem gerechten Prozeß zu entziehen, wobei die fatale Parallele zu Berichten in NS-Akten, in denen es heißt: „Als er wegen Betrügereien zur Rechenschaft gezogen werden sollte, floh er ins Ausland“, kaum zu übersehen ist ${ }^{316}$. Drittens wird schließlich mit dem verpaßten Anschluß an "das neue politische Leben“ suggeriert, als sei diese für etliche Emigranten schwierige und oft mißglückte Rückkehr allein ein Versagen der Emigranten; diesem Irrtum zu begegnen, wird Aufgabe des letzten Kapitels dieser Arbeit sein.

In Wirklichkeit ging es bei dem Untersuchungsausschuß des preußischen Landtags nicht nur um Klepper, sondern um die Republik ${ }^{317}$, es ging darum, der bereits abgesetzten preußischen Regierung, deren Klage gegen das Reich seit dem 10. Oktober vor dem Staatsgerichtshof in Leipzig verhandelt wurde, einen weiteren Stoß zu versetzen und damit indirekt das Verfahren zu beeinflussen, es ging um die bevorstehenden Wahlen im Reich und in Preußen am 6. November und den Versuch, die preußische Regierung als bereits abgesetzt und völlig korrumpiert darzustellen ${ }^{318}$, und es ging schließlich auch um die Preußenkasse, die seit dem 29. Juli einen neuen Leiter hatte und kurz vor ihrer endgültigen Verreichlichung stand ${ }^{319}$. Keiner war so geeignet wie Klepper, um als Zielscheibe für diese Angriffe zu dienen, was er selbst auch klar erkannt und in einer Pressekonferenz vom 15. Oktober zum Ausdruck gebracht hat: „Es entsprach schon nach dem Staatsstreich vom 20. Juli 1932 der Übung, mißliebige, das heißt verläßlich republikanische Beamte durch die Erhebung ehrenrühriger Vorwürfe zu diskreditieren." ${ }^{320}$

${ }^{315}$ Faust, Geschichte, S. 574. Als einzigen Beleg nennt Faust das rechte Blatt „Der Westen“, vom 14. 10. 1932 (DGBkA), ohne dessen politisch einseitigen Charakter zu erwähnen und ohne die Zusammensetzung des Ausschusses zu erklären, in dem die republikfeindlichen Parteien, DNVP, NSDAP und KPD, die Mehrheit hatten, abgesehen davon, daß Klepper, der die Beschuldigungen als juristisch haltlos zurückwies, durch sein Erscheinen den Haftbefehl nichtig machte; am 21. 10. 1932 beschloß der Untersuchungsausschuß, sich für längere Zeit zu vertagen, um auch die Zeitungsstützungen der Reichsregierung zu untersuchen (Steffani, S. 272).

316 BAK, R 58/236, Nr. 90 und 245.

317 Entsprechend wurden fast alle preußischen Regierungsmitglieder und hohe Beamte vernommen, s. DGBkA, ND-P.Z., 8. Jg., Nr. 241, 5. 10. 1932, Bl. 4 und ebenda Zeitungskommentare zu den jeweiligen Vernehmungen.

${ }^{318}$ Dieser Zusammenhang wird sowohl von rechten wie von liberalen Zeitungen hervorgehoben, nur jeweils mit umgekehrten Vorzeichen; so schreibt der Lokalanzeiger am 14. 10. 1932: „Offensichtlich hatten Zentrum und Sozialdemokraten die berechtigte Sorge, daß [...] die Enthüllungen vor dem Untersuchungsausschuß im Zusammenhang mit den Verhandlungen des Staatsgerichtshofes eine für die frühere preußische Regierung recht unangenebme Wendung herbeiführen könne $[n]^{\text {" }}$ (BAK, NL-Zarnow, Bl. 72). Vgl. ebenda, Bl. 75: Vossische Zeitung, 15. 10. 1932. Vgl. auch: BAP, 62 DAF3 und DGBkA, ND-P.Z.

${ }^{319}$ Am 29. 7. 1932 war Hans Helferich, bisher Oberregierungsrat im Reichsernährungsministerium, vom Reichskommissar zum Nachfolger Kleppers ernannt worden. Vgl. dazu den Kommentar in: 2. Beilage des Vorwärts, Nr. 379, 13. 8. 1932 (DGBkA). Zur Verreichlichung am 21. 10. 1932 s.o. und vgl. Faust, Zentralkasse, S. $46 \mathrm{ff}$.

${ }^{320}$ DGBkA, ND-P.Z., Nr. 241, Bl. 4 und Klepper an das Entschädigungsamt in Sachen Pahlke, 19. 3. $1955, \mathrm{KNL}$. 
Wenn man sich diese Verunglimpfungen anschaut, so kann man sich vorstellen, was auf Klepper bei einer nationalsozialistischen Regierung zukommen mußte. Obwohl Klepper das alles kommen sah, hatte er „nicht alle Hoffnung aufgegeben, daß eine baldige Reaktion eintreten könnte“. Zur Illustration erzählt Engelmann eine kleine Episode, die sich am 30. Januar 1933 in der Wohnung Max Reinhardts, des großen Berliner Theaterintendanten, „in einem der Kavalierhäuser des Schlosses Bellevue" zutrug. Klepper hatte die in seiner aktiven Ministerzeit begonnenen Bemühungen um eine Gesundung des "Reinhardt-Konzerns" auch nach seiner Absetzung fortgesetzt und sich deshalb schon längere Zeit vorher für den 30. Januar 1933 in Reinhardts Wohnung verabredet, um fällige Entscheidungen zu treffen. So wurde „unter dem Lärm der zur Siegesparade dicht an Reinhardts Wohnsitz vorbeiziehenden braunen Horden in aller Ruhe beraten, als könne man über die Dinge draußen zur Tagesordnung übergehen. Beim Abschied freilich stimmte Klepper der Bemerkung Reinhardts, der während der Verhandlung nicht minder optimistisch gewesen war, $\mathrm{zu}$, daß sich vielleicht bald herausstellen könnte, daß man an diesem Abend, so anregend und aussichtsreich er verlaufen sei, doch ,einigermaßen leeres Stroh gedroschen' habe.“"321

Die Schlinge zog sich rasch zu. Am 6. Februar wurden durch die Verordnung des Reichspräsidenten alle Geschäfte der preußischen Regierung an das Reich übergeben. Am gleichen Tage versammelte sich noch einmal das preußische Staatsministerium, diesmal in der Leipziger Straße 3, und beschloß, vor dem Staatsgerichtshof zu klagen, weil die Verordnung des Reichspräsidenten der rechtlichen Grundlage entbehrte ${ }^{322}$. Eine gespenstische Sitzung muß das gewesen sein, wohl die letzte für Klepper, denn ob er am 15. Februar noch dabei war, scheint unwahrscheinlich, nachdem am 10. Februar bereits die Streichung der Aufwandsentschädigung und des Dienstwagens für preußische Minister und die Aufforderung zur Räumung der Diensträume durch Papen bekannt gemacht worden war ${ }^{323}$. Am 27. Februar brannte der Reichstag, ob Klepper am 28. noch selbst seinen Bericht über den Fonds zur Bekämpfung von Verbrechertum (ca. 1,8 Mio) ${ }^{324}$ verlesen hat, ist äußerst zweifelhaft, denn nach eigenen Aussagen "wohnte [er] in der letzten Zeit vor [seiner] Emigration exterritorial in der Finnländischen Gesandtschaft " ${ }^{\text {"325, }}$, zu der er gute Kontakte hatte. Der finnische Gesandte, Wäinö Wuoliyoki, war sein Freund und hatte ihm eine Einladung der finnischen Regierung zum Studium des finnischen Genossenschaftswesens besorgt ${ }^{326}$. Diese Einladung „vermochte er laut Engelmann soweit hinauszuschieben, daß er sich an der für den

${ }^{321}$ Engelmann, S. 38.

322 GSTAM, Rep. $151 \mathrm{HB}, 631 / 2$. Ebenfalls am 6.2. bat Braun um eine Unterredung bei Hindenburg, der ablehnte. Vgl. Ehni, S. 287.

${ }^{323}$ Ebenda, B1. 47.

${ }^{324}$ Ebenda, Verhandlungen der preußischen Regierung.

${ }^{325}$ Klepper an Prof. Wolfgang Abendroth (Marburg), 10. 6. 1955 (KNL): Abendroth schickte Klepper anläßlich einer Untersuchung zur Widerstandsbewegung gegen das 3. Reich einen Fragebogen. Klepper schrieb dazu: „Wahrscheinlich könnte ich [...] recht interessante Dinge mitteilen.“ Anfang August 1955 sollte ein Treffen zwischen Klepper und Abendroth stattfinden.

${ }^{326}$ Engelmann, S. 38. Bericht von RA Kurt Stange/Berlin, vom 28. 3.1936 (KNL). Der Briefwechsel zwischen Klepper und Frau Wuolyoki nach dem Kriege spiegelt eine enge Verbundenheit wider. Für Klepper zählten Wuolyokis "zu den Menschen, die [ibm] das Leben gerettet haben“ (K/ Kor.). Wuolyoki war seit 1927 Gesandter in Berlin; zur Biographie vgl. Horkenbach (Hrsg.), S. 546 . 
5. März 1933 anberaumten Wahl gemäß dem Wunsch des, Ministerpräsidenten` beteiligen konnte“. ,Loyal und seriös" bis zu letzten Minute! Da er aber bei einem schlechten Ausgang der Wahl Schlimmstes zu befürchten hatte, wählte er bereits in Stettin, um sich von da aus mit seiner Frau, in Begleitung des finnischen Gesandten, „nach Finnland einzuschiffen" ${ }^{327}$. Doch damit beginnt ein neues Kapitel.

327 Ebenda, bestätigt durch einen Brief Arnold Brechts an das New England Christian Committee for Refugees vom 3.11. 1940 (BAK, NL-Brecht, 89). 